\title{
MONOGRAPHIEEN
}

\author{
AFRIKANISCHER
}

\section{PFLANZEN-FAMILIEN UND -GATTUNGEN}

HERAUSGEGEBEN

VON

A. EN GLER

II. MELASTOVATACEAE

\author{
BEARBEITET \\ VON \\ E. GILG
}

MIT TAFEL I-X

VERÖFFENTLICHT MIT UNTERSTÜTZUNG DER KGL. PREUSSISCHEN AKADEMIE DER WISSENSCHAFTEN

\section{LEIPZIG}

VERLAG VON WILHELM ENGELMANN

1898. 
Alle Rechte, insbesondere das der Uebersetzung, vorbehalten.

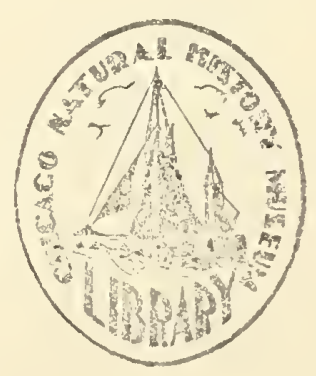


Seit dem Erscheinen der Нооквя'schen Arbeit (18\%1) hat die Kenntnis der afrikanischen Flora ganz ausserordentlich zugenommen; wir sehen jetzt, dass die Melastomataceae in Afrika durchaus nicht verhältnismässig so einförmig und in so geringer Zahl auftreten, wie es noch vor Kurzem schien. Allerdings beherrschen sie wohl nie den Florencharakter eines Gebietes, auch sind sie nie bestandbildend wie in Brasilien. Aber doch fällt uns die Thatsache auf, dass an Punkten, wo man kaum einige Glieder unserer Familie vermuten sollte, dieselben in grosser Zahl und ungemeiner Formendifferenzierung auftreten: gelang es doch StunLuas, auf einem einzigen Zuge nach dem Ulugurugebirge, in dem an Melastomataceae sonst so armen Ostafrika, ausser zahlreichen bekannten und neuen Arten vier gut charakterisierte neue Gattungen aufzunehmen, während 4 von Heinsen im Handeïgebirge zusammengebrachte Memecylon-Arten sich sämtlich als unbeschrieben erwiesen und zum Teil ganz eigenartige und abweichende Typen darstellen. Zweifellos dürfen wir aus diesen Gebieten noch auf zahlreiche bisher unbekannte Arten der Familie rechnen, wenn flüchtige Durchstreifungen solche Resultate ergeben konnten.

Bezuiglich der Abgrenzung der Gattungen bei den Melastomataceae ist gewiss sehr zu bedauern, dass viele derselloen auf sehr geringe Unterschiede hin begründet worden sind. Doch fühlte ich mich nicht berufen, neue Principien einzufiihren, wo schon so zahlreiche genaue Forscher vorgearbeitet hatten, glaube auch, dass dadurch nur wenig erreicht werden würde und bei einer versuchten Zusammenfassung häufig unnatürliche *Gattungen« resultieren müssten. Und dass thatsächlich zahlreiche der Merkmale, welche hauptsächlich zur Gattungsscheidung benutzt werden und die sich auf die Ausgestaltung des Connectivs beziehen, natürliche, d. h. für Verwandtschaftsfragen wichtige sind, erkennen wir am besten daraus, dass manche artenreiche Gattungen durch sie gleichmässig charaliterisiert werden, deren simtliche Arten durch Habitus und Blütenausbildung auf das sicherste als zusammengehörig bezeichnet werden müssen. Es ist ja gevviss keinem Botaniker zweifelhaft, dass man unter "Gattung« bei Melastomataceae, Compositae, Unbelliferae etc. etwas ganz anderes versteht als z. B. bei Dilleniaceae, Ochnaceae, Ranunculaceae, Theaceae etc. Während bei den letzteren meist thatsächlich die Arten einer Gattung als blutsverwandt mit einander bezeichnet werden können (oder sogar müssen), wird bei ersteren die Zusammenfassung von Arten unter einem Gattungsnamen in vielen Fällen nur deshalb geübt, um die Arten practisch »unterzubringen«. Niemand wird glauben, dass viele dieser Gattungen natürliche sind, dass die darin zusammengefassten Arten gleichen Ursprungs sein müssten.

Herrn Prof. Cogniaux, welcher einige der im Folgenden beschriebenen Arten und Gattungen revidierte und mir seine Ansicht uber ihre Stellung im System mitteilte, und Herrn Dr. Stapf, welcher eine Art mit dem in Kew aufbewahrten Original verglich, spreche ich auch an dieser Stelle für ihre Liebenswürdigkeit meinen besten Dank aus. Endlich bin ich der Direction des Herbariums zu Paris, besonders Herrn J. Porsson, ferner Herm Prof. Dr. Hevriques, Director des Herbariums zu Coimbra, und Herrn E. Autran, Custos des Herbariums Boissier-Bankey, für Übersendung von Material, meist von Originalmaterial ihrer Herbarien, sehr dankbar. Es konnten hierdurch manche Lücken ausgefüllt werden, welche trotz der reichen im Kgl. Botanischen Museum zu Berlin enthaltenen Sammlungen aus Afrika bei der Bearbeitung der Melastomataceae geblieben waren. Auf diese Weise war es mir möglich, fast alle beschriebenen Arten zu untersuchen; nur einige wenige Originale des Herbariums zu Kew waren mir nicht erreichbar.

\section{Übersicht über die afrikanischen Gattungen.}

A. Frucht ausserordentlich vielsamig. Embryo wie die Samen winzig klein . . A. Melastomatoideae. a. Kapselfrucht, stets mehr oder weniger dünnwandig.

a. Fruchtknoten (und damit auch Receptaculum) walzlich oder kantig.

I. Samen schneckenförmig oder doch gekrümmt . . . . . . . . .

a. 0sbeckieae.

1. Kapsel 4-5-klappig aufspringend.

$1^{\mathrm{a}}$. Die beiden Staubblattkreise gleich oder fast gleich.

* Connectiv ohne oder mit nur winzigem Fortsatz, ohne Anhängsel oder hüchstens vorn mit 2 Höckern versehen.

- Receptaculum völlig kahl. Blüten klein. Kleine einjährige Krräuter.

† Fruchtknoten frei, am Scheitel borstig . . . . . . . . .

tt Fruchtknoten bis zur Mitte mit dem Receptaculum verwachsen . . oo Receptaculum mehr oder weniger dicht behaart.

1. Nerophila Naud.

2. Guyouia Naud. 
† Fruchtknoten an der Spitze kahl. . . . . . . . . . . t† Fruchtknoten an der Spitze mit einem Haarkranze gekrönt. . . . (Vergleiche auch 8. Tristemma Juss.)

** Connectiv mit ansehnlichem Fortsatz, welcher vorn zwei deutliche Läppchen trägt . . . . . . . . . . . . . . . . .

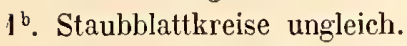

* Kelch mit Aussenzähnen, welche meist mit den Kelchzipfeln abwechseln. o Connectiv der grösseren Staubblätter vorn über der Insertion der Staubfüden in ein ausgerandetes, 2-sporniges oder 2-höckeriges, seltener ungeteiltes Anhängsel vorgezogen. Fruchtlnoten mit borstigem Scheitel oo Connectiv aller Staubblätter vorn lang 2-spornig. Fruchtknoten von 4 2-spaltigen Schuppen gekrönt

* Kelch ohne Aussenzähne. Staubblätter alle fast ganz gleich, Connective

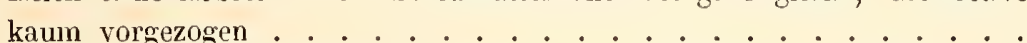

2. Kapsel dünnhäutig, unregelmässig aufreissend. Connectiv kurz vorgezogen, am Grunde verbreitert, vorn ausgerandet . . . . . . . . . . . .

II. Samen gerade. Connectiv hinten in einen langen Sporn ausgezogen .

1. Connectiv nach unten und hinten stark und spitz verlängert, vorn ohne Anhängsel. Blätenstiele und Receptaculum mit Drüsenhaaren besetzt . . . . .

2. Connectiv nach unten und hinten stark und dick verlängert, neben dem Abgang der Verlängerung mit 2 drüsenartigen Höckerchen, vorn ganz ohne Anhängsel. Blütenstiele und Receptaculum mit braunen Haarborsten dicht besetzt . . . .

$\beta$. Fruchthnoten und Kapsel scharf 3 -5-kantig oder $3-ら$-llugelig. . . . .

I. Staubblätter sehr ungleich.

1. Blüten ら̈-zählig. Connectiv der grösseren Staubblätter weit vorgezogen, bogig gekrümmt . . . . . . . . . . . . . . . . . .

2. Blüten 4-zählig. Epiphytische, krautige, mit verdicktem Wurzelstock versehene Pflanze . . . . . . . . . . . . . . . . . . .

II. Staubblätter gleich. Connectiv kurz oder kaum vorgezogen, vorn mit Anhängsel, hinten ohne solche ...................

b. Frucht beerenartig oder lederartig und unregelmässig aufreissend. S. gerade oder gekrümmt . . . . . . . . . . . . . . . . . a. Staubblätter auffallend ungleich.

I. Blüten 5-zählig.

1. Connectiv lang vorgezogen, vorn 2-spornig, hinten anhängsellos. . . . . .

2. Wenigstens das Connectiv der längeren Staubblätter vorn mit 2 langen, hinten mit 1 kurzen Sporn . . . . . . . . . . . . . . . . . . .

II. Blüten 4-zählig. Kelchrand abgestutzt, undeutlich vierlappig. Receptaculum oberhalb des verwachsenen Fruchtknotens sehr eng eingeschnürt, der Saum dann nach oben wieder sehr stark, fast tellerartig, erweitert. . . . . . . . . . 3. Staubblätter gleich oder nahezu gleich.

I. Connectiv vorn 2-lappig oder 2 -spornig oder 2-höckerig.

1. 5 deutliche, lange, bleibende Kelchblätter entwickelt. Krautige Pflanze. . . .

2. Kelchblätter fehlend oder nur als winzige Zähne entwickelt.

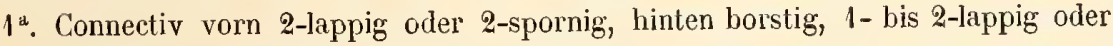
1-spornig. Sträucher . . . . . . . . . . . . . . .

$1^{\mathrm{b}}$. Connectiv hinten in einen dicken, fast quadratischen Fortsatz ausgezogen, vorn mit 2 fast kugeligen, fleischigen Anschwellungen versehen. Ausdauerndes Kraut

II. Connectiv vorn mit 1 deutlichen langen Sporn, hinten mit einem schwachen Höcker versehen . . . . . . . . . . . . . . . . . . . .

III. Connectiv vorn anhïngsellos . . . . . . . . . . . . . . . . . .

B. Frucht $1-\mathfrak{5}$-samig. Samen anselınlich. Embryo (verhältnismässig) gross, mit planconvexen oder fast blattartigen Colyledonen . . . . . . . . . . . Einzige Gattung in Afrika . . . . . . . . . . . . . . . . . . .
3. Afzeliella Gilg

4. Osbeckia $L$.

ร. Antherotoma Hook. $f$.

6. Dissotis Benth.

7. Barbeyastrum Cogn.

8. Tristemma Juss.

9. Dillophora Benth.

b. 0xysporeae.

10. Urotheca Gilg

11. Petalonema Gilg c. Sonerileae.

12. Amphiblemma Naud.

13. Cincinnobotrys Gilg

14. Calvoa Hook. f.

d. Dissochaeteae.

15. Sakersia Hook. $f$.

16. Dicellandra Hook. $f$.

17. Myrianthemnm Gily

18. Tetraphyllaster Gilg

19. Medinilla Gaud.

20. Phaeonenron Gilg

21. Preussiella.

22. Orthogoneuron Gilg

B. Memecyloideae.

23. Memecylon $L$. 


\section{A. a. Melastomatoideae-Osbeckieae.}

Diese Gruppe ist eine sehr natürliche und fest geschlossene. Die hierhergestellten Gattungen gehören fast sămtlich zur afrikanischen und madagassischen Flora, mit Ausnahme zweier, Otanthera und Melastoma, welche im indo-malayischen Gebiete heimisch sind. Diese beiden Gattungen sind sicher sehr nahe mit den afrikanischen verwandt, besonders z. B. Otanthera mit Tristemma, welche Gattungen ïberhaupt vielleicht am besten vereinigt werden müssten. - Die afrikanischen »Gattungen " stehen einander teilweise so nahe, dass sie nur durch ganz nebensảchliche Nerkmale (Haarbekleidung etc.) von einander zu trennen sind. Trotzdem aber lässt sich nicht leugnen, dass die Arten innerhalb dieser Gattungen wirklich zusammengehören. Denn wenn sich auch innerhalb der grösseren dieser Gattungen oft wieder natürliche Sectionen bilden lassen, sind doch die gesamten Arten der Gattungen durch einen ausserordentlich charakteristischen Habitus ausgezeichnet, welcher sie meist scharf zusammenfasst. Wir werden allerdings auch sehen, dass in manchen Fällen Identificierungen auf Grund von habitueller Übereinstimmung — ohne Blütenanalyse — zu grossen lrrtümern geführt haben.

\section{Nerophila Naud.}

I. c. XIV. 119; Benth. et Hook. f. Gen. I. 744; Hook. f. 1. c. 441; Cogniaux l. c. 333̈; Krasser 1. c. 155.

Osbeckiae spec. Baill. Hist. Pl. VlI. 5 und 38.

Nerophila gentianoides Naud. 1. c. XIII. t. 8 und XIV. 120; Triana 1. c. 55, t. IV. f. 38; Hook. f. l. c.; Cogniaux l. c.; Krasser l. c.

Senegambien: In Siimpfen am Senegal (Heudecot. - H. Paris.!).

Die auffallende Pflanze, welche mir in den schönen Exemplaren des Herb. Paris zur Untersuchung vorlag, zeigt thatsächlich — von den Blüten natürlich abgesehen - eine beträchtliche habituelle Übereinstimmung mit manchen Gentianaceae, so z. B. mit Faroa u. a. Ich würde es für vollständig verfehlt halten, Nerophila nach dem Vorgange Balllos's zu Osbeckia zu ziehen.

Abbildung auf Taf. I $A$. - $a$ Blütenzweigchen; $b$ und $c$ Staubblatt von der Seite und von hinten; $d$ Längsschnitt durch Receptaculum und Fruchtknoten.

\section{Guyonia Naud.}

I. c. XIV. 149; Benth. et Hook. f. Gen. I. 743; Hook. f. l. c. 443 ; Cogniaux 1. c. 336 ; Krasser 1. c. 155.

Osbeckiae spec. Baill. Hist. Pl. VII. 5 und 38.

Flores 5-meri. Receptaculum glaberrimum campanulatum. Sepala lanceolata acuta receptaculum paullo superantia. Petala ovato-oblonga, acuta. Stamina 10, aequalia, filamentis filiformibus; antherae conformes, late ovales, apice late rotundatae et 1-porosae, comnectivo basi longiuscule producto subrecto cum filamento articulato inappendiculato. Ovarium "̆-loculare usque ad medium cum receptaculo connatum, apice glaberrimum; stylus filiformis; stigma capitellatum. Fructus capsularis. Semina cochleata.

Eine zierliche, in allen Teilen völlig kahle, einjährige Pflanze mit kriechendem Stengel und aufsteigenden Ästen. Blüten einzeln in den Achseln der rhombischen Blätter, sehr selten endständig, kurzgestielt, rosafarbig.

Guyonia tenella Naud. I. c. 150 t. 6; Triana I. c. 35 t. IV f. 39; Hook. f. l. c. 4.43; Cogniaux I. c. 336; Krasser l. c. 133 .

Senegambien: auf feuchtem Boden an Bächen in der Gegend von Fouta-Dhiallon spärlich vorkommend (Heudelot. - H. Paris!).

Diese vollkommen kahle, habituell an manche Rubiacere erinnernde Melastomatacee stellt in ihren Blüten einen der einfachsten Typen, vielleicht überhaupt 'den einfachsten der Familie dar. Es fehlt hier noch fast alles, was sonst gewöhnlich zur Charakteristik dieser auffallenden Familie beiträgt, und kaum Jemand würde ohne genaue Blütenanalyse glauben, in dieser Pflanze eine Melastomatacee vor sich zu haben.

Abbildung auf Taf. I $B$. - $a$ ein blühender Zweig; $b$ Staubblatt von der Seite; $c$ Längsschnitt durch Receptaculum und Fruchtknoten.

\section{Afzeliella Gilg n. gen.}

Guyoniae spec. Hook. f. 1. c. 44.3; Cogniaux 1. c. 337; Krasser I. c. 155.

Flores 1-meri. Receptaculum canpanulatum pilis longis brunneis laxe aspersum. Sepala lineari-lanceolata, acutissima, receptaculum longit. adaequantia, margine ciliis longis rigidis numerosis notata. Petala oblonga, acutiuscula. Stamina 8 aequalia, filamentis elongatis filiformibus sepala manifeste superantibus; antherae conformes 
late ovales, apice oblusae, et 1-porosae, connectivo basi breviter producto recto inappendiculato. Ovarium 5-loculare usque ad apicem cum receptaculo connatum, apice glabrum; stylus filiformis; stigma crasse capitatum.

Ein zierliches aufsteigendes, an den Knoten wurzelndes einjähriges Pflänzchen. Blüten einzeln endständig. Stengel und die sehr breit rhombischen, langgestielten Blätter beiderseits mit langen braunen Borsten locker besetzt.

Afzeliella ciliata (Hook. f.) Gilg.

Guyonia ciliala Hook. f. 1. c. 443; Cogniaux 1. c. 337; Krasser 1. c. 155.

Sierra Leone: (Arzelius. - H. Berl.!).

Obgleich auch mir, wie Ноoker f., nur ein ziemlich dürftiges Exemplar dieser Pflanze vorlag, habe ich dieselbe doch als Vertreter einer neuen Gattung beschrieben, weil ich nicht glaube, dass sie mit Guyonia tenella zu einer Gattung zusammengestellt werden darf. Ноокег und Cogniaux hatten letztere Art nicht gesehen, so dass sie kein sicheres Urteil fällen konnten.

Dass die Gattungen Guyonic und Afreliella nahe verwandt mit einander sind, ist ja zweifellos. Aber sie stehen einander nicht näher als fast sämtliche Gattungen der Osbeckieae. Wenn wir hier überhaupt Gattungen auseinanderhalten wollen, was im Hinblick auf die grossen habituellen Verschiedenheiten am Platze sein dürfte, so müssen auch alle Consequenzen dieses Vorgehens gezogen werden.

\section{Osbeckia $L$.}

Gen. n. 46\%; D. Don in Mem. Wern. Soc. IV. 292; DC. Prodlr. III. 139; Naud. I. c. XIV. 53; Benth. et Hook. Gen. I. 74.4; Triana 1. c. 33 und 164; Hook. f. I. c. II. 44.4; Baillon Hist. PI. VII. 4 und 38.

Antherotoma Hook. f. 1. c. 4.4. p. p.

\section{Übersicht der Arten.}

A. Receptaculum nach der Blütezeit oben nicht auswachsend.

a. Antheren kurz, dick, an der Spitze abgestutzt, Connectiv unterhalb der Anthere nur wenig verlängert, ohne Anhängsel . . . . . . . . . . . . . . . . . .

b. Antheren linealisch, verlängert.

o. Blüten 4-zählig, stets in dichten Köpfchen stehend.

I. Stengel sehr dicht mit braunen, langen, abstehenden Haaren bedeckt, an den jüngeren Zweigen fast wollig. Ausgewachsene Blätter 7-nervig . . . . . . .

I1. Stengel sehr zerstreut mit kurzen anliegenden Haaren bedeckt. Ausgewachsene Blätter 5-nervig . . . . . . . . . . . . . . . . . . . . . . . . . .

$\beta$. Blüten 5-zählig, meist in mehr oder weniger lockeren Blütenständen. Receptaculum
dicht behaart. Kelchblätter mit langen, an der Spitze verzweigten Zottenhaaren abwechselnd.

I. Blätter eifürmig, lang gestielt.

1. Blumenblätter $7-8 \mathrm{~mm}$ lang. Blüten ohne Bracteen . . . . . . . . .

2. Blumenblätter etwa $1,5 \mathrm{~cm}$ lang. Blüten mit je 2 Bracteen ........

II. Blätter länglich bis lanzettlich, kurz gestielt oder fast sitzend.

1. Kelchblätter nach der Blütezeit nicht verwelkend und abfallend, sondern bis zur reifen Frucht erhalten bleibend . . . . . . . . . . . .

2. Kelchblätter nach der Blütezeit verwelkend und bald abfallend, an der reifen Frucht nie erhalten.

* Kelchblätter fast sichelfürmig schief. Der eine Staubblattkreis ganz ohne Anhängsel . . . . . . . . . . . . . . . . . .

** Kelchblätter eifürmig bis lanzettlich. Beide Staubblattkreise mit Anhängsehn.

o Receptaculum mit einfachen langen Borsten locker besetzt, nur an der Spitze 5 mit den Kelchblättern abwechselnde Haaranhängsel tragend.

† Blüten sehr kilein. Blumenblätter etwa $3 \mathrm{~mm}$ lang. Receptaculum etwa $2,5 \mathrm{~mm}$ lang . . . . . . . . . . . . . . . . t† Blüten grüsser. Blumenblätter $9-10 \mathrm{~mm}$ lang. Receptaculum $7-8 \mathrm{~mm}$ lang oo Receptaculum am Grunde von einfachen Haaren besetzt, etwa von der Mitte an dicke Kugelhaare tragend, welche zahlreiche oft sternartig angeordnete Verzweigungen aussenden . . . . . . . . . . . . . . . . . . . 000 Receptaculum ausschliesslich von Büschelhaaren oder an der Spitze sternartig
verzweigten Zottenhaaren besetzt, selten noch vereinzelte einfache Haare tragend.

※ Receptacularhaare sehr locker stehend, stachlige Kugeln bildend. . . .

Receptacularhaare dichtstehend, aus mehr oder weniger langen, an der

4. 0. Buettueriana $\operatorname{Cog} n$

5. 0. Welwitschii $\operatorname{Cogn}$.

\section{0.zambeziensis Cogn. \\ 3. 0.postpluvialis Gilg}

6. 0. congolensis Cogn.

7. 0.drepanosepala Gilg

[Afzelii Hook. f.)

8. 0. decandra $D C . \quad=$ ? 0 .

9. 0. saxicola Gilg

10. 0. senegambiensis $G$. et $P$.

11. 0. abyssinica Gilg

Spitze stark verzweigten Zottenhaaren bestehend. 
F Stenget sehr locker mit Borsten besetzt. Receptacularzotten mit ziemlich kurzen Ästen . . . . . . . . . . . . . . . . . . . 12. 0. densiflora Gilg

FF Stengel sehr dicht mit langen abstehenden Borsten bedeckt. Receptacularzotten sehr lang, mit langen, weissgelben Ästen, so dass das Receptaculum scheinbar weissseiden behart ist . . . . . . . 13. 0. calotricha Gilg

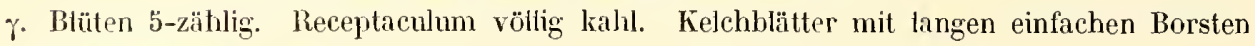
abwechselnd.

1. Blätter 3-nervig, schwach behaart................. . . . 14. 0. Buraeavi Cogn.

2. Blätter ら-nervig, völlig kahl . . . . . . . . . . . . . . . . . . 15. 0.Brazzaei Cogn.

B. Receptaculım nach der Blütezeit an der Spitze in einen langen auffallenden, schlotfürmigen

Fortsatz verlängert . . . . . . . . . . . . . . . . . . . . . 16. 0.tubulosa Smith

1. Osbeckia Afzelii (Hook. f.) Cogn. l. c. 330 .

Antherotoma Afzelii Hook. f. 1. c. 4.4.

Sierra Leone: (Arzenuus. - II. Berl.!).

Cogniaux hat diese Art nicht gesehen. Es mag dies der Grund davon sein, dass er die Pflanze an einen falschen Platz gebracht hat. Sie darf nämlich nicht zu seiner Section V, Antherotoma, gebracht werden, denn sie gehört trotz ihrer grossen habituellen Öhnlichtreit absolut nicht in die Verwandtschaft von Antherotoma Naudini. Zweifellos müsste O. Afzelii ihre richtige Stellung in Cogruux's Section IV, Arthinae, erhatten, für welche alle Befunde anf das Beste passen.

Sehr wahrseheinlich ist es mir, dass $O$. Afrelii nichts anderes ist ats die halbverschollene und nur sehr wenig gekannte o. decandra. Diese Art, welche früher ganz ohne Beschreibung in der Litteratur ging, wurde zuerst von Cogsiaux charakterisiert, alterdings auch nur in sehr kurzer und oft so unbestimmter Weise, dass ich nicht sicher bin, ob ihm die Originalpflanze vorgelegen hat. Seine Beschreibung von $O$. decandra passt ganz ausgezeichnet auf $O$. Afzelii - abgesehen von dem Verhalten der Antheren, weiche zwar von Cogviax nicht hesehrieben werden, die aber nach Cogsraux's Stellung der Art ganz abweichend sein müssten. Vor allem stimmt jedoch in ausgezeichnetster Weise die Kleinheit der Biätter, Receptaculen und Blüten bei O. decandra auch auf $O$. Afrelii, sonst auch nicht annähernd auf irgend eine andere Art der Gattung. Nehmen wir noch dazu, dass beide Arten von Afzecus gesammelt sind, dass ein Exemplar (O. Afrelii) des Berliner Ilerbariums, wahrscheinlich von Afzelıus Hand, als Osbeckia reylanica bestimmt ist (Osbeclia decandra wurde zuerst von Suıт, einem Zeitgenossen Afzelius', als Varietiit der $O$. zeylanica beschriehen!), und dass endlich im Originalherbarium Afzelus' zu Upsala kein anderes Exemplar als $O$. decandra zu bestimmen war, so wird es uns gewiss sehr wahrscheinlich werden, dass wir es hier mit einer und derselben Pflanze zu thun haben, welche doppett beschrieben wurde.

Abbildung auf Taf. I $C$. $-a$ Knospe; $b$ und $c$ längeres und kürzeres Staubblatt von der Seite; $d$ Längsschnitt durch Receptaculum und Fruchtknoten; $e$ Samen.

2. Osbeckia zambeziensis Cogn. 1. c. 331 .

Sambesegebiet: am Sambese Carvaluo a. 1885. - H. Berl.! ex Herb. Conimbr.!).

3. Osbeckia postpluvialis Gilg n. sp.; herba annua erecta vel curvato-erecta, caule humili eramosa pilis brevibus appressis densiuscule hirto; foliis lanceolatis vel oblongis, infimis saepius ovato-oblongis, omnibus apice acutiusculis, basin versus sensim in peliolum brevissimum angustatis, 3-vel si mavis $\ddot{3}$-nerviis, sed nervo marginali angustissimo, utrinque subaequaliter pilis longiusculis appressis laxe aspersis; floribus 4-meris in apice caulis vel ramorum vel rarius in foliorum axillis in dichasia multiflora capitato-conferta collectis, pedicellis minimis; receptaculo pilis longis griseis vel brumescentibus laxe asperso; sepalis lanceolatis, apice setosis, receptaculum longil. subadaequantibus; petalis late obovato-orbicularibus, subrotundatis; staminibus omnibus aequalibus, connectivo basi manifeste producto antice bicalloso; stylo elongato; ovario apice setoso.

Die einfachen oder seltener schwach verzweigten Pflänzchen werden $10-23 \mathrm{~cm}$ hoch. Blätter $2,5-5 \mathrm{~cm}$ lang, $1-1,6 \mathrm{~cm}$ breit, Blattstiel 2-3 mm lang. Receptaculum 3-4 $\mathrm{mm}$ lang, etwa $3 \mathrm{~mm}$ dick. Staubblätter etwa $1 \mathrm{~cm}$ lang. Griffel $1,2-1,3 \mathrm{~cm}$ lang.

Ghasalquellengebiet: Land der Djur, im halbdürren Steppengrase bei der grossen Seriba Ghattas (Schweinfurti u. 4.289. - Blïhend im November 1870. - H. Berl.!).

4. Osbeckia Buettneriana Cogn. ex Büttn. in Verh. Bot. Vereins Brandenburg XXXı. 9̈̈; Cogn. l. c. 333.

Gabun: Sibangefarm (Bürtner n. 23. - Bliihend in September. - H. Berl.!); Ogowe (Thollon. — H. Paris.!).

3. Osbeckia Welwitschii Cogn. l. c. 333 .

Angola: Pungo Andongo, 800-1200 m ü. M. (Welwitsch n. 907. - H. Berl.! und H. Conimbr.!).

6. Osbeckia congolensis Cogn. ex Büttn. in Verh. Bot. Vereins Brandenlourg XXXI. 95; Cogn. 1. c. 314. Osbeckia congolensis, ק. robnstior Cogn. ex Büttn. in Verh. Bot. Vereins Brandenburg XXXl. 93; Cogn. l. c. 314 .

Wie die zahlreichen, mir vorliegenden Exemplare beweisen, lässt sich ein Unterschied zwischen der Hauptform und der Varietai nicht aufrecht erhalten. 
Ich sah die Pflanze von folgenden Standorten:

Sierra Leone(?): (Scott Elliot n. 5172. - H. Berl.!).

Unteres Congogebiet: Interhalb Kibaka (Bütrven n. 24. - Blühend im November. - H. Berl.!), bei Vista (Chaves. - Blühend im December. - H. Berl.!); zwischen Bolobo und Lukolela (Bútrver n. 25. Blühend im November. - H. Berl !); am Slanleypool (Hens).

Gabun-Loango: im Cyperussumpf südlich von Ponta negra (Soraux n. 103. — Blïhend im August. H. Berl.!).

Oberes Congogebiet: Baschilange, am Lulua-Fluss, 91/2 suidl. Br. Pogge n. 137. — Blühend im Iai. — H. Berl.!); am Kassai, $63{ }^{3}{ }^{\circ}$ südl. Br. (Pogge n. 94.1. - Blühend in September. - H. Berl.!); in der Campine am Lulua, $6^{\circ}$ südl. Br. (Pogge n. 943. - Blühend im November. - H. Berl.!).

Die Stellung, welche Cograux dieser Art anweist, scheint mir nicht die richtige zu sein; denn O. congolensis gehört zweifellos (wie übrigens Cognıaux [in Verh. Bot. Vereins Brandenburg XXXI. 95] selbst angiebt) in die Verwandtschaft von O. senegambiensis. Die Unterschiede zwischen diesen beiden Arten sind nur untergeordneter Natur, Artunterschiede, welche aber nicht genügen, um die Arten in weit geschiedenen Sectionen der Gattung unterzubringen. Vor allem konnte ich mit Sicherheit feststellen, dass das Connectiv von O. senegambiensis kaum weiter vorgezogen, auch die Anhängsel kaum grösser sind, als bei unserer Art.

7. Osbeckia drepanosepala Gilg n. sp.; herba (an perennans?) erecta spectabilis caule valido obsolete tetragone, ramoso, pilis longis brunnescentibus densinscule patentibus obsito; foliis lanceolatis vel oblongolanceolatis, breviter petiolatis, apice acutis vel acutissimis, basi cuneatis, manifeste ら-nerviis, integris, utrinque subaequaliter pilis longis subsparsis densiuscule obtectis; horibus b̆-meris in apice caulis ramorumque in cymas multilloras confertas subcapitatas dispositis, cymae ramis numerosis semper in cincinnos $\ddot{0}-7$-floros confertifloros abeuntibus; receptaculo ovato pilis simplicibus longis griseis dense obtecto, in parte receptaculi superiore saepius hinc inde appendicibus breviusculis apice stellato-setosis intermixtis; sepalis falcato-obliquis, anguste lanceolatis, acutissimis, apice dense setosis, mox deciduis; petalis valde obliquis late obovatis; staminibus subaequalibus, aequilongis, antheris 5 conneclivis breviter inferne elongatis antice bicallosis, 5 connectivis haud elongatis ecallosis instructis; stylo elongato; ovario apice setoso.

Dissotis Irvingiana Engl. in Exped. Gazelle; Botanik, S. VII.

Die mir vorliegende, unten unvollständige Pflanze ist über $40 \mathrm{~cm}$ lang. Die Blätter sind $5-8 \mathrm{~cm}$ lang, 1 -2 cm breit. Das Receptaculum ist $7-8 \mathrm{~mm}$ hoch und $5 \mathrm{~mm}$ dick. Die Kelchblätter sind etwa $3,5 \mathrm{~mm}$ lang, 1,5 mm breit. Blumenblätter $8 \mathrm{~mm}$ lang und fast ebenso breit. Staubblätter etwa $1 \mathrm{~cm}$ lang. Griffel $12 \mathrm{~mm}$ lang.

Unteres Congogebiet: auf einer Insel bei Ponta da Lenha (Nauman n. 215. - Bliihend im September 1874. - H. Berl.!).

Eine sehr interessante Art, welche besonders durch die sichelartig schiefen Kelchblätter auffällt.

8. Osbeckia decandra (Sm.) DC. Prodr. IIl. 143; Cogn. l. c. 334.

Osbeckia zeylanica, var. decandra Sm. in Rees Cyclop. ex DC. 1. c.

Dissotis decandra Triana 1. c. 38.

Sierra Leone: (Afzelius).

Ich habe diese Art hier aufgezählt, obgleich ich der Ansicht bin, dass sie mit $O$. Afrelii zusammenfällt, wie ich S. 6 genauer ausgeführt habe. Da ich dies jedoch nicht mit vollster Sicherheit erweisen kann, andererseits auch nicht weiss, ob Cogntaux das Original gesehen und deshalb dic Art in die Nähe der O. senegambiensis gebracht hat, war es für mich das zweckmässigste, die Art hier wenigstens zu nennen.

9. Osbeckia saxicola Gilg n. sp.; lierba (an perennans?) erecta spectabilis caule valido manifeste tetragono, multiramoso, ramis erecto-patentibus pilis longis brunneo-griseis patentibus laxiuscule obtectis, ad nodos dense setosis; foliis lanceolatis vel saepius anguste lanceolatis, apice acutis vel acutissimis, basi sensim

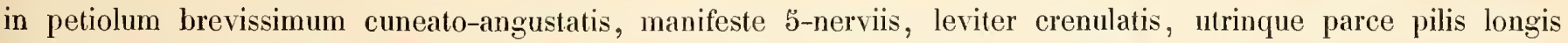

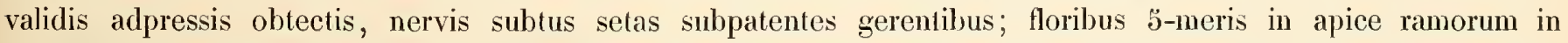
cymas subpaucifloras 3-7-floras dispositis, cymae ramis unifloris vel plerumque in cincinnos 2- vel rarius 3-floros abeunlibus; bracteis parvis tarde deciduis; receptaculo pilis longis griseis simplicibus laxiuscule obtecto, appendicibus non nisi ad receptaculi apicem cum sepalis alternantibus evolulis; sepalis lanceolatis, apice rotundatis et setis longis instructis; petalis obovatis rotundatis; staminibus omnibus aequalibus, connectivo paullo producto et antice bicalloso; stylo elongato; ovario parvo apice setoso.

Die mir vorliegenden Pflanzen sind wohl bis einen Meter lang. Receptaculum etwa $5 \mathrm{~mm}$ lang, $3 \mathrm{~mm}$ breit. Kelchblätter $4 \mathrm{~mm}$ lang, $2 \mathrm{~mm}$ breit. Blumenblätter $9-10 \mathrm{~mm}$ lang, 4-5 $\mathrm{mm}$ breit. Staubblätter etwa $12 \mathrm{~mm}$ lang. Griffel $12-13 \mathrm{~mm}$ lang. 
Ghasalquellengebiet: Land der Niamniam, auf dem Granitfelsen Nambia, östlich vom Bache Kischi (Schweinfurth n. 3764. - Bliihend im Mai 1870. - H. Berl.!); Land der Djur, bei der grossen Seriba Ghatlas, in der Steppe (Schwernfurtu 1. 1994, 1970, 1494. und 1494. ${ }^{\mathrm{a}}$ - Blühend vom April-October. H. Berl.!); Land der Mittu, Mvolo (Schweinforth Ser. III. n. 128. - Blihend im December. - H. Berl.!), am Wege zu Ngamas Dorf (Schweinfurth Ser. III. n. 129. - Blïhend im Dezember. - H. Berl.!).

Abbildung auf Taf. I. $D$. - $a$ Blütenzweig; $b$ Staubblatt von der Seite; $c$ Längsschnitt durch Receptaculum und Fruchtknoten.

10. Osbeckia senegambiensis G. et P. Fl. Seneg. I. 310 ; Naud. l. c. XIV. 60; Hook. f. l. c. 443. Cogn. 1. e. 334 .

Dissotis senegambiensis Triana 1. c. 58 .

Senegambien: (Perrotret, Leprieur. - H. Paris!), »Gambia Boundary Commission 1890-91 « (J. BrownLester n. 521. - Bliihend im März. - H. Berl.!); Cap Verde (Döllixger ex Cogniaux).

11. Osbeckia abyssinica Gilg n. sp.; perennans radice crassa, caule (ut videtur) solitario erecto superne parce ramoso, pilis longiusculis rigidis flavescentibus laxe asperso; foliis lanceolatis vel ovato-lanceolatis, breviter petiolatis, basi subcuneatis, apice acutissimis, margine sermlatis, utrinque pilis longis flavescentibus

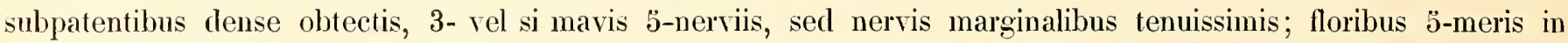
apice caulis ramorumque in cymas paucifloras confertas dispositis, cymae ramis unifloris vel in monochasia 2-, rarissime 3 -flora abeuntibus; receptaculo late orato pilis brevibus crassis apice ramos paucos rigidos emittentibus parce asperso, appendicibus longis non nisi ad receptaculi apicem cum sepalis alterantibus evolutis; sepalis ovatis acutis apice setis longis instructis manifeste ciliatis; petalis suborbicularibus, parce obliquis, manifeste unguiculatis, longe ciliatis; staminibus omnibus aequalibus, connectivo paullo producto et antice bicalloso; orario parvo libero apice setoso; stylo crassissimo, subinflato, elongato.

Dissotis Irvingiana Hook. l. c. 4.33 p. p.; Cogniaux 1. c. 375 p. p.

Die mir vorliegende Pflanze ist etwa $60 \mathrm{~cm}$ hoch und verhältnismässig wenig verzweigt. Die Blätter sind $4-6 \mathrm{~cm}$ lang, $1,3-1,5 \mathrm{~cm}$ breit. Receptaculum etwa $6 \mathrm{~mm}$ hoch, $4 \mathrm{~mm}$ dick. Kelchblätter $3 \mathrm{~mm}$ lang, $2 \mathrm{~mm}$ breit. Blumenblätter gerade vor dem Aufblühen 5-6 $\mathrm{mm}$ lang. Griffel in der blühbaren Knospe 8-9 $\mathrm{mm}$ lang und auffallend dick.

Abyssinien: an trockenen Orten in der wellenförmigen Ebene bei Currata, $2000 \mathrm{~m}$ ï. M. (Schupen a. 1863 n. 1437. - Bliihend in Dezember. - H. Berl.!).

Diese neue Art von Osbeckia wurde von Ноокеr, später auch von Cognuaux, zu Dissotis Ivvingiana gezogen, welcher sie - wie überhaupt alle Osbeclia-Arten aus der Verwandtschaft von O. senegambiensis - habituell allerdings ausserordentlich nahe kommt. Mir standen zwar keine geöffneten Blüten zu Gebote, doch zeigte die genaue Analyse von blühbaren Knospen, dass die Pflanze infolge der völlig gleichartigen Staubblätter zu Osbeclia, und nicht zu Dissotis gehört.

12. Osbeckia densiflora Gilg n. sp.; herba (an annua?) caule erecto vel curvato-erecto, manifeste ramoso, ramis acute tetragonis pilis longis albidis patentibus laxe aspersis; foliis lanceolatis vel oblongolanceolatis vel supremis ovato-oblongis, breviter petiolatis, basi rotundatis vel subrotundatis, apice acutis rel acutissimis, manifeste crenulatis, ə̈-nerviis, utrinque pilis longiusculis appressis laxe vel saepius laxissime aspersis; tloribus "̆-meris in apice caulis in cymas valde confertas subglobosas dispositis, cymae ramis fere senper in monochasia 2-4-flora conferta abeuntibus rarissime unifloris, pedicellis nullis; receptaculo crasse ovato, pilis vel appendicibus subelongatis apice multiramosis (ramis brevibus) densiuscule obtectis; sepalis ovato-lanceolatis, acutis, apice multisetosis; petalis late obovatis, obliquis; staminibus omnibus aequalibus, connectivo, vix producto antice 2-calcarato; stylo elongato.

Die mir vorliegenden Pflanzen sind bis $1 / 2 \mathrm{~m}$ hoch und reich verzweigt. Die Blätter sind $4-8 \mathrm{~cm}$ lang, $1-2,5 \mathrm{~cm}$ breit, Blattstiel 2-8 mm lang. Receptaculum $\breve{5-6} \mathrm{~mm}$ hoch, $3 \mathrm{~mm}$ dick. Kelchblätter $5 \mathrm{~mm}$ lang, $2 \mathrm{~mm}$ breit. Blumenblätter $14 \mathrm{~mm}$ lang, $8 \mathrm{~mm}$ breit. Staubblätter $9-10 \mathrm{~mm}$ lang. Griffel $15 \mathrm{~mm}$ lang.

Nyassaland: (Buchanas a. 1891 n. 114, a. 1895 n. 84. - H. Berl.!; n. 484. -- H. Schweinfurth!).

13. Osbeckia calotricha Gilg 1. sp.; herba (an annna?) caule tetragono manifeste ramoso, pilis longis vel longissimis flavescentibus patentibus vel subrellexis densissime obtecto; foliis breviter petiolatis lanceolatis, basi rotundatis vel subrotundatis, apice acutissimis, serrulatis, らூ-nerviis nervis marginalibus tenuibus, utrinque pilis longis appressis vel subtus subpatentibus laxe aspersis; floribus ö-meris in apice caulis ramorumque in cymas paucifloras (3- 5 -floras) confertas dispositis, pedicellis nullis; receptaculo ovato pilis vel appendicibus longis apice in ramos numerosos longissimos subsericeos albido-flavescentes abeuntibus dense restito; sepalis 
lanceolatis, acutis, apice multisetosis; petalis obovatis obliquis rotundatis; staminibus omnibus aequalibus vel subaequalibus, connectivo paullo producto antice 2-calcarato; stylo elongato.

Das mir vorliegende Stück der Pflanze ist etwa $30 \mathrm{~cm}$ lang. Blätter $3-5 \mathrm{~cm} \mathrm{lang,} 8-11 \mathrm{~mm}$ breit. Receptaculum 6-7 mm lang, etwa $3 \mathrm{~mm}$ dick. Kelchblätter $5 \mathrm{~mm}$ lang, $2 \mathrm{~mm}$ breit. Blumenblätter $11 \mathrm{~mm}$ lang, 6-7 mm breit. Staubblätter $10-12 \mathrm{~mm}$ lang. Griffel $14 \mathrm{~mm}$ lang.

Centralafrikanisches Seengebiet: Madi, zwischen Fort Fatiko und Ismaïlia, $3^{\circ} 1^{\prime} 7^{\prime \prime}-4^{\circ} 34^{\prime} \mathrm{n}$. Br. (S. S. W. Baker n. 201. - H. Scnweinfurth!).

14. Osbeckia Buraeavi Cogn. I. c. $33 \ddot{\text {. }}$

Gabun: in Steppen bei Franceville und Brazzaville (Tuollov n. 443. - H. Paris!).

1ə̈. Osbeckia Brazzaei Cogn. 1. c. 335 .

Gabun: an feuchten Stellen bei Alima-Lekesi(?) (J. de Brazza n. 4\%. - Blithend im December oder Janıar. - H. Paris!).

16. Osbeckia tubulosa Sm. in Rees Cyclop. ex DC. Prodr. III. 14.3; Hook. f. 1. c. 44.2; Cogniaux l. c. 332 .

Dissotis tubulosa Triana l. c. 58 .

Sierra Leone: (Afzeluus, Scott Elliotr n. 3828. - H. Berl.!; Don, Vogel, Barter, Wiletfield. H. Kew), bei Free Town, an Bächen (Preuss n. 54, W. H. Browx [U. S. Eclipse Exped. to western Africa] n. 46. - Blïhend rom November his Februar. - H. Berl.!).

Diese Art weicht von allen übrigen der Gattung durch den charakteristischen Receptacularschnabel der Früchte ab, welcher bei allen Exemplaren sehr deutlich hervortritt.

Abbildung auf Taf. I. E. - $a$ Blüte; $b$ Staubblatt von der Seite; $c$ Frucht, den verlängerten, schnabelförmigen Receptacularfortsatz zeigend.

\section{Antherotoma Hook. $f$.}

in Benth. et Hook. f. Gen. plant. I. 7430 und in Oliver Fl. trop. Afr. II. 4.44; Triana 1. c. 57; Krasser 1. c. 133.

Osbectia Sect. Antherotoma Naud. 1. c. XIII. t. 6, f. 10 und XIV. 36 ; Cogniaux I. c. 330.

Flores 4-meri. Receptacuhum campanulatum setis longis laxe obtectum, appendicibus brevibus crassis apice pauciramosis hine inde intermixtis. Sepalis ovatis tarde deciduis appendicibus longis apice dense setosis alternantibus. Petala obovata, apice setosa. Stamina 8 aequalia; antherae conformes oblongae, truncatae, poro magno apicali hiantes, loculis haud undulatis, connectivo hasi longiuscule producto antice manifeste 2-calcarato. Ovarium receptaculo usque ad medium adnatum, 4-loculari, vertice patella subprofunda membranacea margine valde ciliata coronatum. Stylus filiformis. Stigma punctiforme. Capsula membranacea, 4 -valvis. Semina cochleata.

Ein zierliches, oft winziges $(3-5 \mathrm{~cm}$ hoch), oft ansehnliche Grösse erreichendes (20-25 cm hoch), einjähriges Pflänzchen, unverzweigt oder oft sehr dicht buschig verzweigt (offenbar eine Folge ärmeren oder reicheren Bodens), in allen Teilen mehr oder weniger schwach einfach behaart. Blätter fast sitzend, eifürmig-länglich. Blüten klein und unscheinbar, rosafarben, am Ende des Stengels und der Zweige in wenig- bis vielblütigen doldenförmigen oder kopfigen Cymen.

Hierher nux eine sehr veränderliche Art:

Antherotoma Naudini Hook. f. 1. c.; Triana 1. c.

Antherotoma antherotoma Krasser 1. c.

Osbeckia antherotoma Naud. 1. c.; Cogniaux 1. c.; Taubert 1. c. 295.

Madagaskar: auf Bergen (Bo.ter, Bolvin, Parker, Baron 857 ex Cogniaux), bei Tananarivo (Goudot. H. Paris), im Ankanatra-Gebirge, zwischen Gras (Huddebrandt n. 3857. - Bliihend im Januar. - H. Berl.!', im Amber- oder Ambohitsi-Gebirge, an sterilen, sonnigen Plätzen (Hı́dernaxd n. 3388. — Blihend im März. H. Berl.!).

Comoren: (Cimapeler. - H. Paris), Mayotte (Bowin n. 3418. - H. Berl.!), Comoro, auf Gebirgssteppen zerstreut (Sснипт n. 220. - Blühend im Juni. - H. Berl.!).

Abyssinien: Sanka-Berr, auf Bergen $2200 \mathrm{~m}$ i. M. (Schuper a. 1863 n. 123\%. - Bluibend im October. H. Berl.!).

Ghasalquellengebiet: Dar Fertit, in Sumpfniederungen westl. vom Kuru (Schweinfurth Ser. 11l. n. 126. Fruchtend im Januar. - H. Berl.!); Land der Bongo, am Addaï im Sumpfsteppengrase versteckt (Scıwernfurtı n. 2536. - Bliihend im October. - H. Berl.!). 
Usambara: Mlalo, auf trockenen Hügeln (Houst n. 628. - Bliuhend im Juni. - H. Berl.?).

Centralafrikanisches Seengebiet: Bukoba (Stumuann n. 1561 und 3825. - Blühend rom Februar bis April. - H. Berl.!).

Nyassaland: am Tanganjika (Nutr); Shire-Hochland (Buclunar a. 1891 n. 754. - H. Berl.!, n. 485. H. Schweinfurti!!).

Senegambien: Am Senegal (Brunner ex Cognudx).

Angola oder Huilla: (Welwitsch n. 909 und 920. - H. Berl.!).

Abbildung auf Taf. I. $F$. $-a, b, c$ Staubblätter von der Seite und ron vorn; $d$ Längsschnitt durch Receptaculum und Fruchtknoten.

\section{Dissotis Benth.}

in Hook. Niger Fl. 346; Benth. et Hook. Gen. I. 74.6; Triana 1. c. 57 und 164; Hook. f. 1. c. 447; Cognianx 1. c. 362. IIeterotis Benth. 1. c. 34.7.

Melastomastrum Naud. I. c. XIll. 296.

Argyrella Naud. 1. c. Xill. 300.

Osbeckiac, Sect. Macrodesmiae Naur. 1. c. XIV. 34.

Osbeckiastrum Naud. 1. c. XIV. 118.

Lepidanthemum Klotzsch in Peters Moss. Bot. 64.

Osbeckiae spec. Baill. Hist. PI. VIl. 5 und 38.

\section{Übersicht der Arten.}

A. Blüten 丂̆-zählig; von grossen, umscheidenden und bleibenden Bracteen eingehültt, oft küpfchenförmig zusammenstehend. Kejchblätter während oder nach der Blüte nicht abfallend.

a. Btüten einzeln oder in lockeren, wenigblütigen (2-3) Dichasien an Stengeln und Zweigen endständig, jede einzelne Blïte von den Bracteen eingeschlossen.

๘. Blattstiele kurz, $5-10 \mathrm{~mm}$ lang.

I. Internodien 2-4. cm lang, Blumenblälter etwa 2,5 cm tang . . . . . . . . 1. D. segregata (Bth.) Hook.f.

II. Internodien 0,7-1,4 cm lang, Blumenblätter 1,2-1,4 cm lang . . . . . . . 2. D. minor Gilg

3. Untere Blattstiele 2-3,5 cm lang . . . . . . . . . . . . . . . 3. D. petiolata Hook. $f$.

b. Blüten zu mehreren in dichtgedrängte Köpfchen vereinigt, die Köpfchen von Bracteen umhüllt.

a. Receptaculum ganz mit Sternhaaren besetzl . . . . . . . . . . . . . . . .

ß. Receptaculum von unten bis etwa zur Mitte oder nur in der Gegend der Mitte dicht behaart, von da an ganz kahi.

1. Behaarung des Receptaculums aus einfachen Borsten bestehend. . . . . . . .

II. Behaarung des Receptaculums durch Sternhaare oder Schuppenhaare gebildet. . .

\%. Receptaculum kahl oder höchstens am Grunde von Haarborsten umgeben.

I. Stengel hartholzig mit weisser oder weissgrauer Rinde. Blätter klein, 2-4 cm lang, sehr lurz gestielt. . . . . . . . . . . . . . . . . . .

II. Stengel krautig oder nur sehr schwach verholzt, mit grüner Rinde. Blätter ansehntich gross, $6-12 \mathrm{~cm}$ lang, sehr deutlich gestielt.

1. Blätler mit kurzen, ziemlich starren, angedrückten IIaaren besetzt.

* Stengel straff aufrecht. . . . . . . . . . . . . . . . . . .

** Stengel niederliegend und an den unteren Knoten wurzelnd . . . . . . .

2. Blätter besonders unterseits mit ziemlich langen und weichen, abstehenden Haaren besetzt . . . . . . . . . . . . . 10. D. hirsuta Hook. $f$.

B. Blüten 4-zählig in meist vielblütigen, dicht gedrängten, dichasialen Künüueln oder Köpfchen, selten nur zu wenigen. Bracteen klein, bleibend. Kelchblätter ausdanernd oder wenigstens erst an der reifen Frucht abfallend.

a. Blüten zu wenigen (2-4) locker endständig.

๙. Kejchblïter fast kahl, schwach gewimpert . . . . . . . . . . . . 11. D. gracilis Cogn.

ア. Kelchblitter an der Spitze mit einem Büschel langer Borsten. . . . . . . . . 12. D. penicillata Gilg

b. Blüten in grosser Zahl $(10-30)$ an den Zweigenden dicht zusammengedrängt (an dürftigen

Ästchen manchmal nur 4-6).

a. Stengel mit kurzen, borstigen Haaren locker besetzt ............. 13. D. debilis (Sond.) Triano

$\beta$. Stengel mit langen, braunen, abstehenden Haaren sehr dicht bedeckt

13. D. debilis (Sond.) Triana

[Triane 
C. Blüten $\mathfrak{b}$-zählig, einzeln oder in wenigblütige (2-3-blütige), lockere Dichasien vereint. Bracteen 2, klein, hinfällig, nur selten ansehnlicher. Kelchblätter ausdauernd. Kräuter mit unverholztem, weichem stengel.

a. Receptaculum völlig kahl, am oberen Rande (von den Kelchblältern) mit 10 sehr langen, gefransten Striegelhaaren besetzt. . . . . . . . . . . . . . . . . . . .

b. Receptaculım mit einfachen, langen Striegelhaaren locker besetzt . . . . . . . . . .

c. Receptaculum mit dicken Borsten besetzt, welche an der Spitze sternartig verästelt sind. . Blätter 3-nervig. Blüten gross und schün, Blumenblätter bis zu $2 \mathrm{~cm}$ lang. . . . .

3. Blätter 5-nervig. Blüte klein, Blumenblätter $7-9$ nm lang . . . . . . . . . . . .
üten 5-zählig, meist gross und schön, am Ende der Stengel und Äste zu vielblütigen, meist

D. Blüten 5-zählig, meist gross und schön, am Ende der Stengel und Äste zu vielblütigen, meist
dicht gedrängten Dichasien oder Honochasien vereinigt, oft frühzeitig abfallend. Bracteen klein oder ansehnlich, hinfällig. Kelchblätter ausdauernd. Halbstrüucher oder Sträucher nit holzigem, seltener dickfleischigem Stengel.

a. Receptaculum völlig kahl, an seinem oberen Rande mit einigen langen, starren Borsten versehen.

b. Receptaculum mit kuwzen, zerstreuten, anliegenden Borsten besetzt.

c. Receptaculum ziemlich dicht mit langen braunen, an Grunde bulbüs verdickten Borsten besetzt . . . . . . . . . . . . . . . . . . . . . . . . .

d. Receptaculum locker mit verschieden grossen, dicken, nach oben sehr reich verzweigten Haarborsten besetzt . . . . . . . . . . . . . . . . . . . . . . . . . . . . .

e. Receptaculum sehr dicht mit kurzen Sternhaaren bedeckt, meist fast filzig. Blätter ebenfalls sternhaarig.

a. Receptaculum nur Sternhaare tragend . . . . . . . . . . . . . . . . . . .

3. Receptaculum ausser den Sternhaaren noch von ziemlich langen braunen Borsten besetzt

ö. D. antennina (Sm.) Triana 16. D. deenmbens (P.B.) Triana

17. D. rotundifolia (Sm.)

Triane

18. D. tristemmoides Cogne.

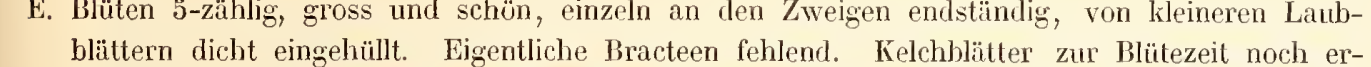
balten, an der reifenden Frucht abfallend. Receptaculum von langen, weissen, seidenartigen Haaren dicht eingehüllt. Strauch.

a. Blätter 3-nervig. . . . . . . . . . . . . . . .

25. D. cryptantha Bak.

b. Blätter sehr kräftig 5-nervig . . . . . . . . . . . . . . . . . . . . . . 26. D. speciosa Taub.

F. Blüten 5-zählig, gross und schön, einzeln an den Zweigen ebenständig, von kleineren Laubblättern und grossen Bracteen eingehüllt. Bracteen frïhzeitig hinfällig. Kelchblätter zur Blütezeit noch erhalten, an der reifenden Frucht abfallend. Receptaculum von langen weissen, seidenartigen Haaren dicht eingehüllt. Strauch

19. D. Johnstoniana Bak. $f$.

20. D. Whytei Bali.

21. D. polyantha Gily

2. D. cordata Gilg

23. D. incana (E. Mey.) Triana

24. D. angolensis Cogn.

G. Blüten 5-zählig, sehr selten 4-zühlig, meist gross und schön, in reichblütigen dichasialen Rispen oder Scheintrauben. Bracteen meist hinfällig, selten bleibend. Kelchblätter sehr frühzeitig, meist schon während der Blütezeit, abfallend.

a. Receptaculum wie die ganze Pflanze vüllig kahl

b. Receptaculum locker mit sehr kurzen, aber an der Basis stark verdickten Haaren besetzt.

๔. Blätter 3-̋̈-nervig, oberseits mit sehr kurzen, dickeu Borsten dicht bedeckt, unterseits an den Nerven rauhhaarig, im übrigen mit kurzen Borsten besetzt. . . . . . 29. D. Melleri Hook. $f$. ア. Blätter 7-nervig.

* Blätter eilanzettlich, undeutlich gekerbt. . . . . . . . . . . . . . . . . .

** Blälter schmal eiförmig oder eilänglich, fein und scharf gesägt . . . . . . . . .

c. Receptaculum mit sehr kleinen, am oberen Rande gefransten Schuppen oder am Grunde verdickten, nach oben verzweigten, kurzen Borsten ziemlich locker besetzt.

๙. Stengel kahl, Blitter fast kahl, nur mit wenigen, sehr kurzen und dicken Haaren besetzt 32. D. longicaudata Cogn.

३. Stengel und Blätter beiderseits dicht behaart . . . . . . . . . . . . . . . 33. D. Canllolleana Cogn.

d. Receptaculum von langen, verzweigten oder ausgefransten Schuppen dicht eingehüllt . . 34. D. Thollonii Cogn.

(Hierher wahrscheinlich auch 35. D. Sizenandii Cogn.)

e. Receptaculum von langen, seidenartigen, aber starren, manchmal verzweigten Haaren dicht eingehüllt.

๙. Blätter beiderseits dicht zottig behaart. . . . . . . . .

36. D. Trothae Gilg

§. Blätter oberseits mit locker gestellten, kurzen Borsten besetzt.

I. Stengel und Blattstiele kahl oder nur mit wenigen Borsten besetzt. Blätter unterseits sehr schwach behaart, an der Basis abgerundet . . . . . . . . . . . . . . .

II. Stengel und Blattstiele sehr dicht mit breiten, stark ausgefransten Schüppchen be-

deckt. Blätter unterseits stark behaart, an der Basis herzförmig. . . . . . . . 38. D. pulcherrima Gilg

f. Receptaculum mit starken Zottenhaaren mehr oder weniger dicht besetzt, welche an der Spitze verdickt sind und hier zahlreiche, sternartig angeordnete Äste tragen.

๗. Blüten 4-zählig. Bracteen sehr lange bestehen bleibend. 
I. Blüten in dichten, kurzen Dichasien stehend. Blätter sehr dicht behaart . . . . 39. D. alpestris Taub.

II. Blüten in langgestreckten vielblütigen Wickeln. Blätter ziemlich locker behaart . . 40. D. cincimmata Gilg

3. Blüten 5̈-zählig. Bracteen frühzeitig hinfällig.

I. Blätter mit abstehenden, lockeren, langen Borsten besetzt.

1. Kelchblätter auffallend schief. Blüten sehr gross . . . . . . . . . 41. D. Barteri Hook. $f$.

2. Kelchb]ätler nicht schief.

* Blumenblätter $10-15 \mathrm{~mm}$ lang. . . . . . . . . . . . 42. D. Irvingiana Hook.

* Blumenblätter $2-2,5 \mathrm{~cm}$ lang . . . . . . . . . . . . . . 43. D. grandiflora (Afi.) Bth.

II. Blätter oberseits mit sehr kurzen, starren, lockeren Härchen besetzt.

1. Blätter lanzettlich . . . . . . . . . . . . . . . 44. D. Schweinfurthii Gilg

2. Blätter eiförmig bis breit herzeiförmig.

* Stengel und Blätter beiderseits dicht mit sehr rauhen, starren Härchen besetzt, fast glaspapierartig . . . . . . . . . . . . . 45. D. scabra Gilg

** Stengel dicht mit einem braunen, feinen Haarfilz überzogen. Blätter unterseits weichhaarig. . . . . . . . . . . . . . . . .

III. Blätter heiderseits mit einem ziemlich langen, weichen, zierlich angeordneten Haarfilze bedeckt.

1. Blumenblätter $1,8-2 \mathrm{~cm}$ lang

2. Blumenblätter $3,5-4 \mathrm{~cm}$ lang.

* Blätter 5-nervig. Venen kaum sichtbar . . . . . . . . . . . . 4.8. D. magnifica Gilg

** Blätter 7-nervig. Venen unterseits deutlich hervortretend. . . . . . . . 49. D. violacea Gilg

IV. Blätter oberseits mit sichelartig gekrümmten, unten verdickten Haaren dicht besetzt, am gekerbten Rande ebenfalls solche Sichelhaare tragend.

1. Blattfläche unterseits mit kurzen weichen Wollhaaren besetzt, die Nerven kurze starre Ilaare tragend . . . . . . . . . . . . . 50. D. crenulata Cogn.

2. Blattfläche unterseits sehr dicht mit langem weichem Wollfilz besetzt, die Nerven zahlreiche lange, gelbe, starre Borsten tragend . . . . . . . . . 51. D. faIcipila Gilg

4. Dissotis segregata (Btl.) Hook. f. 1. c. 448; Cogniaux 1. c. 363; Taub. 1. c. 293 p. p.

Heterotis segregala Benth. 1. c. 350 .

Tristemma segregatum Triana 1. c. $\ddot{6} 6$.

Centralafrikanisches Seengebiet: bei Bukoba, $1130 \mathrm{~m}$ ï. M. (Stuhunan n. 3323. - Blühend im Februar 1892. - H. Berl.!).

Niger-Benuëgebiel: Nupe (Barter n. 1311. - H. Berl.!; am Niger (Anselt. - H. Kew.); am Nun-Fluss (Voger. - H. Kew.).

Unteres Congogebiet: Visla, Rio Zaire (Cuaves. - Blihhend im März 1883. - H. Berl.!).

Oberes Congogebiet: Msuata (Bütrner n. 84. - Blihhend im Norember. - H. Berl.!); im Baschilangegelsiet, obne nähere Angabe (Pogge n. 933̈. - H. Berl.!).

2. Dissotis minor Gilg n. sp.; ramis junioribus petiolisque densissime appresseque strigosis, demum glabris, internodiis brevibus 7-14. mm longis; foliis breviter petiolatis, ovato-oblongis vel ovato-lanceolatis, basi rolundatis, apice sensim acute angustatis, supra laxius, subtus dense strigillosis; floribus plerumque solitariis, rarius binis vel ternis ad apicem ramorum approximatis, $\ddot{b}$-meris, bracteis magnis vaginantibus persistentibus inclusis; calycis lobis persistentibus tubo plus duplo brevioribus.

D. segregala Taub. in Engler, Pflanzenwelt Ostafrikas C, 293 p.p.

Ein offenbar stark verzweigter Strauch mit sehr scharfkantigen, oft fast geflügelten Zweigen. Blattstiel $5-7 \mathrm{~mm}$ lang. Die fast lederartigen Blätler sind 2-4 cm lang, 7-14 mm breit. Bracteen glatt, glänzend, 7-9 mm lang. Receptacuhm nur an der Basis behaart, $8-9 \mathrm{~mm}$ lang. Kelchblätter Ianzettlich, spitz, ca. $4 \mathrm{~mm}$ lang. Blumenblätter 1,2-1,4 cm lang. Griffel $1,5 \mathrm{~cm}$ lang.

Centralafrikanisches Seengebiet: Uganda, Bumbinde (Stumunan n. 33̈83. - Blühend im März. -H. Berl.!).

Steht der D. segregata Hook, f. sehr nahe, so dass sie von Taubert mit derselben vereinigt wurde. Doch summieren sich so zahlreiche kleine Unterschiede (kürzere Internodien, kleinere Blätter und Blüten etc.), dass es mir besser scheint, zwei gesonderle $\Lambda$ rten auseinanderzuhalten.

$\Lambda$ bbildung auf Taf. II $C$. - Blütenzweig.

3. Dissotis petiolata Ilook. f. I. c. 448; Olir. in Bot. Speke et Grant 73 1. 4.0 A; Cogniaux 1. c. 363.

Centralafrikanisches Seengebiet: Madi (Spere et Grant. - H. Kew.). 
4. Dissotis Afzelii Hook. f. l. c. 4.9; Cogniaux 1. c. 364.

Sierra Leone: (Arzeluus. - H. Berl.!).

Oberguinea(?): Axim (Joly ex Cogniaux).

5. Dissotis cornifolia (Bth.) Hook. f. l. c. 4.8\% Cogniaux l. c. 364.

Heterotis cornifolia Bth. I. c. 351 .

Tristemma neglectum Naud. l. c. XJII. 299.

Tristemma cornifolium Triana 1. c. $5 \%$.

Tristemma ovalifolium Engl. in Experl. Gazelle, Botanik S. VI (nomen.

Sierra Leone: (Arzenus. - H. Berl.!).

Oberguinea: Liberia, bei Grand Bassa (Voget. - H. Kew.); bei Monrovia, an sumpfigen Orten hảufig (Naumann. - H. Berl.!); wahrscheinlich aus demselben Gebiet (Garret. - H. Berl.!).

6. Dissotis Autraniana Cogn. I. c. 1180.

Unteres Congogebiet: bei Lutete, auf feuchtem Boden unter Gebiisch, 500-600 m ii. M. (Hens, Ser. A n. 32. - Blühend im Februar 1888. - H. Boissier-Barbey!).

7. Dissotis theifolia (G. Don) Hook. f. l. c. 4.9; Cogniaux 1. c. 364.

Melastoma theaefolia G. Don Gen. Syst. Il. \%64.

Heterolis theaefolia Bth. I. c. 331 .

Tristemma theaefolia Triana 1. c. 56.

Sierra Leone: (Arzeluus. - H. Berl.!).

Oberguinea: bei Onitscha (Barter. - I. Kew.); bei Abbeokuta (Irvng. - H. Kew.); Togo, nicht häufig, aber verbreitet an trockenen, steinigen Stellen des Agomegebirges, bei $700 \mathrm{~m}$ i. II. Baumann n. 319. - Im October blühend. - H. Berl.!).

Kamerun: Yaúnde, auf Laterit des Felsplateaus am Colignate-Berg, in Saranne und Grasfeld (Zenker et Staudt n. 560. - Blühend im December. - H. Berl.!).

Abbildung auf Taf. II $A$. $-a$ Blütenzweig; $b$ Receptaculum; $c$ Samen.

8. Dissotis capitata (Vahl) Hook. f. I. c. 49 ; Cogniaux l. c. 36 ö.

Melastoma capitata Vahl Eclog. 4.5 ; DC. Prodr. III. 199.

Tristemma erectum G. et Perr. 1. c. 312.

Ileterotis capitata Benth. I. c. 352.

Melastomastrum erectum Nand. I. c. XIII. 296, t. V. f. IV.

Tristemma capitatum Triana 1. c. \$6.

Die mir vorliegenden zahlreichen Exemplare machen es wahrscheinlich, dass die ron Hooken als Varietäten dieser Art festgehaltenen:

Var. $\beta$. Vogelii (Bth.) Hook. f. l. c. $4 \ddot{30}$,

IIeterotis Vogelii Bth. I. c. 352 und

Var. $\gamma$. Barteri Hook. f. l. c. 450

nicht abzutrennen sind. D. capitata ist offenbar in Bezug auf die Behaarung des Stengels und der Blätter sehr variabel.

Glbasalquellengebiet: Grosse Seriba Ghattas, im Lande der Djü (Schweinfurth n. 1349. - Fruchtend im April 1869. - H. Berl.!).

Centralafrikanisches Seengebiet: Bukoba (Stuulıann n. 3792. - Blïhend im März 1892. - H. Berl.!).

Senegambien: (Perrotet, Leprieur, Hevdelot. - H. Paris.).

Sierra Leone: (Afzelius. - H. Berl.!; Voger. - H. Kew.): bei Nga Kowuli in der Nähe von Falaba (Scotr Ellot n. כ̈174. - H. Berl.!).

Niger-Benuëgebiet: Nupe (Bantkr. - H. Kew.).

Oberguinea: Togo, Berg Adodo (Bürtner n. 15. - Blühend im Juli 1890. - H. Berl.!); Odoni be: Bismarckburg (Kung n. 138² - H. Berl.!); Weg nach Ketschenki (Burtrer 11. 4.7. - Blïhend im Juli 1890 , Kuisg n. 5. - Blühend im Mai. - H. Berl.!); bei Misahöhe, truppweise an trockenen, sonnigen Stellen der lichten Buschsavanne, sehr weit verbreitet (Bacmann n. 302. - Blihend im Mai 1894. - H. Berl.!). 
Angola: Malandsche (Necuow n. 449, 4.27. - Blühend im Januar. - Herb. Berol.!), Tembo Aluma am Cambo-Flusse (Меснош 11. 346 . - Herb. Berol.!).

Oberes Con gogebiet: Baschilange, Mussumba des Muata Jamwo, 81/2 südl. Br. (Pogge n. 180. - Herb. Berol.!).

9. Dissotis radicans Hook. f. l. c. 4.30 ; Cogniaux 1. c. 36.5 .

Sierra Leone,: (Afzelius. -- H. Berl.!).

10. Dissotis hirsuta Hook. f. l. c. 1.̈0; Cogniaux 1. c. 366.

Sierra Leone: (Arzelus. - H. Berl.!).

11. Dissotis gracilis Cogn. 1. c. 366 .

Huilla: Welwitscu 11. 921. - Il. Berl.!),

1\%. Dissotis penicillata Gilg n. sp.; caule humili lignoso, fere a basi ramoso, erecto, teretiusculo, striguloso; foliis sessilibus vel subsessilibus, oblongis vel rarius, ovato-oblongis, parvis, apice acutis vel acutissimis, basi subrotundatis, 3-nerviis, utringue ad nervos parce setulosis ceterum glabris; tloribus 4-meris ad apicem ramorum 2-3 cymoso-confertis; receptaculo campanulato parce setuloso; sepalis lanceolatis receptaculum longit. aequantibus apice dense penicillatis, pilis apice penicillatis longis cum sepalis alternantibus; petalis brevilous late obovatis; antherarum majoribus connectivo basi profunde bilobo instructis.

Das stark verzweigte Halbstränchlein wird bis $12 \mathrm{~cm}$ hoch. Die Blätter sind $7-10 \mathrm{~mm}$ lang, $3 \mathrm{~mm}$ breit. Die ziemlich frühzeitig abfallenden Bracteen sind sehr klein. Receptaculum etwa $3 \mathrm{~mm}$ hoch, fast ebenso dick. Blumenblätter etwa $5 \mathrm{~mm}$ lang, wahrscheinlich purpurn.

Huilla: (Antunes 11. 126. - H. Berl.!).

Diese Art gehürt wohl sicher in die Verwandtschaft von D. gracilis Cogn., ohne grössere Übereinstimmung mit derselben zu besitzen.

13. Dissotis debilis (Sond.) Triana 1. c. 38, t. IV. f. 4.4a; Cogniaux 1. c. 367.

Osbcclia debilis Sond. in Limnaea XXIII. 4.7 (non Naud.).

Dissolis lanceolata Cogn. 1. c. 366 .

Dissolis villosa Engl. in Experl. Gazelle, Botanik, S. VIl.

Ghasalquelleugebiel: Land der Djur, Agada bei der grossen Seriba Ghatlas, aut Sumpfstellen Scuweinfurtu 11. 25\%3. - Blïhend im October 1869. - 11. Berl.!).

Centralafrikanisches Seengebiet: auf nassen Maisfeldem bei Gonda (Böm n. 180. — Blïhend im Mäz 1882. - H. Berl.!); Fvambo, im Siiden des Tanganjika, $1700 \mathrm{~m}$ i. M. (Nutr. - H. Berl.!).

Nyassaland: Bucinanan a. 1891 11. 636 und 678 , a. 1893 n. 227. - H. Berl.!).

Sambesegebiet: auf den Magalisbergen (Zevuer. - H. Berl.!); Bune (ex Cogr.).

Transvaal: Relihann, Lincke n. 119 ex Cognuux).

Unteres Congogehiet: auf einer Congoinsel bei Ponta da Lenha (Naumans. - Bliihend im September 18\%4. - H. Berl.!).

Angola: Wecworsci 1. 910 und 919. - H. Berl.!); Malandsche, auf Moorwiesen (Bucher 11. 16 $6^{\mathrm{b}}$. Blïhend im Màrz 1879. - H. Berl.!); Nossamedes, Humpata Ramunno. - H. Berl.!); Pungo Andongo (Necuow 11. 37. - Blibhend vom Januar bis April 1879. - H. Berl.!).

Amboland: Unkuembi (Rauranes n. 74. - Bluihend im April 1894. - H. Berl.!).

$D$. debilis und $D$. lanceolata können unmöglich anseinandergehalten werden.

dbbildung auf Taf. II $D$. - a Blütenzweig; $b$ Receptaculum.

14. Dissotis phaeotricha Hochst.) Triana l. c. 88 ; Hook. f. l. c. 4.51 ; Cognaux 1. c. 367.

Osbeckia phacotricha Hochst. in Walp. Repert. V. 708; Harvey et Sonder Fl. Cap. II. šl9.

Argyrella? phaeotricha Naurl. 1. c. XIII. 300.

Dissotis villosa Hook. f. I. c. 4.30 ; Cogniaux 1. c. $36 \%$.

Dissolis phaeotricha var. sericea Triana 1. c. 58 (nomen).

Osbeclia hirsuta Cogn. I. c. 334 .

Ghasalquellengehiel: Land der Niamniam, Sumpfsteppe bei Seriba Merijan (Scuweinfurtu 1. 3854. Blïhend im Juni 18\%0. - Ii. Berl.!); Land der Bongo, im SIV. vom Tondj, auf Sumpfsteppen (Schweinfurtu 11. 4.0.1. - Blïhend im December 1870. - H. Berl.!).

Centralafrikanisches Seengebiel: Buddı (Scotr Eubor n. 7511. - Bliilend im Maiz. - H. Berl.!). Sambesegeliel: Mussangă, Muata-Mlunga? (Ḱ́ıк. - Blïlend im October. - H. Berl.!). 
Transvaal: auf den Spitzkop bei Lydenburg (Wuns n. 388 . - Blühend im April 1887. - H. Berl.!).

Natal: bei Port Natal (Krauss n. 201, Drége, Gerrard ex Cognaux, Guenzius u. 395. - H. Berl.!); bei Clairmont (II. Wood. - H. Berl.!).

Niger-Benuëgebiel: Nupe, an fenchten Stellen (Barter n. 89.̈ und 131:̈. — II. Berl.!).

Angola: Pungo Andongo, 800-1200 m ii. M. (Venwitsci n. 903. - H. Berl.!).

Oberes Congogebiet: Baschilange, Mussumba des Muata Jantwo, 81/\% südl. Br. Pogre n. 131. Blühend im Janıar 1876. - H. Berl.!).

D. villosa Hook. und Osbeckia hirsuta Cogn. sind in keinem Punkte von D. phaeotricha verschieden.

13. Dissotis antennina (Sm.) Triana 1. c. 38 , t. IV. f. 44 e; Hook. f. I. c. 451 ; Cogniaux 1. c. 368.

Osbeckia anlennina Sm. in Rees Cyclop. ex DC. Prorlr. III. 143.

Helerolis antemina Bth. I. c. 349 .

Sierra Leone: (Arzelus. - H. Berl.!).

16. Dissotis decumbens (P. Beauv.) Triana 1. c. 38; Cognaux 1. c. 368.

Melastoma decumbens P. Beauv. Fl. Ow. I. 69, 1. 4.1; Kerner Hort. tab. 584. ex Cognaux.

Osbeckia decumben: DC. Prodr. III. 14.3.

Heterolis laevis Bth. l. c. 34.8 .

Dissolis laevis Hook. f. I. c. $43 \mathrm{I}$.

Dissolis decumbens var. minor Cogn. I. c. 369 .

Oberguinea: Owar (P. Beacrois. - H. Delessert); am Nun-Fluss (Vogel. - II. Kew.).

Kamerun: (J. Braun. - H. Berl.!); Batanga, sehr häufig in der Nähe des Meeres (die Batangaleute essen die zarten fleischfarbenen Blätter) (Dınkage n. $922 .-$ H. Berl.!).

Gabun-Loango: (Grifrox du Bellay ex Cogradux); Chinchoxo, an den Quellen von Makunga, kleine Buische von mehreren Quadratmetern Umfang bildend (Soxaux n. 89. - Blïhend im Juni 1874. - H. Berl.!); SibangeFarm, kriechend in Galleriewäldern und unter Sträuchern in der Savanne (Sovaux n. 4.26. - Bliihend im April 1882. - H. Berl.!).

Angola: (Welwitscu n. 899 ex Cogniaux).

Unteres Congogebiet: (Tıollox. - H. Paris.); bei Bangala, an schatligen Stellen Hevs n. 164 ex Cogniavi:

17. Dissotis rotundifolia (Sm.) Triana 1. c. 58; Cogvudux I. c. 369 ; Engler in Exped. Gazelle, Botanik VIll.

Osbeckia rolundifolia Sm. in Rees Cycl. ex DC. Prodr. III. I 3.

Melastoma plumosum D. Don in Mem. Wern. Soc. IV. 291; DC. Prodr. IIl. 147.

Heterolis plumosa Bth. l. c. 348 .

Dissolis plumosa Hook. f. I. c. 452.

Melastoma prostrala Sch. et Th. Beskr. Guin. PI. 240.

IIeterolis prostrala Bth. I. c. 349.

Osbeckia zanzibariensis Naud. 1. c. XIII. t. 7, f. ̋̈, XIV. ̋̈̋̈.

Lepidanthemum triplinervium Klotzsch in Peters Moss. Bot. I. 64.

Heterolis Iriplinervia Klotzsch msc. ex Triana I. c. ̋̈8.

Ghasalquellengebiet: Land der Niamniam, am Atasilli (Scnweinfurti n. 3093. — Blühend im Februar 1870. - H. Berl.!); am Assika, in offenen Galleriewäldern (Scrwenfurtu n. 3323a. - Blïhend im März 1870. H. Berl.!); Land der Monbuttu, am Bache bei Munsas Dorf (Scliweinfurtir n. 3 4.71. — Bliihend im April 1870. H. Berl.!).

Sansibar-Insel: an Bächen oder auf grasigen, fenchten Flächen, welche manchmal vom Meer iiberflutet werden (Boivin - H. Paris, Spene et Grant - H. Kew; Bojer, Hiloebrandt n. 967 , Scumidr n. 36. - Bliihend fast das ganze Jahr hindurch. - H. Berl.! .

Sansibar-Kiiste: Kimbirlschi, am Bach (Stunlunn n. 6032. - Blühend im Januar. - H. Berl.!); Ruhinga (Stunuanx 1. 6882. - Blïhend im Februar. - H. Berl.!); Kangani (Stuhumann n. 6362. - Bliihend im Februar. - H. Berl.!); Kisserawe, $300 \mathrm{~m}$ ï. M. (Stulumann n. 6230. - Blühend im Januar. - H. Berl.!); Kasi, im dichten Busch des Hïgellandes in Tümpeln (Stumumann n. 8587. - Blühend im September. - H. Berl.!).

Mossambik: (Peters - H. Berl.!), Noramballa, $1000 \mathrm{~m}$ ü. I. (Kirk. - H. Kew). 
Usambara: Mlalo, in Waldungen (Hoss n. $31 \%$ - Blihend im März. — H. Berl.!), Manka Dirlinai, $1000 \mathrm{~m}$ ii. Mr., in der Adlerfaruformation und auf Weickeland (Buciwald n. 423. - Blühend im Januar. H. Berl.!), Plantage Nderema in Handei-Gebirge, $920 \mathrm{~m}$ ï. M., in Waldlichtungen (Heinsen n. 42. - Blühend im März. - H. Berl.!), im Urwald, auch an Flussläufen bei Nderema, 900-1000 m ï. M. (Volkexs n. I35. Blühend im Januar. - H. Berl,!).

Usagara: Ulugurugebirge, Lussangalala, $600 \mathrm{~m}$ ü. M. (Stuhumann n. 8745. - Blühend im October. H. Berl.!); Süd-Uluguru, Rodungsgebiet, $1300 \mathrm{~m}$ ï. M. (Stunuann n. 9269. - Blühend im November. H. Berl.!); Nord-Ost-Lluguru, Hbora, $800 \mathrm{~m}$ ii. M., an Bächen (Stchlmann n. 9018. - H. Berl.!).

Centralafrikanisches Seengebiet: Bukoba (Stumunan n. 1003. - Blühend im November 1890。 11. Berl.!); Rumssoro, im Semliki-Thal (Sсотт Eцıют n. 8060。 - H. Berl.!).

Sierra Leone: (Afzenus - H. Berl.!, Vogel - H. Kew), bei Freetown (Preuss n. 3ä. - Blühend im Februar. - H. Berl.!), in Wäldern (Scotт Eluot n. 3874. - Blïhend im December. - H. Berl.!).

Oberguinea: Accra (Don - H. Kew), Abbeokuta (Invivg - H. Kew), am Quorra (Vogel - H. Kew), in Dahomey (Newton - H. Berl.!), Liberia, Monrovia, an sumpfigen Orten (Naunavn n. 37. - Blühend im August. - H. Berl.!), Lagos (Mulen n. 66. - H. Berl.!), Togo, Bismarckburg, hei Jegge (Bütrnen n. 125, 4.25, 693. Blïhend im August und April. - H. Berl.!, Kunv n. 137. - Blïhend im Mai. - H. Berl.!), Misahöhe, häufig im lichten, feuchten Hochwald zwischen Todome und Kolim (Baumans n. 252. - Blühend im April. - H. Berl.!).

Niger Benuëgebiet: Yoruba (Mussos, - Blihend im Februar. - H. Berl.!).

Kamerun: Abo (Bucumolz. - H. Berl.!), auf Principe (Barter n. 2022. - H. Kew), S. Thomé (Quintas). Unteres Congogebiet: Insel bei Ponta da Lenha (Naumans. - Blühend im September. - H. Berl.!), Lulunka (Demeuse ex Cogniaux).

Angola: Monteino ex Cognuex)

Dissotis prostrata lässt sich unmöglich von D. rotundifolia trennen. Diese Art ist wohl eine der gemeinsten Pflanzen in Afrika überhaupt, welche nirgends an Bachufern, in Sümpfen oder auf feuchtenı Boden fehlt und das ganze Jahr über reichlich und sehr schön blüht.

18. Dissotis tristemmoides Cogn. I. c. $3 \% 0$.

Gabun: Ogowegebiet Thoulon. - H. Paris!).

19. Dissotis Johnstoniana Bak. f. in Trans. Linn. Soc. 2. ser., IV. 14, t. II. f. 13-17.

"Ramis robustis elongatis, plus minusve scabridis, ad nodos parce incrassatis, setosis, obscure tetragonis; foliis petiolatis, coriaceis, ovatis, acutis vel acuminatis, basi rotundatis, utrinque scabridis, palmatim ら-nervatis, petiolis scabridis; floribus terminalibus paniculatis; pedicellis glabris; calycis tubo angulato, sparse hirto, tamen glabro vel subglabro, lobis $\breve{~ o v a t i s ~ v e l ~ o b l o n g i s, ~ m a r g i n e ~ c i l i a t i s, ~ p e r s i s t e n t i b u s ; ~ p e t a l i s ~ m a g n i s ~ o b o v a t i s ~(i n ~}$ sicco purpureo-violaceis); staminibus inaequalibus, connectivo magno ad basin producto; stylis staminibus longioribus; stigmate clavato curvato; capsulis 5-ralvibus, ad apicem setis albis coronatis."

Blätter $5-7,5 \mathrm{~cm}$ lang, Blattstiel 1,3-1,7 cm lang. Blumenblätter $2,5 \mathrm{~cm}$ lang. Blüten 5-zählig, in Rispen stehend (Diagn. von Baker f.).

Nyassaland: Milanji-Hochland, $2000 \mathrm{~m}$ ü. M. (Wнуте 11. 74. - H. Berl.!).

20. Dissotis Whytei Bak. in Kew Bull. 1897, S. $26 \%$.

„Frutex ramulis lignosis 4-angulatis scabris sulcatis validus. Folia brevissime petiolata, oblonga, acuta, 3 poll. longa, basi late rotundata, e basi ad apicem 5̈-nervia, facie viridia scabra, dorso flavo-viridia etian scabra. Cymae ad apices ramulorum in paniculam parvam congestae; bracteae cito deciduae; pedicelli brevissimi, scabri. Calycis tubus (i. e. receptaculum!) campanulatus, 3 lin. longus, selis brevibus sparsis ascendentibus albidis munitus; lobi $\ddot{\partial}$, semiorbiculares, parvi, patuli, persistentes. Petala obovato-cuneata, violacea, 6 lin. longa. Antherae majores $3 \mathrm{lin}$. longae, connectivo elongato basi antice producto." (Baker I. c.).

Nyassaland: Berg Zomba, 1300-2000 m ü. M. (Wиyte. - H. Kew.).

Vielleicht ist diese Art mit der vorigen identisch.

21. Dissotis polyantha Gilg n. sp.; ramis junioribus petiolis pedicellis pilis longiusculis basi incrassatis dense obtectis, internodiis $5-6 \mathrm{~cm}$ longis; foliis ovatis vel ovato-ovalibus usque ovalibus, manifeste peliolatis, apice breviter et late apiculatis, apice acuto, manifeste et graciliter supra bullatis, utrinque subaequaliter dense strigillosis, trinerviis; floribus ad apicem caulis ramorumque in cymas paniculiformes

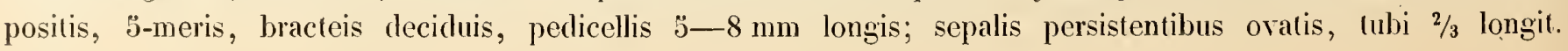


adaequantibus, apice rotundatis; cetera generis, sed ovario apice squamis 4. elongatis carnosis apice obtusis setuloso-ciliatis coronato.

Ein sehr stark blühender Strauch von ca. $2 \mathrm{~m}$ Iöhe, mit weithin leuchtenden Blüten (nach Stuimuns). Zweige undeutlich 4-kantig. Die häutigen Blätter sind $5-7 \mathrm{~cm}$ lang, $2,5-3,5 \mathrm{~cm}$ breit. Receptaculum sehr dicht von langen einfachen, an der Basis verdickten Haaren besetzt, ca. $7 \mathrm{~mm}$ lang. Die aussen fast kahlen Kelchblätter sind $4-5 \mathrm{~mm}$ lang, $3 \mathrm{~mm}$ loreit. Blumenblätter ca. $2 \mathrm{~cm}$ lang, »rotviolett«.

Usagara: Kifuru (Central Uluguru), im Bergwald auf der Passhöhe, $1600 \mathrm{~m}$ ï. M. (SrumLmann n. 9081. Blühend im November 1894. - H. Bert.!).

Eine prachtvoll und ausserordentlich reichlich blühende Pflanze, deren Einführung in unsere Gewächshäuser sehr zu wünschen wäre.

Abbildung auf Taf. II. $E$. - $a$ Blütenzweig; $b$ Blumenblatt; $c, d$ grösseres und kleineres Staubblatt von der Seite; $e$ Receptaculum und Fruchtknoten im Längsschnitt.

22. Dissotis cordata Gilg n. sp.; ramis junioribus petiolisque glabris vel subglabris, intermodiis $1,2-1,5 \mathrm{~cm}$ longis; foliis sessilibus, manifeste cordatis vel cordato-ovatis, apice sensimi longe angustatis acutisque, supra dense strigillosis, subtus molliter densissime hirsutis, septemnerviis; floribus ad apicem caulis in cymas paniculiformes 3-6-floras dispositis, 5-meris, bracteis deciduis, pedicellis 3-7 mm Iongis; sepalis persistentibus lanceolatis tubi $2 / 3$ longit. adaequantibus.

Ein Strauch oder Halbstrauch mit scharf 4-kantigen Zweigen. Die fast lederartigen Blätter sind $2,5-3,5 \mathrm{~cm}$ lang, 2-2,5 cm breit. Receptaculum locker mit sehr kiurzen, an der Basis stark zwiebelartig verdickten Härchen besetzt, 1,6-1,7 cm lang. Kelchblätter $1,1-1,3 \mathrm{~cm}$ lang, 2,5-3 $\mathrm{mm}$ breit. Blumenblätter 2,

Ober es Congogebiet: Baschilange, am Lulualluss, $9 \frac{1}{2}{ }^{\circ}$ s. Br. (Pogge n. 134. - Blïhend in Mai. - H. Berl.!). Abbildung auf Taf. III. B. - Blatt von unten.

23. Dissotis incana (E. Mley.) Triana I. c. 58, 亿. IV. f. 4.4 d; Cogniaux 1. c. 370.

Osbeckia incana E. Hey. ex Hochst. in Walp. Rep. V. 708.

Osbeckia canescens E. Mey. ex Graham in Bot. Mag. t. 3790.

Argyrella incana Nand. 1. c. XIII. 300. I. VI. f. VHI.

Osbeckia Umlaasiana Hochst. ex Harv. et Sond. FI. Cap. II. 518.

Dissotis canescens Hook. f. 1. c. 4.53.

Massaihochland(?): (Fiscien n. 262. - H. Berl.!).

Centralafrikanisches Seengebiet: Mittel-Urundi (Umuesi), in einem Flussthal am Westhang des MgeraGebirges (v. Trotia n. 27. - Blïhend im October. - H. Berl.!), Ukidi-Wald (?) (Speke u. Grant).

Nyassaland: (Buchanan n. 559. - H. Berl.!).

Sambesegebiet: Shibisa to Tschimnze, 600-1200 m ï. If. (Kın. - Blïhend im September. - H. Berl.!).

Transvaal: (Rehmans. - H. Schinz), bei Lydenburg an Flussulern (Wrums n. 485. - Blïhend im October. H. Berl.!).

Natal: (Krauss n. 120, Gueinzius 11. 137, Plant n. 13, Drege. - H. Berl.!), auf feuchtem Boden bei Pinetown, $250 \mathrm{~m}$ ii. M. (Wood n. 237. - H. Berl.!), an Bergflissen bei Clydesdale, $800 \mathrm{~m}$ ii. M. (Griqualand Eası) (Trson n. 880. - Blihlıend im Februar. - H. Berl.!).

Pondoland: am Bachufer unterhalb eines Wasserfalles Bacumann n. 926. - Blühend im Mäiz. - H. Berl.!), 30-500 m ü. M., an moorigen Stellen und Bachrändern der Sandsteinformation (C. Bexricu n. 19. H. Berl.!).

Angola: Malandsche, in der Savanme, wo sie in feuchte Thäler iubergeht und das Gras iiberwiegt (Bucuner n. 145. - Blïhend im Mai. - H. Berl.!), in der Gebiischcampine bei Malandsche (Bucinver n. 46. - Blühend im April. - H. Berl.!), an feuchten Stellen bei Malandsche (MEcrow n. 343. - Bliihend im November und December. - H. Berl.!).

Oberes Congogebiet: Baschilange, am Luluaflusse, $9 \frac{1}{2}^{\circ}$ s. Br. (Pogge n. 135 . — Blühend im Mai. - H. Berl.!). Diese Pflanze wurde vom Jahre 1838-1852 in botanischen Gärten cultiviert.

24. Dissotis angolensis Cogn. 1. c. 371.

Huilla: (Welwitsci n. 914. - H. Berl.!, Antunes n. 14. - H. Berl.!).

25. Dissotis cryptantha Bak. in Kew Bull. 1894, S. 34.5.

„Fruticosa, ramosissima, ramulis pilosis, foliis sessilibus lanceolatis triplinerviis utrinque dense pilosis, floribus paucis ad ramulorum apices aggregatis foliis reductis ascendentibus suboccultis, calyce globoșo dense Engler, Jonographieen. II. 
piloso, dentibus magnis lanceolatis pilosis deciduis, pelalis magnis orbicularibus pulchre violaceis, staminum longiorum connectivo producto basi bicalcarato.

Folia 11/2-2 poll. longa. Calycis tubus 3 lin. longus et latus; lobi tubo aequilongi. Antherae majores 6 lin. longae.* BAKER I. C.)

Nyassaland: (Buchanan a. 1891 n. 625. - H. Berl.!).

26. Dissotis speciosa Taub. in Engler, Pflanzenwelt Ostafrikas, C., 295.

Centralafrikanisches Seengebiet: Uganda, Mengo Stumuax n. 1335. - Blühend im December 1890. - H. Berl.!.

Abbildung auf Taf. III. $C$. $-a$ Blïtenzweig; $b, c$ grösseres und kleineres Staubblatt von der Seite.

27. Dissotis macrocarpa Gilg n. sp.; frutex rel suffrutex caule lignoso tetragono ramoso, ramis junioribus dense brunneo-strigillosis, demum glabratis; foliis breviter petiolatis, anguste oblongis vel sublanceolatis, basi rotundatis, apice acutis, manifeste ̋̈-nerviis, nervis supra valde impressis, subtus prominentibus, supra subtusque dense sed atpresse strigillosis; floribus in apice ramorum solitariis, magnis, foliis superioribus euphylloideis quam cetera paullo minoribus densiuscule confertis, bracteis late ovatis enerviis a foliis valile diversis breviter sericeis florem $\breve{b-m e r u m}$ arcte includenlibus post anthesin deciduis; receptaculo magno subgloboso vel subpyriformi, exlus densissime squamis crassissimis sessilibus apice ramos sericeos elongatos emittentibus obsito; sepalis lanceolatis aculis vel acutiusculis dense sericeis mox deciduis; petalis evolutis ...; staminibus normalibus.

Blätter $3-6 \mathrm{~cm}$ lang, 6-12 $\mathrm{mm}$ breit. Receptaculum $1,2-1,4 \mathrm{~cm}$ lang, fast ebenso dick. Kelchblätter etwa $1 \mathrm{~cm}$ lang, $3 \mathrm{~mm}$ breit. Griffel $2,5-3 \mathrm{~cm}$ lang.

Massaihochland(?): hei Budulu haufig (Scotr Eluot n. 74.80. - Blihend im Marz. - H. Berl.!).

28. Dissotis Welwitschii Cogn. I. c. 371.

Huilla: (Welwitsch n. 917. - II. Berl.!, Antunes n. 13. - H. Berl.!).

29. Dissotis Melleri Hook. f. ex Triana 1. c. 58 und in Oliv. Fl. trop. Afr. 4.53; Cognianx 1. c. 371. Sambesegebiet: Manganja-Berge (Meurer. - H. Kew), Dzomba, 2000-2300 m ï. М. (Kик. - H. Berl.!).

30. Dissotis multiflora (Sm.) Triana I. c. 58.

Osbeckia multiflora Sm. in Rees Cyclop. ex DC. Prodr. III. 143; Hook. f. I. c. 442; Cogniaux 1. c. 332; Engler in Exper. Gazelle, Bolanik, S. VI.

Mclastoma Afzelianum D. Don in Mem. Wern. Soc. IV. 290; DC. I. c. 147.

Dissotis Brazzuei Cogn. I. c. 372.

Diese in Afrika sehr weit verbreitete Pflanze wurde auffallenderweise nur von Triaxa zur richtigen Gattung, Dissotis, gestellı, während Ноокеr f. und Cogntaux sie bei der Gattung Osbeckia beliessen. Wie das reiche, mir zur Verfügung stehende Material in jedem Falle beweist, sind die beiden Staminalkreise so verschieden als nur möglich, bei dem einen Kreise die Connective lang vorgezogen, beim anderen kaum sichtbar, die Antheren des einen Kreises von ganz anderer Färbung als die des auderen, von dem auffallenden Unterschiede in der Lünge gar nicht zu reden. -- Der beste Beweis für die richtige Stellung der $\Lambda$ rt dürfte zweifellos der sein, dass Cognıux sie als Dissotis Brazacei nochmals beschrieb, obgleich er sie vorher als Osbeckia aufgeführt hatte.

Ich sah Dissotis multiflora von folgenden Standorten:

Ghasalquellengebiet: im Lande der Monbutlu, am linken Ufer des Welle Scuweinurtu n. 3187. Bliihend im Marz 1870. - H. Berl.!).

Centralafrikanisches Seengebiel: Bukoba, $1130 \mathrm{~m}$ ii. M. (Stumunn n. 1081, 1456, 15336, 3726, 3850, 3983. - Blïhent rom Novemher bis April. - H. Berl.!); Wes(-Nysóroro, Kajonsa, im Walı, 1600 m ü. M. (Stunlmann n. 3060. - Blïhend im Januar. - II. Berl.!).

Sierra leone: (Arzelius. - H. Berl.!)

Oberguinea: bei Onitscha (Barter n. 1796. - H. Kew); Liberia, bei Monrovia an sumpfigen Orten (Naunann, - Blihend im August. - H. Berl.!; Dusén n. 305. - Bliihend im Juli. - H. Berl.!); wahrscheinlich vom selben Stantort (Garret. - H. Berl.!).

Kamerun: Yaúndestation, in der Savanne (Zenken n. 379. - Blühend im Mai und Juni. - H. Berl.!), auf-Grasland, in Farmen, auf trockenem, somnigem laterit (Zenker et Strude n. 34\%. — Blïhend im Mai. H. Berl.!); Lolodorf, an lichten Stellen auf halbfeuchtem Laterit (Sтаudt 1. 297. - Blihend im Mai. - H. Berl.!); Kribi, im Buṣchwalele (Pneuss n. 270. - Blihend im April. - H. Berl.!).

Angola: (Welwitsci m. 898. - H. Berl.!), bei Malandsche (Necnow n. 425. — Bliihend im Jamuar. H. Berl.!). 
Gabun: bei Franceville, an trockenen Stellen (J. ne Brazza. - H. Paris!).

Oberes Congogebiet: Baschilange, Mussumba des Muata Janwo, 8\%² ${ }^{\circ}$ s. Br. (Pogge n. 133, 139, 141. Blïhend im Januar. - H. Berl.!).

Abbildung auf Taf. II. $F$. $-a$ Blüte; $b, c$ grösseres und kleineres Staubblatt von der Seite; $d$ Receptacularhaar.

31. Dissotis Hensii Cogn. 1. c. 372.

Unteres Congogebiet: bei Bangala (Hens Ser. C, n. 129. - Blühend im Juni. - H. Berl.!).

32. Dissotis longicaudata Cogn. 1. c. 373 .

Huilla: (Welwitscu n. 915. - Il. Berl.!, Antunes n. 9\%. - H. Berl.!).

33. Dissotis Candolleana Cogn. l. c. 373.

Kamerun: Galleriewälder bei Ngaumdere, dichte Büische längs der Bäche bildend, von 500-1200 m ỉ. M. (Passarge 1. 172. - Blühend im Januar. - H. Berl.!)

Angola: Pungo Andongo (Wecwirsci n. $904^{\mathrm{c}}$. - H. Berl.!, n. 904 und 904 ${ }^{\mathrm{b}}$ in H. DC.), auf feuchtem Boden nicht hăufig, 1-1 1/2 $\mathrm{m}$ hohe Büsche bildend (Jechow n. Iä̧̆. - Blühend im Juni. - H. Berl.!).

34. Dissotis Thollonii Cogniaux ex Bütn. in Verh. Bot. Vereins Brandenbg. XXXI. 96. - Cogn. I. c. 373.

Congogebiet: am Quango (Bütrver n. 26. - Blïhend inı August 1885. - H. Berl.!), bei Brazzaville (Tuollon. - H. Paris), Stanleypool (Hens Ser. B. n. 6. - H. Boissier-Barluey).

35. Dissotis Sizenandii Cogn. in Bol. Soc. Broter. XI. 88; frutex ramis setis longiusculis patulis vel subrellexis inaequalilus inferne, incrassatis et hirtellis dense armatis, foliis mrevissime petiolatis, ovatis, acutis, basi distincte cordatis, margine denticulatis, 与̆-nerviis, supra subsparse longeque bullato-setosis, subtus ad nervos setis basi incrassatis et hirtellis densiuscule armatis, caeteris minute foveolatis et dense longeque sericeo-villosis; paniculis laxis, paucifloris; bracteis subnullis; Horibus Ø̋-meris, lreviter pedicellatis; calycis tubo setis patulis breviusculis basi incrassatis et pectinatis densiuscule hirsuto, lobis caducis, Iriangulari-linearibus, acutis, tuho paulo lyrevioribus.

Rami graciles, obscure tetragoni. Petiolıs longiuscule denseque hirsutus, $3-3 \mathrm{~mm}$ longus. Folia patula, rigida, $3,5-4,5 \mathrm{~cm}$ longa, 2-2,5 cm lata. Paniculae $6-7 \mathrm{~cm}$ longae; pedicelli brevissime hirtelli, 2-4. $\mathrm{mm}$ longi. Calycis tubus anguste campanulatus, basi subrotundatus, 9-10 mm Iongus; Iobi vix hirtelli, 6-7 mm longi. Petala purpurea, anguste obovata, apice breviter retusa, margine brevissime ciliata, $2 \mathrm{~cm}$ longa. Antherae subrectae vel leviter arcuatae, antice valde undulatae; majores $11-12 \mathrm{~mm}$ longae, connectivo infra loculos $14-15 \mathrm{~mm}$ longe producto, basi minute Jicalcarato, minores $9-10 \mathrm{~mm}$ longae, connectivo infra loculos 4. $-6 \mathrm{~mm}$ longe producto. Stylus filiformis $2,5 \mathrm{~cm}$ longus. (Diagnose nach Cogniaux 1. c.)

Oberes Congogebiet: an feuchten Stellen am Quango, $19-20^{\circ}$ ö. L., $8-9^{\circ}$ s. Br., $1000 \mathrm{~m}$ ü. M. (Sizenando Marques. - Blihend im August. - II. Coimbra).

36. Dissotis Trothae Gilg n. sp.; suffrutex $2 \mathrm{~m}$ altus (ex Trotus) caule subtetragono parce ramoso, caule ramisque pilis brevibus crassis clense strigillosis, flavescentilsus; foliis ovatis vel ovato-lanceolatis, basi cordatis, apice acutis, longiuscule petiolatis, integris, supra pilis longis griseis eleganter dispositis densissime vestitis, subtus densissime tomentosis et ad nervos 5 insuper setis longis brunneis munitis, venis costae subrectangulo-

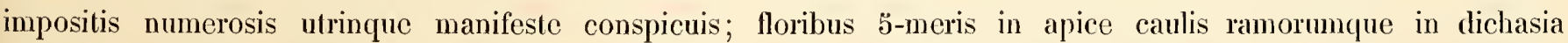
capitata, valde conferta, multiflora, densissima dispositis, pedicellis nullis vel subnullis; bracteis enerviis late ovatis rotundatis dense sericeis mox deciduis; receptaculo oblongo supra medium paullo constricto, densissime pilis longis simplicibus griseo-llavescentibus vestito; sepalis lanceolatis obtusis, dense pilosis, mox deciduis; petalis magnis, lilacinis (ех Trотия); staminum seriebus 2 valde diversis, normalibus; stylo elongato.

Die Blätter dieser prächtigen Pflanze sind $5-12 \mathrm{~cm}$ lang, $2-4 \mathrm{~cm}$ breit, $2-2,5 \mathrm{~cm}$ lang gestielt. Receptaculum etwa $1 \mathrm{~cm}$ hoch, 5-6 $\mathrm{mm}$ dick. Kelchblätter $6-7 \mathrm{~mm}$ tang, 2-2,5 $\mathrm{mm}$ breit. Griffel $2,2-2,5 \mathrm{~cm}$ lang.

Centralafrikanisches Seengebiet: in einem sumpfigen Flussbett am Westabhang des Mgera-Gebirges, Mittel-Urundi, Umuesi (v. Твотна n. 28. - Blühend im October 1896. - H. Berl.!).

Abbildung auf Taf. II. $B$. - $a$ Blütenzweig; $b$ ḱnospe.

37. Dissotis Elliotii Gilg n. sp.; suffrutex caule obsolete tetragono, glaberrimo, ut videtur eramoso; foliis lanceolatis vel anguste lanceolatis, manifeste petiolatis, basi rotundatis, superne longe cuneatis, apice acutis, chartaceis, margine integris vel leviter crenulatis, utrinque parce vel parcissime strigillosis, manifeste ว̈-nerviis, nervis supra impressis, subtus valde prominentibus, venis supra inconspicuis, subtus costae subrectangulo-impositis parce prominulis; floribus in apice caulis, rarius in foliorum axillis in monochasia subelongata 4-8-flora in paniculas collecta dispositis, 5-meris; bracteis enerviis sericcis late ovatis rotundatis mox 
deciduis; receptaculo oblongo-cylindrico, sub vertice saepius paullo constricto, pilis longis griseo-albescentibus, sacpius paullo dilatatis et parce ramosis densissime vestito; sepalis ovatis aculis, dense sericeis, mox deciduis; petalis verosimiliter violaceis; staminum seriebus 2 valde diversis, normalibus; stylo elongato.

Die Blätter sind 10-20 cm lang, 1,8-3,5 cm breit, Blattstiel 1-1,5 cm lang. Receptaculum $7-8 \mathrm{~mm}$ lang, $3-4 \mathrm{~mm}$ dick. Kelchblätter $7-8 \mathrm{~mm}$ breit. Blumenblätter etwa $2 \mathrm{~cm}$ lang.

Sierra Leone: (Scott Ellotot 11. 4513. - H. Berl.!).

38. Dissotis pulcherrima Gilg n. sp.; ramis junioribus petiolis pedicellis densissime pilosis, internodiis valde elongatis $15-20 \mathrm{~cm}$ longis; foliis lanceolatis vel hastato-lanceolatis, manifeste petiolatis, basi rolundatis vel oblusis, apice sensim et acute angustatis, 5-7-nervis, venis costae rectangulariter impositis valde munerosis, lamina supra parce strigillosa, subtus dense et submolliter hirsula; floribus in apice caulis ramormmpue in paniculas implas multilloras uspue ad $50 \mathrm{~cm}$ altas et $20-30 \mathrm{~cm}$ latas dispositis, paniculae ramis cymose vel monochasialiler evolutis, ə̋-meris, bracteis deciduis, perlicellis cr. 1_2 mm longis; sepalis deciduis, lanceolatis, acutis, tubo paullo brevioribus; receplaculo squamis elongatis lanceolatis appressis densissime vestito, pilis aliis simplicilus vel parce ramosis densissime internixtis.

"Ein 3-4 m hoher, steif aufrechter, unverzweigter Strauch, welcher erst nach dem Abblühen Adventivsprosse treibt.\& Zweige deutlich 4-kantig. Dic häntigen Blätter $2-5 \mathrm{~cm}$ lang gestielt, $15-30 \mathrm{~cm}$ lang, 3,5-6 cm breit. Receptaculum $1 \mathrm{~cm}$ Jang. Die wie das Receptaculum behaarten Kelchblätter sind $7-8 \mathrm{~mm}$ lang. Blumenblätter »lilafarbig", 1,8-2 cm lang.

Oberguinca: Togo, Visahöhe, an sumpfigen Stellen in grösseren Trupps (Baumanx n. 387); Bismarcksburg, Steppe am Kelschenkibache (Butrnen n. 369). — Blïhend im Januar und Februar. - H. Berl.!.

$\Lambda$ bbildung auf Taf. III. $F$. $-a$ Blatt von unten; $b$ Knospe; $c$ Blüte.

39. Dissotis alpestris Taub. in Engler, Pflanzenwelt Ostafrikas C, 295.

Usambara: Nanka Didinai in der Adlerfarnformation (Bucuwatn n. 496. - Blibend in Januar. - H. Berl.!), Bumbuli, $1100 \mathrm{~m}$ ii. M. in der Adlerfarnformation (Buchwald n. 488. - Blïlend im December. - II. Berl.!).

Kilimandscharo: (O. Eulers n. 38, Jounston. - H. Berl.!); Marangu, läufig im lichten Gebiisch und im Grase freier Pläze, $1-4,5 \mathrm{~m}$ hoch werdend (Volkess 1. 631. - Blïhend im Juli. - H. Berl.!), untere Urwaldgrenze, $2000 \mathrm{~m}$ ü. M. (Hans Meyer 1. 4.2. - Blïhend im Juli).

4.0. Dissotis cincinnata Gilg n. sp.; suffrutex caule elato tetragono brumeo setis patentihus brumneogriseis dense obtecto; foliis ovatis subsessilibus, basi cordatis, apice acutis vel aculiusculis, pilis longis appressis vel subtus subpatentibus flavescentibus densiuscule obtectis; Horibus 4 -meris in apice ramorum in cincinnos elongatos 6-10-lloros dispositis, magnis, julchris, "rubris« (ex Voukess); bracteis parvis ovatis persistentibus atro-brumeis; receptaculo ovato-oblongo, pilis crassis apice dense ramosis obtecto; sepalis oblongis, apice emarginalis et pila numerosa stellato-patentia gerentibus, mox deciduis; petalis manifeste obliquis; staminibus valde inaequalibus, normalibus; stylo elongato.

Dissolis alpestris Taub. l. c. p. p.

Blätter 4-7 cm lang, 2-4 cm breit, Blattstiel $1-3 \mathrm{~mm}$ lang. Receptaculım $7-9 \mathrm{~mm}$ lang, 4-5 mm dick. Kelchblatter $6 \mathrm{~mm}$ lang, $3 \mathrm{~mm}$ breil. Blumenblätter $2,2 \mathrm{~cm}$ lang, $1,5 \mathrm{~cm}$ breit. Die 4 langen Staubblätter sind $2,4 \mathrm{~cm}$ lang mit weit rorgezogenem Connectiv, die 4 kürzeren Staubblätter $12 \mathrm{~mm}$ lang, mit kaum vorgezogenem Connectiv. Griffel $15 \mathrm{~mm}$ lang. Fruchtknoten an der Spitze mit schwachem IIaarkranz.

Kilimandscharo: Bei der wissenschaftlichen Station Marangu, $10 ّ 50 \mathrm{~m}$ ii. M., sehr häufig im lichten Gebisch (Volkexs n. 722. - Blïhend im August 4893. - H. Berl.!).

Diese neue Art ist zwar mit $D$. alpestris Taub. verwandt, aber durch die Blattform, die grösseren Blüten und vor allem den Blülenstand scharf getrennt.

4.1. Dissotis Barteri Hook. f. ex Triana 1. c. 57 und in Oliv. Fl. trop. Afr. l. c. 4.54; Cogniaux I. c. 374. Kamerungebiet: Insel Principe (Barter. - H. Kew).

4.2. Dissotis Irvingiana Hook. Bot. Mag. t. 544.9; Triana 1. c. 58, t. IV., f. 44c.; Hook. I. I. c. 4.53; Cogniaux 1. c. 375 .

Oberguinea: bei Abbeokuta (Invivg. - Il. Kew); Togo, Bismarchsburg, Grassteppe am Ketschenkiwasser (Bütrner n. 367. - Blïhend im Januar 1891. - H. Berl.!), Misahöhe (Bürtner n. 751. - Blijhend im December. - I. Berl.!); »im Westen des Togogebietes weit verbreitet in höheren und niederen Lagen, feuchten, fruchtbaren Boden und sonnige Lagen bevorzugend, doch auch unter entgegengesetzten Bedingungen vor-

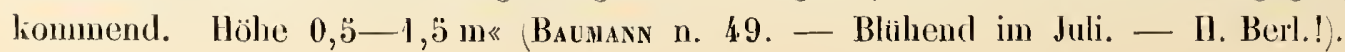


Niger-Benuëgebiel: bei Nupe. (Bartır n. 1023. - H. Berl.!); Yoruba, Othagho Mıuson. - Blühend im Mä̀z. - H. Berl.!).

4.3. Dissotis grandiflora (Afzel.) Bentl. 1. c. 347; Triana 1. c. 58; Hook. f. 1. c. 4.55; Cogniaux 1. c. 374 .

Osbeckia grandiflora Ifz. ex Smith in Rees Cyclop. ex DC. Prodr. Ill. 14.3.

Melastoma elongatum D. Don in Nem. Wern. Soc. IV. 2. 290; DC. Prodr. IlI. 143.

Osbeckiastrum Heudelotii Naud. 1. c. XIII. 1. 7 f. 6 und XIV. 119.

Senegambien: bei Fouta-Dhiallon (Heudelot. - H. Paris).

Sierra Leone: Don - H. Kew, Afzelus - H. Berl.!, Scott Elnot n. 4490. - H. Berl.!); bei Freetown (Preuss n. 22. - Blihhend im Felsruar 1887. - H. Berl.!).

4.4. Dissotis Schweinfurthii Gilg n. sp.; sulfrutex erectus caule subtetragono, ranoso, parcissime strigilloso; foliis lanceolatis, breviter vel lrevissime peliolatis, basin versus cuneatis, apice acutis, olsolete crenulatis, כ̋-nerviis, sed nervis marginalibus tenuissimis, utrinque parce brevilerque strigillosis; lloribus magnis, pulchris, violaceo-rosaceis (ex Scuweinfurtu), in apice ramolum in cymas paucifloras dispositis, in ramulis inferioribus plerumque solitaris; bracteis carlucissimis; receptaculo subgloboso, pilis crassis apice multiramosis dense obtecto; sepalis lanceolatis, elongatis, sericeis, mox deciduis; petalis obovato-oblongis, obticuuis, rotundatis; staminibus valke inaequalibus normalihus; stylo elongato.

Die B]ätter dieser prïchtig blülıenden Pflanze sind 4-8 cm lang, $8-14 \mathrm{~mm}$ breit, Blattstiel 1-2 mm lang. Receptaculum $4 \mathrm{~cm}$ lang, 7-8 $\mathrm{mm}$ dick. Kelchblätter 1,2-1,4 $\mathrm{cm}$ lang, $4 \mathrm{~mm}$ breit. Blumenb]ätter 3-3,3 cm lang, 2-2,2 cm breit. Lüngere Staubb]ätter bis $3 \mathrm{~cm}$ lang, kürzere $1,5-1,8 \mathrm{~cm}$ lang.

Ghasalquellengebiet: Land der Niamniam, in den Steppen bei lsingeria (Scuwenfurtu n. 3/94. Blibend im Mairz. - H. Berl.!); Land der Monbulu, in der Steppe bei Munsa Scuweivfurtu n. 34 4.5. Bliihend im April. - H. Berl.!).

4.5. Dissotis scabra Gilg n. sp.; frutex $1-1,3 \mathrm{~m}$ altus, ramis junioribus petiolis pedicellis dense pilis plumosis obtectis; foliis $1 \mathrm{~cm}$ longe petiolatis, late ovatis, basi manifeste cordatis, apice acutis, margine serulalis, 7-nerviis, nervis supra impressis, subtus valde prominentibus, venis supra inconspicuis, subtus prominentibus pulcherrimeque reticulatis, lamina supra pilis brevilus crassis parce ramosis scaberrima, subtus pilis longioribus inaequaliter (racemoso-) ramosis (ranis brevibus) obtecta; floribus »roseis« in apice caulis ramorumpue

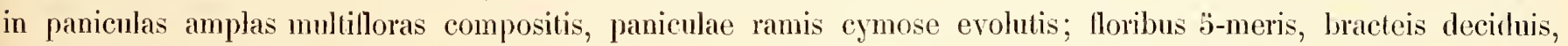
pedicellis 3-4. mm longis; sepalis deciduis lanceolatis extrinsecus parce sericeis, lubum subaequantibus; receptaculo squamis vel appendicibus maximis apice dilatatis et longe ciliatis vestito.

Dissolis princeps Cogn. in DC. Suites VII. 375 p. p. (non Triana); Taubert 1. c. 295 p. p.

Zweige stark 4-kantig. Blätter hüutig, 7-10 mm Jang gestielt, $5-11 \mathrm{~cm} \mathrm{lang,} \mathrm{3-6} \mathrm{cm} \mathrm{breit.} \mathrm{Receptaculum} \mathrm{ca.} 1 \mathrm{~cm}$ lang, fast kngelig; Kelchblätter $1 \mathrm{~cm}$ lang. Blumenllätter sehr breit verkehrteiförmig, 2,5-2,8 cm lang.

Ghasalquellengebiel: Land der Bougo, in den Steppen zwischen Tondj unıl Dugurru (Scuweixfurtu n. 2675. - Bliihend im November 1869. - H. Berl.!; Land der Niamniam, anf Feldern und Culturstellen bei Kulenscho's Dorf (Sciweinfuntı n. 2861. - Bluhend im Februar 1870. - H. Berl.!); in den Steppen bei Gumba's Dorf (Scuweinfurtu n. 3959. - Blïhend im Juni 18\%0. - H. Bert.!).

Die nene $\Lambda$ rt gehört wohl in die Verwandtschaft ron $D$. princeps, mit welcher sie Cogxinux vereinigt, weicht aher von derselben ausser durch den Blütenban besonders durch die starr behaarten, glaspapierartig ranhen, herzförmigen Blätter ab.

$\Lambda$ bbildung auf Taf. III. $E$. - $a$ Blatt von unten; $b$ lịnospe; $e$ Blüte.

46. Dissotis Perkinsiae Gilg n. sp.; ramis junioribus petiolis pedicellis densissime pilosis, internorliis elongatis; foliis ovatis, breviter peliolatis, basi subcordatis, apice acutis vel acutiusculis, margine serrulatis, 7-nerviis, lamina supra parce strigillosa, subtus dense molliterque hirsuta, pilis simplicibus; lloribus in apice caulis ramonumque in paniculas amplas multifloras usque ad $1 \mathrm{~b} \mathrm{~cm}$ longas, $8 \mathrm{~cm}$ latas dispositis,

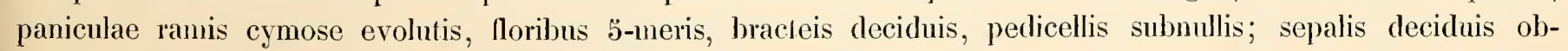
longis tubum aequantibus; receptaculo squanis vel appendicibus magnis »purpureis apice dilatatis et longe stellato-setulosis vestito; ovario fere libero, apice squamis 5 valde incrassatis dense setosis coronato.

"Ein aufrechter $1-1,8 \mathrm{~m}$ hoher IIalbstrauch mit verholzenden, mehr oder weniger braunen Zweigen «. Zweige sehr stark 4-kantig. Blätter häutig, $3-8 \mathrm{~mm}$ lang gestielt, $5-10 \mathrm{~cm}$ lang, $2,5-5 \mathrm{~cm}$ breit. Receptaculum $7-8 \mathrm{~mm}$ lang; Kelchllätter ebenso lang, mit einfachen, kurzen Ilaaren besetzt, »purpurrot«. Blumenblätter schmal verkehrteifürmig, »rötlich-violett«, $2,4-2,8 \mathrm{~cm}$ lang, oben $1,2-1,4 \mathrm{~cm}$ breit. 
Oberguinea: Togo, haufig an trockenen sonnigen Stellen des Agomegebirges bei Misahöhe Baumann n. 320. - Blïhend im October. - II. Berl.!); Bismarckshurg, in den Grassteppen bei der Station (Bürtxer n. 385. - Bliihend im Februar. - H. Berl.!, n. 211. - Blühend im September. —- H. Berl.!); bei Odomi (Kúlvg n. 438. - Blïhend im November. - I. Berl.!).

Diese sehr reich und schön blühende, decorative Pflanze ist mit D. princeps verwandt, weicht jedoch durch die Form und Grösse der Petalen und die Gestalt und Behaarung der Blätter sehr stark ab.

Abbildung auf Taf. III. D. - $a$ Blatt von der Unterseite; $b$ Blüte; $c$ Receptaculım; $d$, e Receptaculum und Fruchtknoten im Längs- und Querschnitt.

47. Dissotis princeps (Bonpl.) Triana 1. c. 57; Cogniaux 1. c. 375; Taubert 1. c. p. p.

Rhexia princeps Bonpl. Rhex. 122 , t. 4.6.

Osbeckia princeps DC. I. c. 14.0 ; Naud. I. c. XIV. ̋̈4.

Osbeckia eximia Sonder in Linnaea XXIll. 4.8; Dietr. FI. Univ. t. 88; Harv. et Sond. Fl. Cap. II. 518.

Dissotis cximia Hook. f. l. c. 434 .

Cognıux giebt von dieser im südlichen Afrika verbreitelen Art an: »foliis . . subtus dense stellato-vehtinis«. Ich konnte bei mikroskopischer Untersuchung stets nur einfache Haare finden.

lch kenne die Pflanze von folgenden Standorten:

Nyassaland: Manganja-Hochland bei Sotshi, $1000 \mathrm{~m}$ ï. II. (Kın. - Blïhend im Mai 1859. - H. Berl.!); Shire-Hochland Bucuavas a. 1891 n. 206 und 467, a. 1895 n. 215. - H. Berl.!); Chiradzulu-Berge (Johsston a. $1895(?)$. - H. Berl.!).

Mossambik: Beira (Braga n. 126. - H. Berl.!).

Nalal: (Guemzius n. 145, Gerrard, Remann, Sutuenland ex Cognaux); bei Pine Town (M. Wood n. 1030. - Bliihend im Februar. — H. Berl.!).

Ich bezweifle sehr, dass die von Hooken und Cogvııux angeführte, von Speke und Graxt im Ukidi-Wald /Centralafr. Seengebiet?) gesammelte Pfianze zı D. princeps gehört. Leider habe ich das Belegexemplar nicht gesehen, so dass ich eine sichere Entscheidung nicht geben kann.

4.8. Dissotis magnifica Gilg n. sp.; suffrutex ramis tetragonis brunneo-tomentosis; foliis ovatis vel ovatooblongis, breviter petiolatis basi subrotundatis, apice acutis, integris, manifeste b-nerviis (venis parallelis numerosis subtus manifeste prominentibus), supra dense strigillosis, subtus densissime griseo-tomentosis; lloribus verosimiliter violaceis, maximis, pulcherrimis, in apice caulis ramorumve in dichasia 3 - 0 -llora, saepius monochasialiter evolula, conferta, dispositis, perlicellis nullis vel subnullis; bracteis ovatis acutis, parce pilosis, mox deciduis; receptaculo ovato pilis brevissimis subgloboso-incrassatis ramos paucos rigidos longitudine inaequales emittentibus obtecto, pilis aliis simplicibus densissime intermixlis, superne pilis longis crassis ad apicem incrassatam dense ramosis hinc inde obviis; sepalis lanceolatis acutis mox deciduis; petalis magnis, obliquis, late obovatis rotundatis; staminibus valde inaequalibus, normalibus; stylo elongato.

Blätter $5-7 \mathrm{~cm}$ lang, 2-2,5 cm breit. Bhattstiel 7-8 mm lang. Receptaculum $1,3-4,4 \mathrm{~cm}$ lang, $7-8 \mathrm{~mm}$ dick. Kelchblätter $1,5 \mathrm{~cm}$ lang, $5 \mathrm{~mm}$ breit. Bhmenblätter $4 \mathrm{~cm}$ lang, $3 \mathrm{~cm}$ breit. Lange Staubhlätter $4,5 \mathrm{~cm}$ lang, kurze höchstens $2,5 \mathrm{~cm}$ lang. Griffel $3 \mathrm{~cm}$ lang.

Centralafrikanisches Seengebiet: Runssoro (Grant Starns n. 13. - Blühend im Juni 1889. - H. Schveiufurtl!!).

49. Dissotis violacea Gilg n. sp.; suffrutex usque $1 \mathrm{~m}$ altus ramis subtetragonis brumneo-strigillosis; foliis oblongis vel oblongo-lanceolatis, breviter petiolatis, basi subrotundatis, apice acutis, integris, manifeste 7-nerviis, supra densissime el eleganter strigillosis, subtus densissime tomentosis, junioribus sericeo-nitentibus, demum griseo-flarescentibus; lloribus magnis $\ddot{3}$-meris in apice ramortim in cymas 3-5-Hloras subcapitatas, plerumque monochasialiter evolutas dispositis, inflorescentiis rarius in foliorum superiorum axillis evolutis, perlicellis Jrevissimis; bracteis ovatis, acutis, densissime et brevissime pilosis, mox deciduis; receptaculo ovato, pilis brevissimis subgloboso-incrassatis ramos paucos rigidos longitudine inaequales emittentibus obsito, pilis aliis simplicibus inferne densissime intermixtis, superne pilis longis crassis ad apicem incrassatam dense ramosis lunc inde obviis; sepalis ovato-lanceolatis, acutis, dense griseo-vel flavescenti-pilosis, mox deciduis; petalis magnis, late obovatis, obliquis, rotundatis; staminibus valde inaequalibus normalibus; stylo elongato.

Dissolis princeps Taub. 1. c. 295 p. p. (non Triana!).

Blätter $5-7 \mathrm{~cm}$ lang, $2,3-3 \mathrm{~cm}$ breit, Blattsticl $5-10 \mathrm{~mm}$ lang. Receptacuhum $7-8 \mathrm{~mm}$ lang, $6 \mathrm{~mm}$ dick. Kelchblätter $11 \mathrm{~mm}$ lang, $3 \mathrm{~mm}$ breit. Bhmenblätter $3,5 \mathrm{~cm}$ lang, $2 \mathrm{~cm}$ breit. Die grösseren Staubblätter sind bis $4 \mathrm{~cm}$ lang, die kürzeren hüchstens $1,6-1,7 \mathrm{~cm}$. 
Centralafrikanisches Seengebiet: West-Lenılu, auf Grashiigeln der Abunbi-Ituri-Wasserscheide, auf Laterit, $1300 \mathrm{~m}$ i. M. (Stunlmann 1. 2674 ${ }^{\mathrm{a}}$. - Blühend im September 1891. - H. Berl.!); Walegga-Plateauabfall, $700 \mathrm{~m}$ ï. M. (Stumluan n. 2880. - Blühend im November 1891. - H. Berl.!).

50. Dissotis crenulata Cogn. 1. c. 376 .

Angola oder Huilla (Welwitscil n. 916. - H. Berl.!).

51. Dissotis falcipila Gilg n. sp.; ramis junioribus petiolisque pilis squamiformil)us inaequaliter fissis ca. $2 \mathrm{~mm}$ longis densissime obtectis; foliis pulcherrimis, oblongis rel oblongo-lanceolatis, ca. 3 mm longe petiolatis, basi rotundatis, apice acutis, ̋̈-nerviis, venis inconspicuis, lamina supra et in margine pilis falciformibus 2-2,3 mm longis basi valde incrassatis densissime aequaliter obtecta, subtus pilis longis argenteis simplicibus densissime vestita, sed nervis 5 pilis squaniformil)us inaequaliter fissis 3 - 4 mm longis aureis confertis notatis; floribus in apice caulis ramorumque in capitula pauciflora (2-3-llora) confertis, 5-meris, sessilibus, bracteis ovato-oblongis brunneis parce strigillosis (an deciduis?) suffultis; sepalis deciduis, ovatis, acutis, apice pilum longum acumine dilatatum et densissime et longissime ciliatum gerentibus; petalis contortis; staminibus 10, subaequalibus, antheris aequilongis et aequicrassis, filamentis seriei atterius ceteris paillo tenuioribus brevioribusque, connectivo in omnilus longe producto et in laminulas 2 carnosulas exemte; receptaculo squanis elongatis vel appendicibus apice dilatatis et longe stellalo-setulosis vestito; ovario sublihero, apice squanis 5 incrassatis dense setosis coronato.

Wahrscheinlich ein Strauch, mit verholzten, stielrunden Zweigen. Die etwas starren Blätter sind 2-6 cm lang, 7-15 mm breit. Receptaculum der noch nicht geöffneten Blüte (geöffnete lagen mir nicht vor) 8-10 mm hoch. Kelchblätter fast ebenso lang.

Oberes Congogebiet: Baschilange, Mussumba des Muata Jamwo, $8 \frac{1 / 2}{}{ }^{\mathrm{s}} \mathrm{s}$. Br. (Pogge $11.132 .-\mathrm{Im}$ Januar mit fast blühenden Knospen. - II. Berl.!).

Diese neue Art ist in mancher Beziehung sehr auffallend. Sie weicht von der Gattungsdiagnose von Dissotis in folgenden Punkten ab: Die Staubblïtter sind (an einer eben aufbü̈henden Knospe untersucht) fast völlig gleich und zeigen nur sehr untergeordnete Unterschiede, wälırend bei Dissotis sonst die beiden Staubblattkreise ausserordentlich von einander abweichen, sowohl was Grösse, als auch was die Ausgestaltung derselben anlangt. Ferner ist hier der Fruchtlinoten fast vollständig frei, während er sonst melır oder weniger hoch mit dem Receptaculum vereint ist. - Ich glaube jedoch sicher, dass $D$. falcipila mit $D$. crenulata verwandt ist. Und da diese Art ebenfalls nicht im Blütenzustand bekannt ist, so lasse ich diese beiden Pllanzen vorläufig bei Dissotis.

Abbildung auf Taf. III. A. - $a$ Blatt von oben; $b$ von unten.

\section{Barbeyastrum Cogn.}

l. c. 376 ; Krasser 1. c. 130 .

Barbeyastrum corymbosum Cogn. l. c.

Gabun: bei Osika, Distr. Bateke (J. de Brazza n. 4.5. - Bliilıend im Juni 1883. - H. Paris!).

Diese Gattung, welche mir in schönen Exemplaren vorgelegen hat, ist in ausgezeichneter Weise von Dissotis verschieden.

$A$ bbildung auf Taf. I. $G$. - $a$ Blüte; $b$ Staubblatt von der Seite; $c$ Längsschnitt durch Receptaculum und Fruchtknoten.

\section{Tristemma Juss.}

Gen. 329; DC. Prodr. III. 144. und Mém. Melast. 52; Endl. Gen. 11. 6216; Naud. 1. c. XllI. 297; Benth. in Hook. Niger Fl. 353; Bentham et Hooker f. Gen. plant. I. 746; Triana 1. c. 36 mnd 164; Hook. f. 1. c. 4.5; Cogniaux 1. c. 359 ; Krasser 1. c. 157.

Osbeckiae spec. Baill. Hist. pl. VII. 5 t.nd 38.

\section{Übersicht der Arten.}

A. Blüten einzeln oder zu zweien zusammenstehend, selten zu dreien, dann aber nicht von einer gemeinsamen Bracteenhüile eingeschlossen.

a. Receptaculum völlig kahl.

๙. Niederliegendes, kriechendes Pflänzchen mit kleinen, länglichen Blättern . . . . . . 1. T. vincoides Gilg

$\beta$. Aufrechte ansehnliche Halbsträucher mit eifürmigen oder breit eiförmigen Blättern. 
I. Kelchb]ätter vötlig kahl, schmal dreieckig, sehr spitz . . . . . . . . . . . 2. T. leiocalyx Cogn.

11. Kelchb]ätter fein behaart, linglich-linealisch, fast stumpf. . . . . . . . 3. T. roseum Gilg [Benth.

b. Receptaculum in seiner oberen Hälfte dicht mit starken braungelben Haaren besetzt . . 4. T. involucratum (Don)

c. Receptaculum mit $4-6$ Ringen von gelhtichen Borstenhaaren versehen. . . . . . 5. T. coronatiun Bth.

B. Blüten zu mehreren bis vielen kopfig zusammengedrängt.

a. Receptaculum völig kaht.

a. Blattsliel kurz, $5-8$, selten bis $15 \mathrm{~mm}$ lang.

I. Blaitter beiderseits kurz striegethaarig . . . . . . . . . . . . 6. T. littorale Bth.

11. Blätter oberseits sehr spärlich striegelhaarig, unterseits kahl, aber feine Papillen tragend 7. T. papillosum Gilg

ß. Blattstiel lang, meist über $2 \mathrm{~cm}$, oft über $3 \mathrm{~cm}$ lang . . . . . . . . . 8. T. oreophilum Gilg

b. Receptaculum einen einzigen Ring von gelblichen Borstenhaaren tragend.

œ. Blälter unterseits kahl oder fast kahl . . . . . . . . . . . . . . 9. T. incompletum $R . B r$.

ß. Blätter unterseits sehr dicht gelbbraun behaart . . . . . . . . . . 10. T. f'ruticulosnm Gilg

c. Receptaculum 2-4 Ringe von gelblichen Borsten aufweisend.

o. Stengel und Zweige mit kurzen striegehtaaren locker oder sehr locker besetzt.

I. Blätter 5-nervig, sehr selten ausserdem die beiden Randnerven noch deutlich vortretend . . . . . . . . . . . . . . . . . . 11. T. virusamum Vent

II. Blätler sehr gross und breit, stets dentlich 7-nervig . . . . . . . . . 12. T. grandifolium (Cogn.)

ß. Stengel und Zweige dicht mit langen steifen Haaren bedeckt.

I. Blätter unterseits an den Nerven mit langen braunen, abstehenden Haaren dicht besetzt, fast zottig . . . . . . . . . . . . . . . 13. T. hirtum Vent.

Il. Blätter unterseits dicht mit weisslichen, weichen, an den Nerven der jungen Blïtter seidenartig głänzenden, angedrückten Härchen bedeckt. . . . . . . . . . 14. T. Dusenii Gilg

III. Blätter unterseits gleichmüssig mit sehr kleinen, anliegenden Striegelhaaren ziemlich dicht besetzt. . . . . . . . . . . . . . 15. T. angolense Gilg

1. Tristemma vincoides Gilg n. sp.; herba annua caule tenui repente ramoso, superne breviter densiuscule strigoso, inferne glabrato; foliis petiolatis, basi subrotundatis, apice longe cuneato-acutatis vel saepius acuto-acuminatis, integris, utrinque parce vel parcissime breviterque strigillosis; floribus in apjice caulis ramorumque solitariis, rarius binis, bracteis receptaculum aequantilus vel saepius paullo superantibus ovatis acutiusculis parce pilosis; receptaculo glabro, ovato; sepalis ovatis vel ovato-oblongis acutis; petalis "Jallide lilacinis" obovatis, rotumdatis.

"Ein einjühriges, auf dem Boden wie Immergrün kriechendes Pflänzchen«, ziemlich stark verzweigt. Blätter $2-5 \mathrm{~cm}$ lang, 1-2 $\mathrm{cm}$ breit, Blattstiel 5-10 $\mathrm{mm}$ lang. Receptaculum 6-7 mm lang, 3-4 $\mathrm{mm}$ breit. Kelchblïtter etwa $3 \mathrm{~mm}$ lang, $2 \mathrm{~mm}$ breit. Blumenblätter $8-9 \mathrm{~mm}$ lang.

Oberes Congogebiet: Baschilange, an baumfreien Stellen am Bache bei Mlukenge, $6^{\circ}$ s. Br. (Pogre $n$. 934. und 936. - Bliihend im Februar und August. - H. Berl.!).

2. Tristemma leiocalyx Cogn. l. c. 1179.

Unteres Congogebiet: Stanleypool, an Rande eines Baches unter Bäumen (Ilexs Ser. B. n. 13. Bliihend das ganze Jahr. - Il. Berl.!).

3. Tristemma roseum Gilg n. sp.; herba erecta ramosa ramis parce strigulosis, mox glabratis; foliis manifeste petiolatis, ovatis vel ovalo-oblongis, hasi rolundatis vel inferioribus saepius subcumeatis, apice breviter lateque acuminatis, apice ijsso acutis, integris, 5-nerviis, smpra parce strigillosis subtus glabris; llorilsus in apice caulis ramormmue binis rel ternis, rarius solitariis, sessilibus, bracteis parvis rel saepius minimis ovatis acutiusculis; receptaculo pyriformi glaberrimo; sepalis lanceolatis acutissimis; pelalis »roseis" obovalis.

Blätter 2,5-7 cm lang, $1,5-4 \mathrm{~cm}$ lbreit, Blattstiel $\ddot{b}-12 \mathrm{~mm}$ lang. Receptaculum etwa $8 \mathrm{~mm}$ hoch, $5 \mathrm{~mm}$ dick. Kelchb]ätler etwa $3, \ddot{3} \mathrm{~cm}$ lang, $2 \mathrm{~mm}$ breil. Blumenb]ilter elwa $8 \mathrm{~mm}$ lang.

Ghasalquellengehiet: Land der Niamniam, an Assika in offenen Galleriewäldern (Scuweısurtu n. 3 I61 und 3323. - Bliihend im März. — H. Berl.!); Land der Monbutlu, am Kussumba, im Sumpfe offener Gallerien (Scuweinluitu D. 3656. - H. Berl.!).

Abbildung auf Taf. I. J. - $a$ Staubblatt von der Seite; $b$ Receptaculum.

4. Tristemma involucratum Benth. I. c. 354 ; Hook. f. 1. c. 445̈; Cognianx I. c. 360.

Melastoma involucrata D. Don in Men. Wern. Soc. IV. 290; DC. Prodr. III. 147.

Sierra Leone: (Arzelus. - H. Berl.!; Don, Banter. - H. liew).

Abbildung auf Taf. 1. $K$. - Receptaculum mit der charakteristischen Behaarung: 
5. Tristemma coronatum Benth. I. c. 3ä4; Hook. f. l. c. 446; Cogniaux 1. c. 360.

Sierra Leone: (Arzelus. - H. Berl.!, Don. - H. Kew).

Abbildung auf Taf. I. L. - Receptaculum mit den Wimperkränzen.

(j. Tristemma littorale Benth. 1. c. 353; Triana 1. c. t. IV. f. 4.1 ${ }^{\text {b }}$ Cogniaux 1. c. 362.

Tristemma Schumacheri, $\beta$. littorale Hook. f. l. c. 4.4.6.

Kamerungebiet: Insel Fernando-Po (Voged, Barter, Mann. - H. Kevv); Insel Principe (Barter. - H. Kew).

Cogniaux zieht zu dieser Art auch eine von Weswitsch unter n. 906 in Angola oder Huilla gesammelte Pflanze, welche mir aus dem Jerb. Coimbra, leider allerdings nur in dürftigen Exemplaren, vorlag. Obwohl ich nun kein Original der T. littorale gesehen habe, glaube ich doch, dass die WeLwirscn'sche Pflanze unmöglich hierher gehören Kann. Denn das mir vorliegende Exemplar zeigt fast durchweg einzelnstehende, selten zu zweien genäherte Blüten, dürfte also wohl in die Gruppe des T. in volucratum und deren Verwandten zu bringen sein.

\%. Tristemma papillosum Gilg n. sp.; herba ut videtur erecta parce ramosa, ramulis parcissime et brevissime strigulosis, mox glaberrimis; foliis ovatis vel ovato-oblongis, basi in petiolum longiusculum cuneatoangustatis, apice breviter angusteque acuminatis, apice ipso acutis, supra parcissime breviter appresseque strigulosis, subtus papillis brevissimis semiglobosis parce obsitis, ceterum glabris, manifeste b̆-nerviis; floribus in apice caulis ramorumve in capitula 3 - 5 -flora confertis, bracteis brevibus late ovatis rotundatis receptaculum haud adaequantibus; receptaculo ovato glaberrino; sepalis ovatis acutis; petalis obovatis.

Blätter 4-8 cm lang, 2-4 cm breit, Blattstiel $1-2,3 \mathrm{~cm}$ lang. Receptaculum etwa $8 \mathrm{~mm}$ hoch, $3 \mathrm{~mm}$ dick. Kielchblätter etwa $3 \mathrm{~mm}$ lang, $1,5 \mathrm{~mm}$ breit. Blumenblätter $7-9 \mathrm{~mm}$ lang.

Oberguinea: Lagos (MllLen. - H. Berl.!).

8. Tristemma oreophilum Gilg n. sp.; »herba $1,5 \mathrm{~m}$ alta «, ramulis densiuscule brunneo-strigulosis, demum glabris; foliis oblongo-lanceolatis usque lanceolatis, basi sensim in petiolum elongatum angustatis, apice longe vel longissime acutatis, integris, 7-nerviis (nervis marginalibus temuibus), renis numerosis manifeste inaequaliter reticulatis, supra parce appresseque strigulosis, subtus pilis brevibus appressis laxissime aspersis, demum glabrescentibus; floribus in apice caulis ramorumque in capitula 3-8-flora confertis; bracteis ovatis acutis densiuscule pilosis; receptaculo ovato-oblongo glaberrimo; sepalis lanceolatis vel ovato-lanceolatis, acutis, receptaculi $3 / 4$ longit. aequantibus; petalis latissime obovatis.

Die Blätter dieser hübschen Pflanze sind $6-14 \mathrm{~cm}$ lang, $1,8-4,5 \mathrm{~cm}$ breit, Blattstiel $1-3 \mathrm{~cm}$ lang. Receptaculum etwa $7 \mathrm{~mm}$ lang, 4-5 mm dick. Kelchblätter 4-5 mm lang, $2 \mathrm{~mm}$ breit. Blumenblätter »rosa ", 1-1,1 $\mathrm{cm}$ lang, wohl ebenso breit.

Kamerun: im Buschwald westlich Buea, $970 \mathrm{~m}$ ü. M. (Preuss n. 961. — Blühend im September. H. Berl.!).

9. Tristemma incompletum R. Br. 1. c. 16.

Tristemma Schumacheri Guill. et Perr. 1. c. 311, 1. VI., f. 6; Naul. I. c. XIII. 298, t. Vl., f. 6; Hook. f. 1. c. 4.46 ; Cogniaux 1. c. 361 .

Tristemma albiflorum Bth. 1. c. 353 ; Cogniaux 1. c. 362.

Melastoma albiflorum G. Don Gen. Syst. 11. 764.

Tristemma Schumacheri, $\gamma$. albiflorum Hook. f. I. c. 4.6.

Ghasalquellengebiet: Land der Niamniam, am Nabambisso (Scuweinfurm Ser. Ill. n. 127. - Blühend im Februar. - H. Scineinfurtu!).

Senegambien: (Penrottet, Lepreur. -- H. Paris; Ingram. - H. Kew; Heudelot. -- H. Berl.!).

Sierra Lcone: (Scott Ellot n. 4.41. - H. Berl.!; Vogel, Barter, Don. - H. Kew).

Oberguinea: (Tuonning); Togo, Station Bismarcksburg, am Jeggehache (Bütrner n. 4.25 und 191. Blühend das ganze Jahr. - H. Berl.!); am Adadia, halb im Wasser stehend (Kung. n. 136. - Blühend im November. - H. Berl.!); Station Misahöhe, häufig an feuchten, schattigen Stellen, besonders üppig im Sumpf (Baumann n. 303. - Blühend im Mai. - H. Berl.!).

Kamerungebiet: auf der Insel S. Thomé, monte Café, $860 \mathrm{~m}$ i. Ml. (Moluer. - Blühend im Juli. H. Berl.!).

Gabun: (Afzeluus. - H. Berl.!, Midpleton. - H. Kew); Sibange-Farm, an Waldrvegen (Soyaux n. כ̋4, Bùttner n. 83. - Blühend das ganze Jahr. - H. Berl.!); »Poste du Diele« und bei Franceville (J. de Brazza, Thollon. - H. Paris).

Benguella: (Curror. - H. Kew).

Engler, Monographieen. II. 
Unteres Congogebiet: (Sminn. - H. Kew), Bangala, an feuchten Stellen (Hens n. 181, ex Cognuux); Lutete (Flens Ser. A. n. 32 \%. J. ex Cogniarx).

Trotz genauester Untersuchung ist es mir nicht gelungen, einen Unterschied zwischen Tristemma incomplełum und T. albiflorum aufzufinden, wenn wenigstens die von Cogxuaux zu letzterer Art gezogene Pflanze von S. Thomé-(Molrer), die mir im Original vorlag, wirklich zu T. albiflorum gehört.

10. Tristemma fruticulosum Gilg n. sp.; frutex vel fruticulus lignosus humilis ramosus, ramulis acute tetragonis densissime fulvo strigosis, tarde glabrescentibus; foliis breviler petiolatis, ovatis vel late ovatis, basi subrotumdatis vel saepins cmeatis, apice longe acutatis, apice ipso aculissimis, 5- vel si mavis 7-nerviis, sed nervis marginalibus tenuissimis, margine manifeste semalis, supra pilis longis brumeis appressis dense strigosis, sublus pilis llavescentilus rigidulis densissime tomentosis; floribus in apice caulis ramorumque in capitula 5-8-llora confertis; hracteis exteriorihus plermmque enjliylloideis, interioribus valde diversis lalissime ovatis, sulgglabris; receptaculo late campanulato, pilis thavescentibus longis in zonam unicam sacpius interruptam disposilis; sepalis lanceolatis acutis, receptaculi $2 / 3$ longit. subadacpuantilus; petalis late obovatis brevibus.

Tristemma Schumacheri Taul. I. c. 293 (non Guill. et Perr.!).

Dic ganze, hitholzige, stranchartige Pflanze wird etwa $30-40 \mathrm{~cm}$ hoch. Blätter $4-8 \mathrm{~cm}$ lang, $1,8-3,8 \mathrm{~cm} \mathrm{breit.}$ Blatlstiel 5-8 mm lang. Receptaculum 7-8 mm hoch, etwa $6 \mathrm{~mm}$ dick. Kelchblätler 4-5 mm lang, $2 \mathrm{~mm}$ breit. Blumenblïtler $6-8 \mathrm{~mm}$ lang.

Centralafrikanisches Seengebiet: Bukoha (Stunzann n. 1002. - Bliihend im November. - H. Berl.!).

Abbildung auf Taf. I. M. - $a$ Knospe; $b$ Blüte; $c$ und $d$ Staubblatt von der Seite und von vorn.

11. Tristemma virusanum Comm. in Juss. Gen. 329; Vent. in Mém. Inst. de France a. 1807, 15 und Ch. de Pl. t. 35 ; DC. Prodr. III. 144; Nautl. I. c. 298 t. 5., f. V; Cogniaux 1. c. 360.

Tristenuma mantiliannm Pers. Syn. 1. 4.76; Poir. in Lam. Encyel. Bot. VIII. 956.

Melastoma virnsamm D. Don in Mem. Wem. Soc. IV. 290.

Osbeckia virusana Baill. Hist. PI. VII. 34.

Diese Art, welche zwar aus Afrika noch nicht bekannt ist, aber zu den folgenden Arten in enger Verwandtschaft steht und deshalb hier angefüht wurde, sah ich von folgenden Jnseln: Madagascar, Maurilius, Bourbon, Mayolle, Johanna, Angasija.

T. rimusanum ist also offenbar ülJer das ganze madagassische (iebiet verbreitet und, wie aus der Angabe der Sammler hervorgeht, überall schr läufig.

12. Tristemma grandifolium (Cogn.) Gilg; herba clata caule tetragono, ramulis laxe strigulosis, mox glabratis; foliis magnis ovalis vel ovalo-oblongis, plerumque manifeste 7-nerviis, basi sulorotundalis vel saepius breviter in petiohum elongatum angustatis, apice acutatis, integris, supra parce appresseque strigosis, subtus pilis minimis densiuscule vestitis, demum glabrescentilous; floribus in apjec caulis ramorumve in calpitula 4-7-110ra confertis; bracteis exterioribus enphylloideis, interioribus valde diversis late oratis aculis, inferne subglabris, superne densiuscule pilosis; receptaculo oblongo, pilis llavescentibus longis in zonas vel annulos 2 clansos disposilis; sepalis orato-oblongis, acutis.

Tristemma Schmmacheri, ß. grandifolia Cogn. 1. c. 361.

Blätler $12-22 \mathrm{~cm}$ lang, 6-12 cm breit, Blattsticl der ausgewachsenen Bhätter $3-4 \mathrm{~cm}$ lang. Receptaculum $1 \mathrm{~cm}$ Jang, etwa $7 \mathrm{~mm}$ dick. Kelchblitler $2-3 \mathrm{~mm}$ lang, $1,5 \mathrm{~mm}$ breit.

Ghasalquellengebiet: Land der Djur, Grosse Seriba Ghatlas, im tiefsehattigen, sumpligen Hochwald (Schweiventu 11. 23̈98. - Blühend im November. — H. Berl.!).

An gola: (Welwitscin n. 900. - H. Berl.!).

Wie ich mich auf das sicherste an dem schönen Exemplar des Berliner Iterhars überzeugen konnte, hat Cocivıaux diese Pflanze nicht an die richlige Stelle gebracht. Sie gehört nicht in die Verwandtschaft von T. Schumacheri, sondern von T. virusanum, da ihr Receptaculum zwei deutliche Cilienringe aufweist.

Abbildung auf Taf. I. $N$. - Receptaculum mit den Wimperliränzen.

13. Tristemma hirtum Vent. Ch. de PI. 35, in athot.; DC. Prorlr. III. 144; Pal. de Beaur. I. c. 94, t. 37 ; Benth. I. e $3 \ddot{4} 4$; Triana I. c. I. IV. f. $44^{\mathrm{a}}$; Hook. f. I. c. 446.

Melustoma sessilis Sch. et Th. Guinea Pl. 239 (ex descript.!).

Oberguinea: (Beavors); bei Aguapim (Thonning); am Nun-Fluss (Vogeu, Barter. - II. Kew); am Niger bei Nupe (Banten n. 1314. - H. Berl.!); Lagos (Mulen n. 131. - I. Berl.!). 
Kamerungebiet: bei Abo (Bucumozz. - Blihend im Januar. - H. Berl.!); auf der Insel Fernando-Po (Mann. - H. Kew).

Gabun: (Grifron du Belloy. - H. Paris).

Oberes Congogebiet: Baschilange, Kimbundo, $10^{\circ}$ s. Br. (Pogre n. 138. - Bliihend im Mugust. H. Berl.!).

14. Tristemma Dusenii Gilg n. sp.; herba verosimiliter spectabilis erecta caule tetragono, ramis densissime pilis longis subpatentibus brunneis obtectis, tarde glabratis; foliis ovatis vel ovalo-olblongis, manifeste petiolatis, basi sulmotundatis, ima basi saepius breviter cuneatis, apice longe acutatis vel late acuminatis, apice ipso acutissimis, integris, supra dense appresseque strigosis, subtus pilis albis nitentibus mollibus brevibus densissime tomentosis; floribus in apice caulis ramormmque in capitula multiflora, densil\}ora (8-15-flora), confertis; bracteis exterioribus plerumque rarissime eupluylloideis, plerunque ommibus bracteoideis llores saepius longit. paullo superantibus; receptaculo late campanulato, pilis llavescentibus longis in zonas vel annulos 2 clausos dispositis; sepalis triangulari-oratis, acutissimis.

Blätter $7-11 \mathrm{~cm}$ lang, $3,5-5,5 \mathrm{~cm}$ breit, Blattstiel $1-3,3 \mathrm{~cm}$ lang. Receptaculum $1 \mathrm{~cm}$ lang, $7 \mathrm{~mm}$ dick. Kelchblätter etwa $4 \mathrm{~mm}$ lang, $3 \mathrm{~mm}$ lang.

Kamerun: (Dusén n. $356^{a}$. - H. Berl.!).

1ə̈. Tristemma angolense Gilg n. sp.; herba spectabilis erecta caule herbaco acute tetagono, ramis densissime pilis longis patentibus brunneis obteclis, tarde glabualis; foliis manifeste peliolalis, basi subrotmmdatis, apice acutis, integris, supra densiuscule appresseque strigulosis, subtus pilis brevilus rigidulis appressis densiuscule obtectis; floribus in apice caulis ranorumpue in capitula 3-ə̈-flora confertis; bracteis exterioribus semper euphylloideis, interioribus rerosimiliter purpureis omnino bracteoideis, inferne glabris, apicem versus albidopilosulis; receptaculo campanulato pilis albescentibus longis in zonas vel annulos 2 clausos clispositis; sepalis lanceolatis; petalis parvis obovatis.

Blätter $5-8 \mathrm{~cm}$ lang, 3-5 cm breit, Blattstiel 2-2,3 cm lang. Receptaculum $7 \mathrm{~mm}$ hoch, 3 mm dick. Kelchblätler $3-4 \mathrm{~mm}$ lang, $1,3-2 \mathrm{~mm}$ breit.

Angola: Malandsche (Mecuow n. 4.46. - Blïhend im lanuar. - H. Berl.!).

\section{Dinophora Benih.}

in Hook. Niger Flora 355; Bentham et Hooker Gen. plant. I. 745; Hook. f. I. c. 44.4; Baillon Hist. Pl. VII. 39; Krasser I. c. 157.

Die cinzige Art dieser charakteristischen Gattung ist lesunders in Kamesun sehr verbreitel und fehlt fast in keiner dortigen Sammiung.

Mir ist die Ptlanze von folgenden Standorten bekannt:

Oberguinca: westliches Jagos (Rownaxd. - H. Berl.!).

Kamerungebiet: auf der Insel Fernando-Po (Voges. - H. Kew); anf dem Feslland, olme nähere Standortsgabe (Dusḱx n. 60. — H. Berl.!); bei Mungo (Bucnuoz. - Bühend im Seplember. - H. Berl.!); bei Kribi, im Buschwald (Pususs 13. 267. - Blibend in April. - II. Berl.!); im Buschwal, bei Kake (Prevss 1. 364. - Blïhend im Octoher. - H. Berl.!); Lolodorf, in alten sonuigen, hallsfenchten Farmen (Stavot n. 164. - Blihend im Mäz. - H. Berl.!); Bipinde, an somigen Stellen (Zenken n. 1060. — Bliihend im August. II. Berl.!).

Gabun: Sibange-Farm (Dinklage n. 538. - Blïhend im Februar. - II. Berl.!), an Waldwegen selten (Soraux n. 56. - Blühend vom Januar bis Mä\%. - II. Berl.!):

Oberes Congogebiet: Baschilange, Unkraut in Garten der Station bei Mulienge, $6^{\circ}$ s. Br. (Pogge n. 942 und 94.4. - Blibhend in Februar. - H. Berl.!).

Abbildung auf Taf. I. H. $-a$ Blüte; $b$ und $c$ grösseres und kleineres Staubblalt von der Seite. 


\section{A. b. Melastomatoideae - Oxysporeae.}

Von den Gattungen dieser Gruppe war bisher noch keine vom festländischen Afrika bekannt; die meisten sind heimisch im tropischen Asien, besonders im indisch-malayischen Gebiet, wenige (3) auf Madagaskar.

\section{Urotheca Gilg}

in Engler-Prantl Nat. Pflanzenfam., Nachtrag 263.

Flores :"-meri. Receptaculum obovatum vel obconicum ita ut rami juniores atque pedicelli pilis longiusculis glanduligeris dense obtectum. Sepala vix evoluta (receptaculo margine superiore vix undulato). Pelala late obovata, valde obliqua, breviter sed acule apiculata, contorta. Stamina 10, aequalia, in aestivatione intlexa; antherae oblongae crassiusculate aequales, connectivo postice valde elongato acuto, calcariformi, antice exappendiculato. Stylus columnaris, staminibus subduplo longior, basi squamis $\mathbf{b}$ crassiusculis apice emarginulatis cinctus. Ovarium in parte receptaculi $1 / 2 \mathrm{cr}$. inf. totaliter adnatum, 5-loculare, placentis multiovulatis. Fructus capsularis, apice verosimiliter valvis 5 dehiscens.

Herba (an perennans?) ascendens vel erecta, tola (petiolis foliisque exceptis) pilis glanduligeris obtecta. Rami teretiusculi vel subtetragoni. Folia opposita el decussata vel terna verticillata. Flores merliocres, rosei, in apice caulis vel ramorum umbellati, ebracteati.

Urotheca hylophila Gilg l. c.; herba humilis (an perennans?) $30-4.0 \mathrm{~cm}$ alta; foliis oppositis et decussatis (n. 8864 rel ternis verticillatis (n. 8761), ommilus longe petiolatis, oblongis vel oblongo-lanceolatis, apice in acumen longun angustum acutum sensim angustatis, basi acutis vel aculiusculis, glabris, ̋̈-nerviis, venis paucis sulorectangulariter in nervis impositis; lloribus rosaceis (ex collect.), in apice caulis ramorumgue in umbellas pauci- (2) usque multilloras (13) collectis, longipedunculatis, ebracteatis.

Blätter ca. $2 \mathrm{~cm}$ lang gestielt, $5-8 \mathrm{~cm}$ lang, $1-2,5 \mathrm{~cm}$ breit. Blüten $1,2-1,5 \mathrm{~cm}$ lang gestielt. Receptaculum ca. $5 \mathrm{~mm}$ hoch, oben ebenso dick. Blumenblïtter ca. $1 \mathrm{~cm}$ lang, fast ebenso breit. Griffel $7-8 \mathrm{~mm}$ lang.

Usagara: Ulugurugebirge, Nghwénn, in der unteren Partie des Bergwaldes, $1600 \mathrm{~m}$ ü. M. (Stunlmann $\mathrm{n}$. 8864. - Blihend im October. - H. Berl.!); an Bachen und in Pterisfelderu auf feuchtem Boden, in Rodungen und an Waldraindern, $1400 \mathrm{~m}$ ii. M. (Stumlman n. 8761 . - Blihend im October. - H. Berl.!).

Abbildung auf Taf. IV. $A$. - $a$ Blütenzweig; $b$ Knospe; $c$ Blumenblatt; $d$ Staubblatt von vorn; $e$ von hinten; $f$ von der Seite; $g$ Antherenquerschnitt; $h$ Receptaculum mit Fruchtknoten im Längsschnitt; $i$ Fruchtknotenquerschnitt; $l i$ Griffel; $l$ Frucht von der Seite; $m$ Frucht von oben; $n$ Samen; o lieceptacularhaar.

\section{Petalonema Gilg}

in Englex-Prantl Nat. Pflanzenfan., Nachtrag 264.

Flores 5̈-meri. Receptaculum obconicum, acute 5 -angulum vel potius alis $\ddot{3}$ manifestis instructum. Sepala lineari-lanceolata acutissima vel potius in acumen longum filiforme attenuata persistentia. Petala valde obliqua, contorta, late vel latissime obovata, apice longissime filiformi-acuminata, acumine involuto. Stamina petalorum numero dıpla, aequalia; antherae ohlongo-lineares crassiusculac, in aestivatione inflexae, aequales, connectivo postice crasse et longe clongato, acutissimo, juxta processum callis 2 manifestis demum carnosis instructo, antice inappendiculato. Stylus colunnaris, basi squamis $ٌ$ crassiusculis longiusculis cinctus. Ovarium receptaculo in parte $2 / 5$ infero adnatum, 5-loculare, placentis multiovulatis.

Herba perennans vel suffrutex procerus, ercetus, pilis longis brunneis fere undique laxe vel laxissime obtecta. Rami acutissine tetragoni. Folia opposita et decussata. Flores magni, pulcherrimi, rosei, in apice caulis vel ramorum umbellati, ut videtur elsacteati.

Petalonema pulchrum Gilg l. e.; herba perennans vel suffrutex procerus, puleherrimus, ramis junioribus tomento brevissimo brumnco obtectis pilis aliis longis brumneis laxe intermixtis, demum glabris; foliis longe petiolatis, ovatis vel late ovatis, basi cordatis, apice in acumen longum tenue sensim angustatis, utrinque glabris, »supra intense viridibus atque leviter bullatis, subtus purpureis «, subcharlaceis, manifeste denticulatis, 7-9nerviis, venis omnibus subtus valule prominentilus in costa reclangulis, inter sese parallelis; floribus »roseis « magnis, in apice caulis vel lamorum in umbellas ut videtur multilloras longipedunculatas collectis. 
Blätter 3-6 em lang gestielt (Stiele dieht mit braunen Borstenhaaren besetzt), $7-15 \mathrm{em} \mathrm{lang,} 4-10 \mathrm{em}$ breit. Blütendolden 2-2,5 em lang gestielt. Blütenstielehen er. 2,:3 em lang. Reeeptaculum blätter $2,5-3 \mathrm{em}$ lang und fast ebenso breit, Blüte also meist $6 \mathrm{em}$ im Durchmesser.

Usagara: Ulugurugebirge, Nghwénn, $1300 \mathrm{~m}$ ï. M. (Stunlman n. 8764), $1300 \mathrm{~m}$ ii. M., an der Wald-

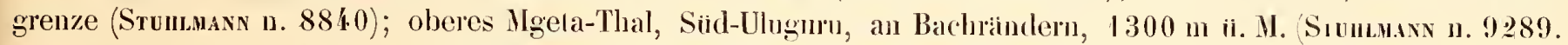
- Blühend im Oetober und November. - H. Berl.!).

Abbildung auf Taf. IV. $B$. - $a$ Blütenzweig; $b$ Blalt von unten; $c$ Knospe; $d$ Blumenblatt; $e, f$ Staubblatt von vorn und von der Seite; $g$ Receptaeulum und Fruchtknoten im Längssehnitt; $h$ Fruchthnotenquerschnilt; $i$ firiffel.

\section{A. c. Melastomatoideae - Sonerileae.}

\section{Amphiblemma Naud.}

I. c. XV. 50; Benth. et Hook. Gen. plant. I. 754; Triana I. c. 79 und 167; Hooker f. 1. c. II. 4.65; Cogniaux

l. c. 526 ; Krasser 1. c. 174.

\section{Übersicht der Arten.}

A. Blütenstand und Blatt, beide sehr lang gestielt, gehen gesondert von einem winzigen, kriechenden Stengelorgan (Wurzelstoek) ab . . . . . . . . . . . . . . . 1. A. acanle Cogn.

B. Stets ist ein ansehnlicher aufreehter, beblätterter Stengel entwickelt, an dem die Blüten in axillären oder terminalen Cymen stehen.

a. Cymen alle oder fast alle terminal.

a. Blätter an der Basis abgerundet, beiderseits dicht behaart. . . . . . . . . . . . 2. A. moIle Hook. f.

$\beta$. Blätter an der Basis herzförmig, oberseits spärlieh mit Borsten besetzt, unterseits kahl oder nur sehr schwach behaart.

I. Blätter ganzrandig oder nur äusserst undeutlieh gezühnt, am Rande nur sehr spärlich und kurz gewimpert. Receptaeulum dieht und lang drüsenborstig . . . . .

II. Blätter sehr deutlieh und regelmässig buchtig grobgezähnt, jeder Zahn in eine lange, starre Wimperborste auslaufend. Reeetaculum kahıl . . . . . . . . .

III. Blätter sehr fein und reiehlieh gezähnt, jeder Zahn in eine selır kurze Wimperborste auslaufend. Receptaeulum kahl .

b. Cymen alle axillär.

ø. Stengel und Blattstiele kahl. . . . . . . . . . . . . . . . . 6. A. lateriflornm Cogn.

ß. Stengel und Blattstiele mit langen abstehenden Borsten locker besetzt . . . . . . . . A. Soyauxii Cogn.

1. Amphiblemma acaule Cogn. in Bol. Soc. Broler. XI. (1892-93). 89.

Caule nullo; foliis solitariis vel binis, longe petiolatis, late ovatis, acutiuseulis, basi profunde emarginatocordatis, margine remotiuscule minuteque denticulatis, utrinque breviuscule sparseque setulosis; petiolis pedunculisque subsparse breviterque retrorsim setulosis; ealyce longiuscule et densiuscule setoso, lobis triangularisubulatis, tubo paullo brevioribus; pelalis anguste obovatis, non ciliatis.

Petiolus robustiusculus, eireiter 1 deeim. longus. Folia tenuiter membranacea, laete viridia, suh-9-nervia, $11 \mathrm{~cm}$ longa, 9-10 cm lata. Cymae bifidae, subeongestae, paueiflorae, floribus subseeundis; peduneulus communis satis gracilis, 6-7 em longus, infra medium minute bibraeteolatus; rami divergentes; pedicelli dense hirtelli, $2-3 \mathrm{~mm}$ longi. Calyeis tubus obeonicus, $3 \mathrm{~mm}$ longus; lobi leviter flexuosi, $2-2,5 \mathrm{~mm}$ longi. Petala $6 \mathrm{~mm}$ longa. Antherae anguste oblongae, rectae, apiee subtruneatae, majores 1,5 mm, minores $2 / 3 \mathrm{~mm}$ longae. (Diagn. ex Cogniaux.)

Oberes Congogebiet: Baschilange, im Distr. Lenbanguli (oder Cobanguli?), in feuchten, schattigen Thailern, $800 \mathrm{~m}$ ii. M. (Siz. Manques n. 211. - Blühend im October und November. - H. Berl.!).

2. Amphiblemma molle Hook. f. 1. c. 4.56; Triana 1. c. 79; Cogniaux 1. c. 327.

Gabun: Sierra del Crystal (Mans. - Blühend im Mai. - H. Kew).

3. Amphiblemma setosum Hook. f. 1. c. 456; Triana 1. c. 79; Cogniaux 1. c. 527.

Gabun: Sierra del Crystal (Mann. - Bluhend im Mai. - I. Kew); Ogowegebiet? (Thollon. - H. Paris). Cogriaux citiert bei dieser Art (ohne Nummerangabe) anch ein von Soraux in Gabun, Mundadistriet, gesammeltes Exemplar. Da sich diese Pflanze weder im Berliner IJerbar, noeh im Hert. Scuwensururu findet, welehe Herbarien die ersten Nummern der Sammlung von Soyaux enthalten, so nehme ieh an, dass hier ein Versehen vorliegen muss. 
4. Amphiblemma ciliatum Cogn. 1. c. 528 .

Gabun: Ogowegebiet, bei Lambareme (Thollon n. 4.39. - II. Paris!); im Uferwald bei Adolinalongo Soyux 1. 286. - Blïhend im April. - II. Berl.!).

Abbildung auf Taf. Y. B. - Frucht.

๖. Amphiblemma cymosum (Schrad.) Naud. І. c. XV. 30 und XlV. t. 7 f. VII.; Bot. Mag. 1. 3473; Triana 1. c. 79 , เ. VI. f. 77 ; Iook. f. I. e. 4.56; Cogniaux 1. c. 328; Krasser 1. c. 174.

Melastoma cymosum Schrat. Sert. Hann. 1. 10; Vent. Jard. Nlalm. t. 14; Rbch. Mag. Bol. t. 4.3; Lois. Herls. Amat. II. 1. 135; DC. Prodr. II. 14.7; Nart. Nor. Gen. et Spec. Ill. 160 in adnot. I. 241 f. II.

Melastoma corymbosa Sims in Bot. Mag. t. 904; Loda. Bot. Cab. t. 98'.

Melastomu leonensis Lodd. ex Steud. Nomencl. Bol., Ed. II. vol. Il. II6.

Sierra Leone: (Afzeuus. - H. Berl.!; Banter. - H. Kew; Iornemann ex Cognumx.

Auch bei dieser Art eitiert Cognuax (ohne Nummerangabe) ein von Soraux in Gabun gesanmeltes Exemplar, welches mir nicht vorlag. Es handelt sich hier wohl zweifellos um ein Exemplar von A. ciliatum, welche Art Soratx in reichlichen und schönen Exemplaren gesammelt bat (Herb. Berl.! und Schweinfurth!), ohne dass sie Cognuax aufführte.

6. Amphiblemma lateriflorum Cogn. I. c. 529.

Gabun: Ogowe (Thollon m. 245. - H. Paris!).

7. Amphiblemma Soyauxii Cogn. 1. c. 1184.

Gabun: Munlagebiet, Sibangefam, an einem morschen, im Sumpfe liegenden Stamme (Soyax n. 207. Bliihend im Februar. - H. Berl.!).

Abbildung auf Taf. V. A.; $a$ Blütenstände; $b$ Bläte; $e$ Blumenblatt; $d, e$ grösseres und kleineres Staubblall von der Seite.

\section{Cincinnobotrys Gilg}

in Engler-Prantl Nat. Pflanzenfam., Nachtrag 265.

Flores 4-meri. Receptaculum campanulatum densissime pilis lrevibus simplicibus rigidis obtectum, apice truncatum. Sepala ad denles 4 brevissimas acutas reducta. Petala obovato-oblonga, apice rolundata, filiformiapiculata hasin versus sensim angustata. Stamina pelalorum numero dupla, inaecuilonga, 4 episejaala majora, 4 epipetalis eormu cr. 1/2 longit. adaequantibus, onnibus forma aequalibus; antherae oblongae, non curvatae, commectivo valde incrassato, paullo infra antherae basin antice annulo incrassato nolato, annulo postice inferne elongato breviterque bicalcarato. Stylus colunnaris elongatus, sligmate dilatato, inferne concavo. Ovarium receptaculo adnatum 4-loculare, vertice subconcavum et squamis 4 elongatis basi connatis membranaceis apice emarginalis et pilis glanduligeris dense obsitis coronatmm. Capsula matura campanulata, chartacea, apice 4valvis. Semina minuta, numerosissima, recta.

Herba acaulis, bulbosa, hirsuta, epiphytica (ex Stumuman). Folia longissime peliolata, 9-nervia. Flores in apice pedunculi valule elongati e bulbo enascentis cymosi, i. e. cincimnose congesti, ramo infimo cincimi plerumpue solo modo esmae regularis 3-florae evoluto.

Cincinnobotrys oreophila Gilg I. c.; herba humilis $20-30$ cm alta, erecta, hulbosa vel potius rhizomate subgloboso brevi instrucla; foliis membranaceis, $12-13 \mathrm{~cm}$ longe petiolatis, late ovatis vel orbiculari-ovatis, basi profunde cordatis, apice acutis, margine semulatis, supra subusque pilis brevissimis simplicihus lanissime

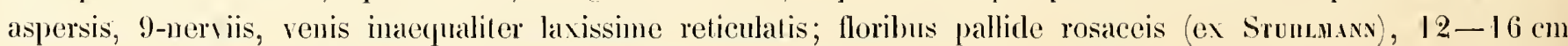
longe pedunculatis, pedicellis $5-6$ mm longis; bracteis nullis.

Blitter 4-8 cm lang, 4-6 cm breit. Receptaculum cr. $3 \mathrm{~mm}$ hoch, oben fast ebenso dick. Kielchblatter kaum sichtbar. Blumenblïtler $4-5 \mathrm{~mm}$ lang. Staubfäden $+\Lambda$ nthere $3,5-4 \mathrm{~mm}$ lang. Griffel ziemlich dick, $5 \mathrm{~mm}$ lang.

Usagara: Ulugurugebirge, Nghwém, im Bergwald, 1600 m ii. M., toten Stammen aufsitzend (Stumbmx 1. $880 \%$. - Bliihend und firuchtend im October. - II. Berl.!).

Jiese auffallende Pflanze hat keine Verwandten in Afrika. Meiner Meinung nach gebört sie in die Verwandtschaft der chinesischen Gattung Gymnagathis Stapf, welche ich zwar leider nicht untersuchen konnte, deren Beschreibung aber in manchen Punkten auffallend mit unserer Pflanze übereinstimmnt.

Abbildung auf Taf. VI. A. - $a$ ganze Pllanze; $b$ Knospe; $c$ Blüte; $d$ Blunenblatt; $e, f, g$ eines der grüsseren Staubblïlter von vorn, von hinten und von der Seite; $h$ eines der kleineren Stanbhlitter von der Seite; $i$ Receptaculum und Fruchtknoten in Lïngsschnitl; $l_{i}$ Fruchtknotenquerschnilt; $l$ Grilfel; $m$ lrucht; $u$ Samen; $o$ Samenlïngsschnitt. 


\section{Calvoa Hook. f:}

in Benth. et Hook. f. Gen. plant. I. 755 und in Oliver Fl. trop. Afr. 11. 457; Triana I. c. 78 und 167; Cogniaux

l. c. 32 ; Krasser 1. c. 176.

\section{Übersicht der Arten.}

A. Halhstrüucher orler ausdanernde ansehnliche Krïuter, kahl oder mit winzigen anliegenden IÏ̈rchen, oft Spreuschuppen besetzl.

a. Blätter 7-nervig. . . . . .

b. Blätter 5-nervig.

๗.. Blitter ganzrandig .

ß. Blätter buchtig gezihhnt.

I. Stengel an den Knoten auffällig verdickt, schwach und fein behaart. Blätter succulent.

1. Blätter stumpf, an der Basis abgerundet. . . . . . . . . . . . .

2. Blätter in eine lange scharfe spite ansgezogen, unten keilfürmig, of am Übergang zum Blattstiel alogestumpft .

Il. Stengel an den Knolen nur wenig verd̉ickt, vüllig oder fast völlig kahl. Blätter succulent, stumpf acuminat. . . . . . . . . . . . . . . . . .

III. Stengel an den Knoten unverdickt, schwarh und fein behaart. Blätter dünn membranös, in eine kurze, breite, scharfe spitze ausgezogen, seltener fast alggerundet

B. Einjährige, niedrige, striegellaarige Kräuter.

a. Blätter an der Basis deutlich schief herzförmig

b. Blätter an der Basis abgerundet, wenig schief .

I. C. grandifolia Cogn.

2. C. integrifolia Cogn.

3. C. crassimoila Itook. $f$.

4. C. Molleri Gilg

5. C. sinuata IIool: $f$.

6. C. orientalis Taub.

7. C. Hemiquesii Cogn.

8. C. hirsuta Hook. f.

1. Calvoa grandifolia Cogn. I. c. ว̈24.

Kamerungebiet: Insel Rolas bei der Insel S. Thomé (Quñas. - Blühend im December. - H. Beri.!).

2. Calvoa integrifolia Cogn. 1. с. 523.

Kamerungebiet: Insel S. Thomé, auf dem Monte Café, 700 m ü. M. Quintas. — Blïhend im December. — H. Berl.!).

3. Calvoa crassinoda Hook. f. 1. c. 437 ; Triana 1. c. 78, 1. VI, f. $76^{\text {b }}$; Cogniaux 1. c. 525 p. p. Kamerungebiet: Insel S. Thomé, anf dem Gipfel des Pies (Mans. - H. Kew).

4. Calvoa Molleri Gilg n. sp.; caule ramisque acule tetragonis brevissime lenuissimeque brinneo-pilosis mox glabratis, ad nodos valde incrassatis et grosse verucosis; foliis carnosulis longe petiolatis, oblongis vel plerumque obovato-oblongis, apice longiuscule acmminatis vel saepius longe angustatis, apice ipso acutissimis, basin versus cuneatis, apice ipso saepius breviter truncatis, inaequaliter atque plerumpue obsolete sinuatodentatis, dentibus in setam longiusculam abeuntibus; floribus breviter perlicellatis in apice caulis in paniculas effusas laxas multifloras dispositis, paniculae ramis semper in monochasia elongata spiciformia tenuissima abeuntibus; receptaculo ovato-oblongo, brevissime el tenuissime brunneo-piloso; sepalis ovato-triangularibus acutis; pelalis obovatis rolundatis, obliquis.

Calvoa crassinoda Cogn. I. c. p. p.

Die Blitter der offenbar halhstrauchigen und kräftig verholzte Zweige aufweisenden Pflanze sind $3-8 \mathrm{~cm}$ lang und $1,5-3,5 \mathrm{~cm}$ breit. Blattstiele $5-18 \mathrm{~mm}$ lang. Blütenstände $10-13 \mathrm{~cm}$ lang. Blütenstielchen etwa $3 \mathrm{~mm}$ lang. Receptaculum etwa $4 \mathrm{~mm}$ lang, $3 \mathrm{~mm}$ dick. Kelchblätter etwa $2 \mathrm{~mm}$ lang, fast ebenso breit. Blumenblätter $13-15 \mathrm{~mm}$ lang, $7-8 \mathrm{~mm}$ breit.

Kamerungebict: S. Thomé, Nova Moka, 900 m ii. M. (Moleer. - Blihend im Juni. - H. Berl.!).

Cogniacx zog diese Pflanze, welche ich infolge der Liebenswürdigkeit der Herren Prof. Henriques und Garteninspector Mollen zu Coimbra in guten Exemplaren untersuchen konnte, zu C. crassinoda. Obgleich ich nun das Original zı dieser Art nicht gesehen habe, glaube ich sicher zu sein, dass beide P(lanzen sehr verschieden sind. Übereinstimmend ist allerdings bei beiden, dass die Knoten der Zweige stark verdickt und mit blasenartigen Auftreibungen (Ameisenwohnräume?) versehen sind. Dagegen weichen die Blätter in der Form ausserordentlich von einander ab, wie aus den Diagnosen wohl genügend hervorgehen dürfte.

Abbildung auf Taf. V. C. - $a$ Knospe; $b$ Blüte; $c, d, e$ Staubblatt von der Seite, von vorn und von hinten; $f$ Receptaculum und Fruchtknoten im Längsschnitt.

5. Calvoa sinuata Hook. f. 1. c. 437; Triana 1. c. 78, ı. V1, f. 76 ; Cognıux 1. c. 595 ; Krasser 1. c. 176.

Kamerungebiet: auf Felsen bei der Insel Principé (Barter. - H. Kew). 
6. Calvoa orientalis Taul, in Engler, Pllanzenwelt Ostafr., C, 296.

Gluasalquellengebiet: Land der Niamniam, am Diaghe bei Uando's Dorf (Scnwernfutn n. 3116. Bliihend im Mairz. - H. Sclıweinfurth!).

Usambara: Buha-Wald bei Gonja (Houst n. $42 \% 8$. - H. Berl.!).

Centralafrikanisches Seengebiet: Bukoba, 1130 m i. M. (Srumsux n. 994 und 3261. - Bhihend vom November bis Februar. - H. Berl.!).

Abbildung auf Taf. V. D. - $a$ Fruchtstand; $b$ Frucht; $c$ Samen.

7. Calvoa Henriquesii Cogn. 1. c. 226 ; Krasser 1. c. 176.

Kamerungebiet: S. Thomé, Roga Tras-os-Montes, $1000 \mathrm{~m}$ ii. M. (Quntas. - Bliihend im Mai. - H. Berl.!).

8. Calvoa hirsuta Hook. f. I. c. 437 ; Triana 1. c. 78, 1. VI. f. $76^{\text {c }}$; Cognianx 1. c. 526.

Kamerungebiel: Insel Fernando-Po, 2000 m ü. M. (Manv. - H. Kew); S. Thomé (?) (Quntas [ex Cognaux] in H. Conimb. et Berl.!).

Abbildung auf Taf. V. E. - Frucht.

Die beiden letzteren Arten lagen mir in den Cognuax'schen Originalen in schönen Exemplaren aus dem Ilerb. Coimbra zur Ansicht vor, die als C. hirsuta bezeichnete Pflanze auf S. Thomé, Matta de Macambrará, von Qunsas gesammelt. Das IIоокеR'sche Original von C.hirsuta habe ich leider nicht geselıen, kann also nicht angeben, wie sich die beiden Pflanzen von S. Thomé zu der von Fernando-Po verhalten. Das aber scheint mir sicher zu sein, dass die von Cogvaux als $C$. hirsuta bezeichnete Pflanze von seiner $C$. Henriquesii nicht specifisch verschieden ist. Kein einziger der in den Diagnosen angeführten Unterschiede hat sich als stichhaltig erwiesen. Entweder muss also überhaupt C. Hermiquesï als Synonym zu C. hirsnta gestellt werden, oder C. hirsuta kommt auf S. Thomé nicht vor.

\section{A. d. Melastomatoideae - Dissochaeteae.}

\section{Sakersia Hooli. $f$.}

in Benth. et Hook. f. Gen. pl. 1. 737 und in Oliver 1. c. 4.58; Triana 1. c. 168; Cogniaux 1. c. 546; Krasser 1. c. 179.

Dissochacla spec. Baill. Ilist. Pl. VII. 15 und 51.

\section{Übersicht der Arten.}

A. Blütenstandsachsen dicht nil dicken Borstenhaaren besetzt . . . . . . . . . . . . . 1. S. africana Hook. $f$.

B. Blïtenstandsachsen völlig kahl . . . . . . . . . . . . . . . . . . . . 2. S. echinulata Hook. f.

1. Sakersia africana Hook. f. 1. c. 458 und in Ilook. lc. P. t. 1086 ; Triana I. c. 81, I. Vll, f. 86; Cogniaux 1. c. $54 . \%$.

Kamerun: an Kamerunlluss (Mlans. - H. Kew); Yaúnde, $800 \mathrm{~m}$ it. M., ein $5-8 \mathrm{~m}$ und noch mehr hoher Bam im Urwald (Zexken n. 735. - Blihend im Felsuar. - II. Berl.!); bei der Stadt Kamerum, an fenchten und trockenen Plätzen iilıerall, ein pyramidaler, 5-6 $\mathrm{m}$ hoher Baum mit weissen und roten Blüten in einem und demselben Büschel (Lemmacu n. $4{ }^{a}$. - Blibend im December. - H. Berl.!).

Gabun: in Wädern bei der Siluange-Farm (Dınkage n. 5\%6. - Blïhend im Februar. - II. Berl !), ein 8- $10 \mathrm{~m}$ hoher sehr verzweigter Baun, ein hoher Schmuck des Waldes mit seinem Überreichtum hyacinthenroter Bliten und dem sich goldig und rot beim Fallen faibenden Laub, an feuchten Platzen, an Bachufern und Sumpfräandern (Sovaux n. 52. - Blihend im Januar. - H. Berl.!).

2. Sakersia echinulata Ilook. f. l. c. 458 ; Cogniatx I. c. 547.

Sierra Leone: (Armens. - H. Berl.!).

$\Lambda$ bbildung auf Taf. V. $F$. - $a$ Blütenzweig; $b$ Kinospe; $e$ Blüte; $d$ Staubblatt von der Seite; $e$ Fruclst; $f$ Samen.

16. Dicellandra Hook. $f$ :

in Benth. et llook. f. Gen. plant. I. 757 und in Oliver I. c. 459; Triana 1. c. 168; Cogniaux 1. c. ä4.̈; Krasser 1. c. 179.

Dissochaela spec. Baill. Hist. PI. VIl. 15 und 51. 


\section{Übersicht der Arten.}

A. Blütenstandsachsen sehr kurz und angedrückt dicht braun behart.

a. Stengel scharf vierkantig, rauhhaarig, besonders an den Kanten . . .

1. D. Barteri Hook: $f$.

b. Stengel fast stielrund, kaum kantig, kahl oder fast kahl

2. D. liberica Gilg

3. D. setosa Hook. $f$.

B. Blütenstandsachsen und Blattstiel mit langen, scharfen Borsten sehr locker besetzt

1. Dicellandra Barteri Hook. f. 1. c. 4.59; Triana 1. c. 1. VII, f. 85 ${ }^{\text {b }}$ Cogniaux I. c. 3046.

Oberguinea: am Nun-Fluss (Barter. - H. Kew); Lagos (Holoney, - H. Kew).

Kamerungehiel: auf der Insel Fernando-Po (Mhns. - I. Kew).

Bezüglich der von Ноoker f. und Consuatx angegebenen Standorte: Gabun, Sierra del Crystal (Mavs) und Mtonluttuland Sснweivfurtu n. 3166) vergleiche das unter Pliaeonewron dicellandroides Gilg Gesagte

2. Dicellandra liberica Gilg n. sp.; frutex vel suffrutex erectus ramis obscure tetragonis vel inferne subteretibus, junioribus laxiuscule et hrevissime brunneo-furfuraceis, setis longiusculis rigidis parcissime intermixtis, mox glabratis et inferne glaberimis; foliis longiuscule petiolatis oblongis vel oblongo-lanceolatis, basi subrotundatis vel saepius subcuneatis, apice longe angusteque acuminatis, apice ijso acutissimis, acute serralis vel dentatis, supra glabris, subtus undique, praesertim ad nervos, laxe brunneo-furfuraceis, mox glabrescentibus, manifeste $\check{\partial}$-nerviis, renis inter sese parallelis costa rectangulariter impositis numerosis, manifeste conspicuis; tloribus in apice caulis in cymas valde ramosas paniculam pulchram formantes dispositis, 5 -meris, normalibus.

Blätter $8-11 \mathrm{~cm}$ lang, 2,5-3,5 cm breit, Blattstiel 1,2-2,5 cm lang. Blütenstand $3-6 \mathrm{~cm}$ im Durchmesser. Blütenstielchen $6-9 \mathrm{~mm}$ lang. Receptaculum $8 \mathrm{~mm}$ hoch, $8-9 \mathrm{~mm}$ dick. Bhumenblätter $1,7 \mathrm{~cm}$ lang.

Oberguinea: Liberia, Grand Bassa, sumpfige Stellen des sandigen Vorlandes, 2 m ii. M. (I)ıкkage 1. 1767. - Blihhend im October. - H. Berl.!). $f$ Frucht

Abbildung auf Taf. V. $G$. - $a$ Blütenzweig; $b$ knospe; $e$ Blüte; $d, e$ grösseres und kleineres Staubblatt von der Seite;

3. Dicellandra setosa Ilook. f. l. c. 4399 ; Cogniaux l. c. ̈̈ 6 .

Sierra Leone: (Afzeluss. - H. Berl.!).

Das Original dieser Pllanze, welches mir vorlag, zeigt nur reife Früchte; aus diesem Grunde hat Hooker F. diese Art nur mit Zweifel zu Dicellandra gestellt. Nach dem ganzen Habitus und dem Fruchtbau zweille ich jedoch nicht, dass die Pllanze ihre richtige Stellung erhalten hat.

\section{Myrianthemum Gily}

in Engler-Prantl, Nat. Pllanzenfam., Nachtrag 266.

Flores 4-meri. Receptaculum cyathiforme tubo superiore hemisphaerico, limbo integro vel obsolete emargimulato (i. e. sepalis obsoletis). Petala latissime ovata vel suborbicularia, acuta, valde concara, carnosula. Stamina 8 inaequalia, \& exterioribus quan cetera multo longioribus. Antherae lineares, elongatae, subincurvae, apice 1-porosae, connectivo in staminibus exterioribus in lobos antherarum 1/2 longit. subarlaecfuantes, in interioribus ad calcara 2 minima crassiuscula reductos producto, postice semper 1-calcarato. Ovarimm 4-loculare, vertice disco nectarifero auplo coronatum; slylus elongatus filiformis crassiusculus.

Frutes scandens glaber. Folia 3 vel b̈-nervia. Flores ad caulis basin supra radices inllorescentiam globosan confertam multifloram (1000-1500-lloram) usque ad $13 \mathrm{~cm}$ diametientem formantes, inflorescentia ex cymulis valde confertis e nodis erumpentilous composita; pedicellis elongatis gracilibus, bracteis nullis rel subnullis.

Myrianthemum mirabile Gilg I. c.; frutex scandens glaber, ramis teretibus longiludinaliter striatulis; foliis longe petiolatis, inlegris, infimis altemantibus, superioribus ternis vel quaternis verticillatis et linea valde incrassato-elevata inter sese connexis, oblongis vel obovato-oblongis, apice acutis vel breviter acciminatis, basi subrotundatis rel saepius subsensim in petiolum angustatis, chartaceis, maximis, a basi ̈̈-nerviis, jugo inferiore tenuissimo in foliis minoribus vix conspicuo ad marginem fere ipsum percurrente, jugo superiore costae subaequivalido, supra impresso, subtus valıle prominente, venis inaequaliter laxe reticulatis.

Blaltstiel $3-6 \mathrm{~cm}$ lang. Blätter $15-30 \mathrm{~cm}$ lang, $5-13 \mathrm{~cm}$ breit. Einzelblütenstände bis $4 \mathrm{~cm}$, Blütenstielchen bis $3,5 \mathrm{~cm}$ lang. Receptaculum ca. $6 \mathrm{~mm}$ lang, der obere freie Teil ca. 2,5 mm hoch. Blumenblätter $4-5 \mathrm{~mm}$ lang, ca. $4 \mathrm{~mm}$ breit.

Gabun: Sibange-Farm (Munda-Geliet, im Wald Soraux n. 361. - Blihend in December. - H. Berl.!! Englor, Monographieen. Il. 
Die neue Gattung; welche durch ihren Blütenstand sehr anffallend ist, gehört in die Verwandtschaft der indisch-malayischen Gattung Dissocliaeta. Auch mit Medinilla hat sie manches gemein. Doch ist sie von beiden Gattungen durch zahlreiche charakteristische Merkmale getrennt.

Abbildung auf Taf. VIl. - $a$ eine obere Partie des dünnen Stengels mit den quirligen Blättern; $b$ unterer Teil des Stengels mit Wurzeln und dem auffailenden, fast kugeligen Blütenstand; $c$ einer der zahlreichen Partialblütenstände; $d$ linospe; e Bhïte; $f$ grösseres Staubblatt von der Seite; $g$ Antherenquerschnitt eines der grösseren Staubblätter; $h$ kleineres Staubblatt; $i$ Querschnitt durch die Anthere eines der kleineren Staubblätter; $l$ Receptaculum und Fruchtknoten im Längsschnitt; $l$ Fruchtknoten im Querschnitt.

\section{Tetraphyllaster Gilg}

in Engler-Prantl, Nat. Pflanzenfam., Nachtrag 266.

Flores :3-meri. Receptaculum obovatum glabrum. Sepala magna ovata, acuta. Petala late obovata, brevissime unguiculata, apice rotundala. Stamina petalorum numero dupla, aequalia; antherae lineari-subulatae, elongatae, paulo curvatae, apice 1-porosae, connectivo non producto, antice breviter bicalcarato, postice annulo incrassato ornato. Stylus columnaris, stigmate punctiformi, basi pilis longis rigidis cinctus. Ovarium tofum receptaculo adnatum 5 -loculare, vertice leviter convexum. Fructus verosimiliter baccatus sepalis coronatus, polyspermus.

Herba ascendens basi prostrata atque radicans, ramosa, pilis simplicibus dense vel densissime obtecta. Rami tetragoni. Folia semper opposita et decussata. Flores mediocres, rosei, in apice caulis rel ramorum solitarii, bracteis :3 magnis persistentibus arcte cincti.

Tetraphyllaster rosaceum Gilg l. c.; herba humilis usque ad $4.3 \mathrm{~cm}$ alta, ascendens; foliis longe petiolatis, membranaceis, oralibus vel ovali-ovatis, apice breviter acuminatis acutisque basi sensim angustatis vel

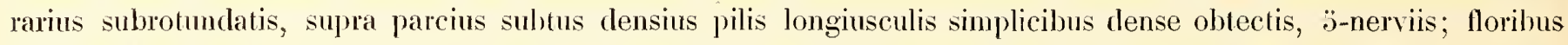
rosaceis (ex collect.) solitariis terminalibus, sessilibus, foliis involucrantibus quam cetera multo minoribus, bracteis 4. pallescentibus oppositis et decussatis late ovatis, margine manifeste pectinato-ciliatis.

Kamerun: Buea, im Buschwald, $1000 \mathrm{~m}$ ii. M. Preuss n. 702. - Bliihend im Janwar 1894. - H. Berl.!)

Blätter mit einem 1-1,5 cm langen Blattstiel, 4-6,5 cm lang, 1,7-2,8 cm breit. Bracteen 7-8 mm lang, 5-6 mm breit. Receptaculum $8 \mathrm{~mm}$ hoch, oben $4 \mathrm{~mm}$ dick. Kelchblätter $4-5 \mathrm{~mm}$ lang, an der Basis ca. $3 \mathrm{~mm}$ breit. Blumenblïtter ca. $1 \mathrm{~cm}$ lang, $7-8 \mathrm{~mm}$ breit. Griffel $8-9 \mathrm{~mm}$ lang, ebenso lang wie Staubblatt + Anthere.

Die neue Gattung Tetraplyllaster gehört wohl in die Verwandtschaft von Medinilla, mit welcher sie manches übereinstimmende besitzt. Sie weicht jedoch in folgenden Punkten ab: Tetraphlyllaster ist ein einjühriges Kraut, während die Arten von Medinilla stets Sträucher von sehr übereinstimmendem Ilabitus darstellen. Bei Tetraphyllaster ist stets eine einzelne endständige Błüte vorhanden, während bei Medinilla stets mehr-, meist vielbłütige Inflorescenzen entwickelt sind. Während ferner bei $M$. die Kelchblätter stets nur in sehr reducierter Form als winzige Zähnchen oder meist mur noch andeutungsweise entwickelt sind, finden wir hier jene gross, deuttich und persistierend ausgebildet. Es sei endlich noch angeführt, dass anch die Staubblätter von $T$. in ihrer Ausbildung nicht ganz mit denjenigen von $M$. übereinstimmen.

Im Habitus gleicht $T$. rosaceum am meisten manchen Arten von Osbeckia. Doch kann sie hierher unmöglich gehören, da ihre Frucht wohl zweifellos eine Beere darstellt, ferner das Receptaculum vollständig kahl ist und die Kelchblätter nicht abfallen, sondern an der Frucht erhalten bleiben.

Abbildung anf Taf. VItI. A. - a Blütenzweig; $b$ junge Blüte von den Bracteen umhültt; $c$ ältere Blüte, die Bracteen abgeschnitten; $d$ Blumenblatt; $e, f, g$ Staubblatt von der Seite und von vorn, und Querschnitt durch dessen Anthere; $h$ Receptaculum und Fruchtknoten im Längsschnitt; $i$ Fruchtknotenquerschnitt; $k$ Griffel.

\section{Medinilla Gaud.}

in Freycin. Voy. Bot. 484; Triana 1. c. 83 und 168; Hook. f. I. c. 460; Cogniaux 1. c. 372.

Nirr I Art:

Medinilla Mannii Hook. f. ex Triana 1. c. 87 und in Oliver 1. c. 460; Cogniaux 1. c. 3̈82.

Kamerungebiet: Insel Fernando-Po (Mavs. - H. Kew).

Ich habe diese Art leider nicht gesehen, bezweifle aber sehr, dass dieselbe zu Medinilla gehört. Bisher ist keine neue Art der Gattung aus Afrika bekannt geworden, und das Verbreitungsgebiet von Medinilla ist das indisch-malayische.

\section{Phaeoneuron Giily}

in Engler-Prantl, Nat. Pflanzenfam., Nachtrag $26 \%$.

Flores b̈-meri. Receptaculum obovatum, pilis minimis brunneis densissime obtectum. Sepala 0, receptaculo margine superiore non vel vix unclulato, sed saepius filiculis z̈ minimis selaceis loco sepalorum instructo. 
Pelala late oralia, $\doteq$ olliqua, acutiuscula. Stamina 10 , aequalia, aequilonga vel subiequilonga; antherae crassiusculae, linerares, ita ul filamenta rectae, connectivo postice in appendicen crassiusculum, subquadralum producto, antice callis \& subglobosis carnosulis instructo. Stylus columnaris elongatus stamina subchuplo superans. Ovarium receptaculo in parte $1 / 2$ inf. sepris artnatum, $\ddot{3}$-loculare, placentis multiovulatis. Fructus capsularis, fragilis, irregulariter dehiscens. Semina $\infty$, minima, manifeste curvala, flavescentia.

Sulfrutex vel herba peremnans, ramis subtctragonis, denum teretiusculis. Folia opposita et decussata, oppositis plerumque inaequilongis. Flores mediocres violacei vel rosei, in aprice caulis rel ramorum in cymas multilloras paniculatas dispositi; bracteis minimis saepiusque vix conspicuis.

Phaeoneuron dicellandroides Gilg I. c.; herba peremnans vel suffrutex $0, \ddot{j}-2 \mathrm{~m}$ altus, ramis junioribus ita ut petioli perhmeuli pedicelli pilis brunneis brevissimis densissime obtectis; foliis longe, serl opjositis plerumque inaequilonge peliolatis, oblongis vel ovatis usque late ovalis, saepius oblicuis, apice aculis vel sacpius acutissimis, hasi aculis vel acutinsculis vel oblusis usque cordatis, glabris, serl nervis supra in parte inferiore, subtus undique pilis brunneis minimis obtectis, membranaceis, manifeste denticulatis, $\ddot{j}$ - 7 -nerviis, venis numerosis, omnibus inter sese parallelis et in costa rectangulis; lloribus violaccis vel roseis in apice caulis vel ramorum in cymas paniculatas effusas vel saepius subconlractas multilloras dispositis.

B]ätter $\nmid, \ddot{0}-8 \mathrm{~cm}$ lang geslielt, $6-20 \mathrm{~cm}$ lang, $2,5-10 \mathrm{~cm}$ breit. Blïtenstielchen $2-3 \mathrm{~mm}$ lang. Receptacuhum ca. $5 \mathrm{~mm}$ hoch und ebenso dick. Bhumenblätter $1-1,2 \mathrm{~cm}$ lang, $7-8 \mathrm{~mm}$ breit. Girffel 1,2-1,5 cm lang.

Kamerun: Kribi, im Bache zwischen der Tahahisfarm und dem Dorfe Kribi Preuss n. Q(il. -- Bliihend im April. - H. Berl.!; Yaúnde, in Sumpf, an Bachufern und an lichten Stellen gemein Zexkek et Stavd n. 159, Zexкек n. 148. - Blïhend im Januar. - H. Berl.!); Bipinde, an schatligen Bachulern (Zexken n. 90\%. - Blihhend im Mai. - H. Berl.!; Gross Batanga, auf sumpfigen Waldboden und an Bachrändern (Dixklage n. 633. - Blïhend und mit reifen Frïchten im Oktober. - H. Berl.

Ghasalquellengebiet: Laudder Nonbutu, am Kussumbo Scuwenwurtu n. 3166. - Blïhend im Mär. - H. Berl.!).

Diese Pflanze, welche das ganze Jahr über blüht und offenbar durch ihre zahlreichen schünen Blüten sehr auffallend sein muss, ist in Westafrika sehr verbreitet und dringt bis Centralafrika vor. Es war mir deshalb, nachdem ich das zahlreiche mir vorliegende Nlaterial untersucht hatte, sehr auffillend, dass die Pflanze noch nicht beschrieben wurde. Denn obwohl Cogriatx das .xon Scunenfuntu gesammelte Exemplar als Dicellandra Barteri auffülnt, konnte ich leicht feststellen, dass dies auf einem Irrtume beruhen müsse. Her'r Dr. StapF in Kew, der die grosse Liebenswürdigkeit hatte, eine eingesandte Pflanze mit dem mir nicht zu Gebote stehenden Original von Dicellandra Barteri zu vergleichen, bestätigte mir, dass von einer Identität keine Rede sein könne, da die Beschreibung Ilooker's sowie die Abbildung Triavs's durchaus für die Exemplare vom Nun-Fluss (Bırten) und von Fernando-Po (M $\mathbf{M n x}_{\mathbf{N}}$ ) zutreffend sei (während allerdings die Pflanze von der Sierra del Crystall [Manx] nicht hierher gehört). Herr Dr. StapF riet mir jedoch, meine Pllanze trotz der grossen Abweichungen als Dicellandra zu beschreiben. Diesem Rate hätte ich sehr gerne Folge gegeben; doch sagte ich mir, dass dies unmöglich sei, solange das jetzige System der Mclrstomataceae bestehen bleibt. Denn die durchaus gleichen Antheren, die total abweichende Ausgestaltung des Connectivs, endlich auch die dünnhäutige Kapsel entfernen Ph. dicellandroilles weit von Dicellandra. Im Blütenbau scheint diese Pflanze sogar Medinilla bedeutend näher zu stehen, weicht jedoch auch von dieser Gattung durch den ganzen Habitus, den Blülenstand und die Kapselfrucht so erheblich ab, dass sie nicht hierher gestellt werden kann. Ich habe deshalls die Pflanze als neue Gattung beschrieben, welche ihren Platz wohl am besten in der Nähe der Gattung Medinilla finden wird.

Abbildung auf Taf. VIIt. $B$. - $a$ Blatt von unten; $b$ Blülenzweig; $c$ Kinospe; $d$ Blïte, die Blumenblälter entfernt; $e$ Blumenblatt, $f$ kleineres Staubblalt von der Seite; $g$ grösseres Staubblatt ron der Seite; $l$ grösseres Staubblatt ron rorn; $i$ Antherenquerschnitt; li Receptaculum und Fruchtknoten im Längsschnitt; l Fruchtknotenquerschnitt; $m$ Griffel; $u$ Samen.

\section{Preussiella Gilg}

in Engler-Prantl, Nat. Pflanzenfam., Nachtrag 267.

Flores "̈-meri. Receptaculum patelliforme limbo integro vel subintegro vel obsolete emarginulato (i. e. sepalis obsoletis), lobis 5 cum petalis altermantibus (pro sepalis) valde carnosulo-incrassato. Petala 3 obovato-oblonga, ut videtur rotundata, tenera, basin versus angustata. Stamina 10 aequalia, elongata, superne geniculata. Antherae sublineares, apice 1-porosae, connectivo antice inferne longe in calcar ca 2 mm longum crassiusculum exeunte, postice sub locellis tuberculo 1 obsoleto instructo. Ovarium ə̈-gonm, vertice depressum, ̈̈-loculare, slylus elongatus filiformis.

Fruticulus epiphyticus glaber. Folia 3- (vel 3 -) nervia. Flores in apice caulis in cymam paucilloram dispositis, cynae ramis iterum ramosis; perlicellis brevibus tenuibus. 
Preussiella kamerunensis Gilg I. c.; fruticulus epiphyticus brevis vix $30 \mathrm{~cm}$ alus , glaber, radicibus fusiformibus numerosis elongatis, ramis crassiusculis subtetragonis; foliis oppositis ef alecussatis, longe petiolatis, ovatis, basi rotundatis, apice sensim angustatis rel saepius loreviter acuminatis, apice ipso acutiusculo, integris, (in sicco) membranaceis (sed ut videtur in vivo crassiusculis), a basi 5-nerviis, jugo inferiore tenui prope marginem percurrente, jugo superiore quam costa paullọ tenuiore, omnibus utrinque (infra manifestius) prominentibus, venis (paucis) supra paullo prominentibus, infra impressis, semper costae rel nervis rectangulo-impositis; floribus roseis.

Blattstiele in der Länge ungleich, z. B. die der Blïtter eines Paares 1,5 und $3 \mathrm{~cm}$ betragend, die oberen Blätter kürzer gestielt. Blütenstand $1,5-2 \mathrm{~cm}$ lang. Blütenstielchen $2-3 \mathrm{~cm}$ lang. Receptaculum ca. $5 \mathrm{~mm}$ lang. Blumenblätter etwa $6 \mathrm{~mm}$ lang, 3-4 $\mathrm{mm}$ breit.

Kamerun: Barombi-Station, Norlufer des Elefunten-Sees, auf einem Baumstamme über dem Wasser sitzend (Preuss n. 4.2. - Blühend im August. - H. Berl.!).

Die neue Gattung ist mit Medinilla nahe verwandt, unterscheidet sich aber schr gut von tezterer durch die vorn nur mit einem Sporn versehenen Antherenconnective.

Abbildung auf Taf. IX. - a ganze Pflanze, einem Bamme aufsitzend; $b$ Knospe; $c$ Blumenblatt; $d$ kleines Staubblatt von der Seite; $e$ dessen Anthere von vorn; $f$ grösseres Staubblatt von der Seite; $g$ Antherenquerschnitt; $h$ Griffel; $i$ Recepta-

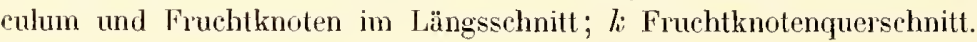

\section{Orthogoneuron Gilg}

in Engler-Prantl, Nat. Pllanzenlan., Nachtrag $26 \%$

Flores ä-meri. Receptaculum late obconicum, teres, pilis glanduligeris subelongatis laxe aspersum. Sepala sul,nulla, receptaculo margine subintegro vel obsolete emarginulato. Petala contorta obovata, breviter vel acute apiculata. Stanina 10 in aestivatione inflexa, aequalia; antherae crassiusculae oblongae, connectivo inappendiculato, sed dorso callis 3 manifeste prominentibus ornato callis 2 lateralibus antice conspicuis. Stylus columnaris basi squamis $\breve{5}$ crassiusculis alte inter sese connatis cinctus. Ovarium receptaculo in parte $1 / 2$ inferiore adnatum 5-loculare, placentis multiovulatis.

Suffrutex erectus, foliis oppositis et decussatis. Flores mediocres, purpurei, in apice caulis vel ramorum in umbellas multilloras confertas subcapitatas collecti, ebracteati.

Orthogoneuron dasyanthum Gilg l. c.; suffrutex ramis subteretibus vel junioribus subtetragonis, pilis longiusculis brunneis glanduligeris dense obtectis, demun glabris; foliis longiuscule petiolatis, oblongis rel oblongo-ellipticis, hasi ovatis rel aculiusculis, apice sensim longe et anguste angustatis, integris, glabris, membranaceis, subtus roseis, Ц̆-nerviis, venis paucis sed subtus manifeste prominentibus, ommibus in nervis rectangulis; floribus infus purpureis, extus albido-roseis (ex collect.), in apice caulis rel ramorum in umbellas multilloras, confertas, 15 -20-lloras collectis, umbellis $6-10 \mathrm{~mm}$ longis, pedicellis $3-3 \mathrm{~mm}$ longis.

Blätter 1,5-2 cm lang gestielt, $7-13 \mathrm{~cm}$ lang, $3-5,5 \mathrm{~cm}$ breit. Receptaculum ca. $4 \mathrm{~mm}$ hoch und oben ebenso dick. Blumenblätter ca. $1-1,3 \mathrm{~cm}$ lang, ca. $0,8 \mathrm{~cm}$ breit.

Usagara: Ulugurugebirge, Tegetero, im Bergivald, $1000 \mathrm{~m} \mathrm{ii.} \mathrm{M.} \mathrm{(Stumlann} \mathrm{n.} \mathrm{9035.} \mathrm{-} \mathrm{Blühend} \mathrm{im}$ Ohłober. - H. Berl.!); Nghwénn, Rodungsgebiet, an einem Abhang, $1200 \mathrm{~m}$ ii. M. (Stunlmann 11. 8861. Im Oktober mit Ǩnospen. - H. Berl.!).

Die neue Gattung gehört zweifellos in die Gruppe der Dissochaeteae und nähert sich unter diesen am meisten der Gattung Pachycentria.

Abbildung auf Taf. VI $B$. - a Blütenzweig; $b$ Knospe; $e$ Bhumenblatt; $d$, $e$ Staubblatt von der Seite und von vorn; $f$ Receptaculum und Fruchtknoten im Längsschnitt; $g$ Fruchtknotenquerschnitt; $h$ Griffel.

\section{B. Memecyloideae - Memecyleae.}

\section{Memecylon $L$.}

Gen. 11. 481; DC. Prodr. III. 5; Blume Mus. Bot. I. 353; Naud. I. c. XVIII. 264; Bentham et Hooker Gen. I. 773; Triana 1. c. 1530 ; Hooker f. 1. c. Il. 460 ; Baillon Hist. Plant. VIl. 28 und 65; Cogniaux 1. c. 1130; Krasser 1. c. 198.

Spathandra Guill. et Perr. FI. Seneg. Tent. I. 313 ; Endl. I. c. n. 6268; Naud. 1. c. 262. 


\title{
Übersicht der Arten.
}

A. Blätter sehr deutlich 3-nervig, Seitennerven stark, gerade, nicht oder nur ganz in der Nähe der Spitze zwischen den Transversahnerven ein oder zweimal hogig.

a. Blüten in mehrfach geteilten, ansehnlichen Rispen.

๙. Transversalnerven unterseits sehr deutlich hervorstehend.

I. Blätter sitzend, schmal eifürmig .

II. Blätter kurz gestielt, breit eiförmig.

1. B]ätter sehr dick lederartig, an der Basis herzförmig oder seltener abgerundet, in eine sehr kurze Spitze ausgezogen.

2. Blätter lederartig oder dünn lederartig, an der Basis mehr oder weniger zugespitzt, lang und sehr spitz acuminat.

§. Transversalnerven unterseits völlig unsichtbar, oherseits deutlich vortretend. Blattober-

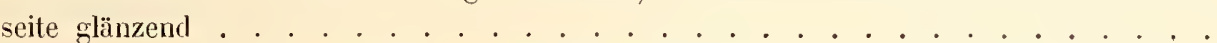

$\gamma$. Transversalnerven beiderseits unsichthar; Blatt auf der Ober- und Unterseite matt.

b. Blïten in kleinen, oft winzigen, fast sitzenden Cymen.

a. Junge Zweige stielrund

今. Junge Zweige vierkantig.

I. Blätter in eine kurze, breite spitze auslaufend.

1. Spitze abgerundet. Blüten meist in endständigen Blütenständen an den Zweigen

2. Spitze meist deutlich zugespitzt. Blüten stets in axillären Blütenständen.

Il. Blätter in eine lange, schmale spitze ausgezogen, Blütenstände meist axillär.

1. Blüten in deullichen, sehr kleinen, 3-blütigen, lockeren Cymen .

2. Bläten zu wenigen in gedrüngten, sitzenden, fast koptigen Cymen.

* Transversalnerven sehr spärlich, oberseits unsichtbar, unterseits schwach hervortretend. Venen unsichtbar.

** Transversalnerven sehr zahlreich, beiderseits deutlich vortretend. Venen netzartig angeordnet. . . . . . . . . . . . . . . . . . . . .

c. Blüten an axillïren, stark verdickten Wülsten in dichten, halbkngelfürmigen Büscheln.

a. Blätter an der Spitze kaum ausgezogen und breit abgerundet, beiderseits matt . . .
३. Bläiter in eine ziemlich lange und meist schmale, schmal abgerundete spitze ausgezogen, oberseits glänzend. nerven schwach bogig. Tergl, auch M. sansibaricmu und II. Buchananii.)

a. Ziveige stielrund.

๙. Blütenstände kurz, höchstens $1-1,5 \mathrm{~cm}$ lang. Blätter $6-9 \mathrm{~cm}$ lang .

3. Blütenstände $2, \check{-}-3 \mathrm{~cm}$ lang. Blätter $10 ّ-30 \mathrm{~cm}$ lang, selten nur $12 \mathrm{em}$ lang.

1. Blütenstände stets nur zu wenigen oder einzeln in den Blattachseln.

14. MI. Barteri Hool. $f$.

7. M. strychnoides Gilg

8. II. jasminoides Gilg

9. II. heterophyllum Gily

10. M. longicauda Gilg

11. M. leucocarpum Gilg

I2. II. sansibaricum Taub.

3. M. Buchananii Gilg

16. M. pnlclerrimum Gilg

b. Zweige deutlich vierkantig.

ø. Blätter eiförmig, lederartig . . . . . . . . . . . . . . . . . . . . 17. M. fasciculare (Planch.)

ア. Blätter eilänglich, lang acuminat, dünnhäntig . . . . . . . . . . . . . . . . . 18. M.memblanifolium Hook.f.

t. Zweige schwach 4-flügelig, d. h. mit 4 starken Leisten versehen.

๙. Blätter an der Basis mehr oder weniger herzförnig . . . . . . . . . . . . 19. M. erubescens Gilg

ß. Blätter an der Basis mehr oder weniger keilfürmig. . . . . . . . . . . . . . . 20. M. Heinsenii Gilg

C. Blätter 3-nervig, Seitennerven viel schwächer als der Hauptnerv und meist vom unteren Teil des Blattes bis an dessen Spitze zwischen den Transversalnerven sehr stark bogig.

a. Zweige stielrund.

э. Blätter sehr kurz gestielt, kurz und stumpf acuminat. . . . . . . . . . . . . . 21. M. virescens Hook. f.

3. Blälter ansehnlich gestielt, in eine lange, gerade, scharfe spitze auslaufend . . . . . 22. MI. calophyllnm Gilg

$\%$. Blätter ansehnlich gestielt, in eine sehr lange und schmale, stets schwach, aber deutlich sichelartig gebogene Spitze auslaufend.

I. Nerven oberseits völlig unsichtbar. Transversalnerven $10-12$, unterseits schwach, aber deutlich hervortretend. . . . . . . . . . . . . . . . . . . . . . . .

II. Nerven oberseits stark eingedrückt, unterseits kräftig vorragend. Transversalnerven nur 5-8. . . . . . . . . . . . . . . . . . . . . . . . . Machairacme Gilg

b. \%weige scharf vierkantig.

a. Nerven nur sehr undeutlich hervortretend. . . . . . . . . . . . . . . . . . . 25. M. candidum Gilg

3. Nerven sehr deutlich sichtbar.

1. Nerven heiderseits (oberseits nur schwach) hervorragend 26. II. Engleriaumn Cogn. 
II. Nerven oberseits eingesenkt, unterseits stark hervortretend.
1. Transversalnerven $5-6$
27. (?) M. Vogelii Naud.

2. Transversalnerven $10-15$.

28. II. Zenkeri Gilg

D. Blätter 1-nervig. (Die beiden Seitennerven vüllig unsichtbar.) Auch die Transversalnerven und Venen meist kaum oder nicht sichtbar. (Vergl. auch M. candidum.)

a. Blüten in Cymen in den Achseln der Laubblätter.

\%. Blätter breit eiförmig, beiderseits völlig matt, sehr dick lederartig, fast holzhart, in eine sehr lange, gerade, ansserordentlich schmale und scharfe Spitze ausgezogen. Blütenstände $6-8 \mathrm{~mm}$ lang, wenighütig.

ß. Blätter elliptisch bis eilanzettlich, lederartig, beiderseits schwach glänzend, in eine lange Spitze ausgezogen. Blütenstände in gestielten Cymen, $2-3 \mathrm{~cm}$ lang. Beere eiförmig oder breit eifürmig .

$\curlyvee$ Blätter eifürmig, lederartig, beiderseits matt, in eine lange Spitze ausgezogen. Blütenstände sehr vielblütig, meist vielverzweigte Rispen, selten wenigerblütig. Beeren kugelig oder sogar von oben etwas zusammengedrückt.

¿. Blätler länglich elliptisch, sehr kurz acuminat, spitz . . . . . . . . . . . . 32. M. Donianum Planch.

31. II. myriantlıun Gilg

ミ. Blätter sitzend, verkehrt-eiförmig-keifförmig, an der Spitze stumpf oder unbedentend ausgerandet

b. Blüten in sehr lang und fein gestielten, axillären, fast kugelig-vielblütigen Dolden.

c. Blüten in dichten Büscheln an knotigen Verdickungen des blattlosen Stammes kurz oberhalb der Wurzel

\section{Memecylon nitidulum Cogn. I. c. 1132.}

Memecylon coeruleum, var. $\beta$. Hook. f. 1. c. 461.

Oberguinea: an Kongui-Fluss (llans, - H. Kew).

2. Memecylon Spathandra Bl. Mus. Bot. I. 361; Cogniaux 1. c. II3I.

Spathandra coerulea Guill. et Perr. 1. c. 313, 1. 71; Naud. 1. c. XVIII. 263 und Xll. t. 10, f. D.

Memecylon coeruleum Hook. f. I. c. 1.6I (non Jack).

Senegambien: (Perrotert, Heubelot. - H. Paris).

Sierra leone: (Arzeluss. - H. Berl.!; Don, Voger, Wurtrield. - H. Kew .

Oberguinea: (Garret. - H. Berl.!); am Bagroo-Fluss (Mann. - H. Kew); Liberia, Grand Bassa, an feuchten, bebuschten Stellen des sandigen Vorlandes, $3 \mathrm{~m}$ i. Il., ein aufrechter, bis $4 \mathrm{~m}$ hoher Strauch (DınkLAGE 1. 4689. - Bliihend im August. - H. Berl.!).

Gabun: Duparquet (H. Paris ex Cogniaux).

3. Memecylon purpureo-coeruleum Gilg n. sp.; frutex vel arbor glaberrima ramis leretibus; foliis breviler petiolatis ovalibus vel late ovalihus, basin versus sensim angustatis vel ima basi oblusis, apice manifeste acuminatis acutissimisque, coriaceis, supra nitidulis, subtus opacis, 3-nerviis rel si mavis $\ddot{b}$-nerviis, sed jugo inferiore tenui juxta marginem percurrente ad venas curvato, jugo superiore quam costa vix tenuiore paullo supra laninae basin abeunte stricte el margini vix parallelo fere usque ad folii apicen percurrente, venis inaequaliter laxissime reliculatis, nervis supra subimpressis subtus valde prominentibus, renis utrinque prominulis; floribus purpureo-coeruleis (ex collectore) $1-1,2 \mathrm{~cm}$ longe pedicellatis, pedicellis pedunculo $\mathrm{cr} .1-1,1 \mathrm{~cm}$ longo umbellatim impositis, bracteis 2 ad basin pedicellorum, 2 in parte pedicellorum 1/5 inf. insertis; receptaculi parte superiore pateriformi, limbo 4-emarginulato; petalis late ovatis, acutiusculis.

Blätter 8-14 cm lang, 1-8 cm breit, Blattstiel $3 \mathrm{~mm}$ lang. Blütenstände höchstens $2 \mathrm{~cm}$ lang. Blüten $3-4 \mathrm{~mm}$ im Durchmesser.

Kamerun: Limbareni (Buchuouz. - Blihend im Juni 1875. - H. Berl.!). - Vielleicht gehört hierher auch ein auteres Exemplar, welches Bucunouz hei llungo sammelte und das ron Evalen als M. Vogelii Naud. bestimmt wurde. Doch isl das Material zu spärlich, um die Frage mit Sicherheit beantworten zu könuen.

4. Memecylon Millenii Gilg n. sp.; frutex vel arbor ramis teretibus vel teretiusculis; foliis glaberrimis breviter et crasse petiolalis ovalibus vel late ovalibus usque ovato-ovalibus, basi rotundatis vel rarius subacutis, apice brevissime acuminalis, acumine aculiusculo, coriaceis, supra nilidis, subtus opacis, 3-nerviis, jugo laterali valido ad laminae basin abeunte et margini manifeste revoluto usque ad partem folii $4 / 5$ superiorem semper parallelo, deinde evanescente, venis perpaucis vix conspicuis ita ut nervis supra subtusque prominulis; floribus ca. $3 \mathrm{~mm}$ longe pedicellatis in cymas longipedunculatas axillares corymbiformes, multifloras subumbelliformes, folii 1/2 longit. superantes dispositis, bracteolis al basin pedicellorum numerosis fasciculatis; pedunculis pedicellisque flarescenti-tomentosulis; receptaculi parte superiore paterilormi, limbo obsolete 4-lobo; petalis acutiusculis. 
Blätter $7-10 \mathrm{~cm}$ lang, $4-6 \mathrm{~cm}$ breit, $5-8 \mathrm{~mm}$ lang gestielt. Blütenstand $4-6 \mathrm{~cm}$ lang, $\mathrm{cr} .3 \mathrm{~cm}$ breit. Blütenstandsstiel cr. $3 \mathrm{~cm}$ lang.

Oberguinea: Lagos (Millen n. 168. - H. Berl.!).

วั. Memecylon Mannii Hook. f. I. c. \$61; Cogniaux 1. c. 1132

Memecylon coeruleum Biitner msc. in H. Berl.

Gabun: (Manv. - H. Kew), in Wald bei Sibange (Butrner n. 4.87. - Blihend im September. - H. Berl.!).

6. Memecylon cinnamomoides Gilg n. sp.; frutex vel arbor glabra, ramis teretilus rel teretiusculis; foliis 4-6 mm longe petiolatis ellipticis vel elliptico-ohlongis, subcoriaceis vel rigitle chantaceis, basin versus sensim angustatis, apice breviter rel brevissime acuminatis, acumine rotundato vel obluso, utrincue opacis, 3-nerviis, jugo laterali valido paullo supra laminae basiu abeunte et margini subparallelo usque ad folii apicem percurente, venis inaecualiter laxe reticulatis, nervis supra parce, renis vix conspicuis, subtus omnibus manifeste prominentibus; floribus $3-4 \mathrm{~mm}$ longe pedicellalis, pedicellis pedunculo $7-10 \mathrm{~mm}$ longo unbellatim impositis, bracteolis pluribus ad basin pedicellorum insertis; calyce pateriformi, limbo manifeste 4-emarginulato.

Blätter $6-8 \mathrm{~cm}$ lang, 3-4,5 cm breit. Blüten ca. $2,5 \mathrm{~mm}$ im Durchmesser.

Sierra Leone: (Afzeluus. - H. Berl.!).

Die vorliegende Pflanze, welche im Iterbar. Afzecurs schon den von unbekanntem Autor zugefügten Manuscriptnamen M. cinnamomoides führt, kann ich mit keiner Art der Gattung identificieren.

7. Memecylon strychnoides Gilg n. sp.; frutex vel arbor glaberrma, ramis acute tetragonis; foliis breviter petiolatis, eflipticis vel saepius obovalo-elliplicis, subchartaceis rel charlaceis, basin versus cuneatis, apice breviter lateque acuminatis, apice ipso rotundatis, utrinque nitidulis vel superne nitentibus, 3-nerviis, jugo laterali valido paullo supra laminae basin abeunte el margini subparallelo usque ad folii apicem percurrente, inter nerros transversales haud curvato, nervis transversalibus numerosis subparallelis costae subrectangulariter impositis, renis inaequaliter anguste reticulatis, nervis supra impressis, subtus manifeste prominentibus, venis supra vix conspicuis subus prominulis; toribus plerumcue in apice caulis ramorumpue, rarissime in folionm axillis, in cymas minimas plerumpue 3-1loras, rarus 2-1-lloras dispositis, bracteolis semper 2; receptaculi parte superiore patcriformi sepalis 4 late ovatis apice rolundatis manifeste evolutis.

Memecylon membranifolium Cogn. I. c. 113 ;) P. P. (non Hook. f.).

Blätter 7-12 cm lang, 3,5-ă cm breit, Blattstiel 2-4 mm lang. Cymen 8-10 mm lang. Oberer freier Receptacularteil etwa $3 \mathrm{~mm}$ in Durchmesser. Kelchbläter $1 \mathrm{~mm}$ hoch, $2 \mathrm{~mm}$ breit.

Angola oder Huilla: (WeLwirsci n. 912. - H. Berl.!).

8. Memecylon jasminoides Gilg n. sp).: »frute ", ramis acule telragonis; foliis breviter peliolatis, ovatis rel adultis late ovatis, hasi subrotundatis rel rarius subcuneatis, apjice hreviter late acuminatis, apice ipso acutis vel rarius acutiusculis, charlaceis vel subcoriaceis, supra manifeste nitentibus, subtus subopacis, 3-nerviis, jugo laterali valido ad laminae basin abeunte et usque ad folii apicem margini subparallelo percurente, inter nervos transversales haul vel vix conspicue curvatis, nervis transversalibus numerosis inter sese parallelis costae subrectangulariter impositis, venis inaefuliter angustissime reticulatis, nervis supra paullo, subtus valde prominentibus, venis utrinque subaequaliter. manifeste conspicuis; horihns semper in foliorum axillis in cymas minimas 3-2-floras dispositis, rarius solitariis, bracteolis 2 mox deciduis; baccis globosis nigris.

Blätter 6-9 cm lang, 3-5, $5 \mathrm{~cm}$ breit, Blattstiel $3-4 \mathrm{~nm}$ lang. Cymen $5-13 \mathrm{~mm}$ lang. Beere etwa $7 \mathrm{~mm}$ im Durchmesser.

Ghasalquellengebiet: Land der Monbuttu, am Bache bei Bongula's Dorf (Scuwennurth n. 3609. Fruchtend im April. - H. Berl.!).

9. Memecylon heterophyllum Gilg n. sp.; frutex vel arbor glabra ramis acute tetragonis; foliis breviter petiolatis, forma valde variabilibus, plerumque oblongis, sed saepius angustis usque lanceolatis rel latioribus usque ovato-orbicularibus, basi plerumque cuneatis, rarissime subrotundatis, apice longe vel longissime el anguste acuminatis, apice ipso acutis vel acutiusculis, chartaceis, supra manifeste nitentibus, subtus opacis, 3-nerviis, jugo laterali costae subaequivalido paullo supra laminae basin abeunte et usque ad folii apicem margini subparallelo percurrente, inter nervos transversales haud curvatis, nervis transversalibus numerosis inter sese subparallelis et costae subrectangulariter impositis, venis laxe inaequaliter reticulatis, nervis supra manifeste impressis, subtus valde prominentibus, renis utrinque subaequaliter prominulis; floribus plerumque in foliorum axillis, rarissime in apice ramorum in cymas breves 3 -floras, rarius $2-1$-lloras dispositis, bracteolis 2 tarte 
decichis; receptaculi parte superiore pateriformi, sepalis 4. late ovatis manifeste evolutis; baccis globosis ut videtur nigris.

Memecylon membranifolium Taub. in Engler, Pllanzenwelt Ostaft., C, 296 (non Hook f.).

Blätler 4-9 cm lang, 2-4,3 cm breit, Blattstiel 2-5 mm lang. Cymen $1-1,5 \mathrm{~cm}$ lang. Oberer freier Receptacularteil $2 \mathrm{~mm}$ im l)urchmesser. Kelchblätter $1 \mathrm{~mm}$ lang, fast $2 \mathrm{~mm}$ breit.

Centralafr. Seengebiet: Bukoba, $1130 \mathrm{~m}$ i. M. (Srunuman 13. 937 mol 1349. — Bliihend und fruchtend im Norember und in Februar. - II. Berl.!).

10. Memecylon longicauda Gilg n. sp.; frutex 1/2-2m alus (es collect.) glaberrimus ramis tetragonis; foliis breviter petiolatis, leviter inaequlibus, ovalibus vel ovato-ovalilus, membranaceis vel rigide membranaceis, Jasin versus sensim angustatis vel rarius subrotundatis, apjee longissime acmminatis, acumine $1 / 4$ usque 1/3 laminae longil. adaefunnte angusto, manifeste curvato, apice rotundato, utrinque opacis, 3-nerviis, nervis supra manifeste impressis subtus prominentibus subaequivalidis, jugo laterali ad basin laminate abeunte et margini subparallelo usque ad apicem percurente, stricto, renis inaequaliter lase reticulatis utrinque praullo prominentibus; 13orilus rubro-coerulescentibus (ex coll.) in foliormm axillis paucis (1- fasciculatis, sessilibus rel subsessilibus hasi bracteolis mumerosis confertis notalis; receptaculi parte superiore pateriformi, limbo profuncle 4-lobo.

Blätter 2,5-i cm lang, 1,2-3,5 cm breit, Blattstiel $5-6 \mathrm{~mm}$ lang, Träufelspitze $1-1,5 \mathrm{~cm}$ 1ang, $2,5 \mathrm{~mm}$ breit. Btütenbüschel $3-4 \mathrm{~mm}$ hoch. Blüte ca. $2,5-3 \mathrm{~mm}$ im Durchmesser.

Kamerun: Johann-Albrechtshöhe (Elephantensee) (Sтамdт n. 471 u. 763. - Bhihend im Dezember I89ä. - H. Berl.!).

Abbildung auf Taf. $\mathrm{X}$ E. - Zweigchen mit Blütenstand und Blatt.

11. Memecylon leucocarpum Gilg n. sj); frutex $2 \mathrm{~m}$ altus (ex collect.) glaberrimus, ramis tetragonis; foliis breviter petiolatis, oblongis rel elliptico-oblongis, rigide chartaceis, basin versus angustatis, apice longissime acuminatis, acumine $1,3-2 \mathrm{~cm}$ longo angusto curvalo, apice acutiusculo, utrinque nitidulis, 3-nerviis vel si maris ö-nerviis, sel jugo inferiore temuissimo ad marginem ipsum percurrente ad venas curvato, jugo superiore valido, :7-7 mm supra folii basin abeunte et usque ad folii apicem margini sulparallelo stricte percurrente, venis inacqualiter dense reliculatis, nervis 3 smpra impressis, subtus valde prominentibus, renis utrinque subaetpualiter manifeste conspicuis; loribus ca. 2-2,5 $\mathrm{mm}$ longe pedicellatis in pedunculo incrassato $2-3 \mathrm{~mm}$ longo bracteolis obtecto racemoso-congestis psendocapitatis rel pseudo-fasciculatis; receptaculi parte superiore pateriformi, limbo prolunde 4-lobo; petalis hreviter unguiculatis, obovatis; staminibus longe exsertis; bacea ohlonga, alba (ex collect.).

Blätter 6-14 cm lang, 3-3,5 cm breit, Blattstiel ca. $3 \mathrm{~mm}$ lang. Blüten $5-6 \mathrm{~mm}$ im Durchmesser. Beere 1,2 cm lang, 。 $4 \mathrm{~mm}$ dick.

Kamerun: Yaúndestation, im Urwald als Unterholz im Schatten, 800 m ii. M. (Zenker et Staud n. $577^{a}$. - Bliihend in December. - H. Berl.!).

12. Memecylon sansibaricum Taub. in Engler, Pllanzenwelt Ostafr., C, 296.

Sansibar-Insel: im östlichen steinigen Sansibar bei Jambiana (Stumumans Ser. 1. 1. 718. - Bliahend int Juli. -- H. Berl.!).

13. Memecylon Buchananii Gilg n. sp.; frutex vel arbor glabra ramis junioribus acute tetragonis; foliis breviter petiolatis, ellipticis vel ovato-ellipticis, basi cuneatis, apice longiuscule acuminatis, apice ipso anguste rotundatis, coriaceis, supra nitentihus, subtus opacis, 3-nerviis, jugo laterali validiusculo uscque ad folii apicem margini subparallelo percurrente, in parte ca. $1 / 3$ superiore inter nervos transversales parce sed manifeste curvatis, nervis transversalibus numerosis, inter sese parallelis et costae in angulo acuto impositis, venis angustissime et densissime reticulatis, nervis venisque utrinque manifeste prominentibus; 1loribus in foliorum axillis ad callos paullo incrassatos dense fasciculatis, basi bracteolatis, pedicellis gracilibus elongatis stylum longit. aequantibus; receptaculi parte superiore pateriformi, sepalis \& oratis rotumdatis manifeste evolutis.

Blätter 5-7 cm lang, $2-3 \mathrm{~cm}$ breit, Blattstiel 3-4 $\mathrm{mm}$ lang. Biütenstiele etwa $6 \mathrm{~mm}$ lang. Oberer Receptacularteil etwa $1,5 \mathrm{~mm}$ im Durchmesser. Kelchblätter etwa $4 \mathrm{~mm}$ hoch, $2 \mathrm{~mm}$ breit.

Nyassaland: (Buchanan a. $1895 \mathrm{n}$. 14.1. - H. Berl.!).

Diese Art ist mil $M$. srmsibaricum nahe verwandt, weicht aber in mehreren wichligen Punkten (Blattform, Länge der Btütenstiele) von derselben ab. Während M. samsibaricum zur Abteilung I. der Gattung Memecylon gehürt infolge der gestreckten Seitemnerven, kann man bei M. Buchanamii sehr zweifelhaft sein, ob sie zu Abteilung I. oder II. zn stellen ist. Hier nehmen nämlich die Seitennerven nach der Spitze der Spreite zu bedeutend an Stärke ab und beginnen schon in etwa $2 / 3$ der Blatthühe 
sehr deutlich gegen die Transversalnerven zu bogig zu verlaufen. Infolge ibrer unzweifelhaften Verwandlschaft mit MI. sarsibaricum habe ich aber anch M. Buchananii zur Abteilung I. gestellt.

14. Memecylon Barleri Hook. f. l. c. 461; Cogniaux I. c. 1132.

Oberguinea: Lagos (Barrer. - H. Berl.!).

15. Memecylon polyneuron Gilg n. sp.; frutex rel arhor glaberima, ranis terelibus; foliis breviter et crasse petiolatis, oblongis rel ovato-oblongis vel ovalibus, basi rotundatis, apice lueviter acuminatis acutisque, subcoriaceis, supra nitidulis, subtus opacis, 3-neiviis rel si mavis 5̈-nerviis, sed jugo inferiore ad marginem ipsum valde curvato-percurente tenuissimo, jugo superiore subreclo costa vix tenuiore, renis transversalibus מ-7-jugis ita ut nervis supra impressis, sublus valde prominentilus, venis aliis numerosis laxe sed manifeste reticulatis; floribus longe pedicellatis in cymas axillares (an semper?) corymbiformes, multilloras, umbellatas manifeste perlunculatas dispositis; receptaculi parte superiore pateriformi, limbo profuncle 4-loho, lobis late oratis.

Blïtter $1-1,3 \mathrm{~cm}$ lang.

Sierra Leone: (Afzeuts. - H. Berl.!).

16. Memecylon pulcherrimum Gilg n. sp.; arbor (ex Soraw) glaberima, ramis teredbus; loliis brevissime crassefue petiolatis, oblongis vel oblongo-lanceolalis, maximis, basin versus sensim anguslatis, sed lasi ipsa rotundatis, apice longe acuminatis acutissimistue, subcoriaceis vel coriaceis, supra subtusçue nilenlibus vel nitidulis, 3-nerviis vel si mavis $\ddot{b}$-nerviis, sed jugo inferiore ad marginem ipsun valde curvato-percurrente tenuissimo, jugo superiore costae subaequivalido in parte 3/, folii inf. margini subparallelo recto, dein hine inde subcurvato sensim marginem petente, venis transversalibus 8-12-jugis valde prominentibns, venis aliis numerosis laxe sed manifeste reticulatis, nervis venisque supra subtusque (subtus manifestius) prominentibus; lborihus in axillis foliorum jamdudum delapsorum, i. e. e ligno vetere e tuberculis maximis infraranealibus orientibus, dichasia umbelliformia numerosa conferta 4-9-1lora referentibus; receptaculi parte superiore paleriformi, limlo profunde 4 -lobo, lobis late ovatis acutiusculis.

Blitter 2-4 mm lang gestielt, 20-32 cm lang, 9-11 cm breit. Blütenstände 2-2, כ̆ $\mathrm{cm}$ lang. Blütenstielchen ca. $1 \mathrm{~cm}$ lang. Gabun: Sibange-Fam, in Walde an Mavelinfer (Soraux n. 309. - Blihend in Ohtoher. - H. Berl.!

17. Memecylon fasciculare Naut. 1. c. XT1l. 263 und 282; Hook f. 1. c. 463; Cognianx I. c. II33. Spalhamdra fascicularis Planch. in Hook. Niger Fl. 357.

Memecylon Ileudelotii Naud.

Senegambien: (Hacdelot. - H. Paris und Kew)

Sierra Leone: (Arzenus - H. Berl.!, Dox. - H. Kew); auf dem Berg Gonkwi im Talla Gebirge (Scont Ezlot 1. 4830, 4864, 4916. - Blijhend im Februar. - H. Berl.!).

Das mir vorliegende, sehr gute, reichlich Plïten und Früchte tragende Afzeuss'sche Exemplar stimmt ganz genau mit der Beschreibung der Autoren, und ich glaube besonders nach der Form und Grüsse der Beeren nicht zweifelhaft zu sein, dass dieses Exemplar das Original von 1 . fasciculare Naud. darstellt. Auffallend ist mir aber, dass zwei mir vorliegende ron Scotr Butor gesammelte Exemplare (n. 4830 und 4864), welche mit der Afzulus'schen Pllanze genau übercinstinmen. von den Botanikern in Kew als Memecylon Togelii bestimmt wurden. Dies dïrfte wohl anf einem Irrtmm heruhen, denn einmal zeigen diese beiden Planzeı den von Нооки für $M$. fasciculare angegebenen Blülenstand, mad dann zeigt ein driltes von Scott lillot gesammeltes, unbestimmles, aljer mil den beiden anderen Pflanzen genau übereinstimmendes Exemplar (n. 4916 ) die für M. fasciculare charakteristischen kleimen, kugeligen (nicht länglichen wie bei M. Vogelii!) Beeren.

18. Memecylon membranifolium Hook. 1. I. c. 4.62; Cognian 1. c. 113:3.

Kamerungebiel: auf der Insel Fernando-Po (Mans. - II. Kew); auf dem Festland an der Ambas-Bas (Mans. - H. Kew).

19. Memecylon erubescens Gilg n. sp.; frutex 3-4.m altus ex collectore) glaberimus, ramis manifeste 4-alatis; foliis breviter petiolatis, orato-Janceolatis vel corlato-ovatis usque cordato-oblongis, paullo emarginatis rel manifeste corlatis, apice sensim in acumen longum apice rotundatum angustatis, sulscoriaceis, supra subtusque nitidulis, 5-nerviis, jugo inferiore conspicuo $2-3 \mathrm{~mm}$ a laninae margine percurente ad renas curvalo, jugo superiore paullo supra laminae basin abeunte valislo substricte usque ad folii apicem percimente, venis inaequaliter dense reticulatis, nervis renisque utrinque manifeste prominentibus; noribus erubescentibus (ex collectore), in axillis foliorum fasciculatis, sessilibus, in fasciculo numerosis; receptaculi parte superiore pateriformi, limlıo profunde 4-lobo, lobis ovatis; petalis lanceolatis vel obovato-lanceolatis; staminibus longe exsertis.

B]ïtler $7-15 \mathrm{~cm}$ lang, $3-6 \mathrm{~cm}$ breit, Blattstiel $6-7 \mathrm{~mm}$ lang. Blüten ca. $4 \mathrm{~mm}$ im Durchmesser.

Engler, Monographieen. II. 
Lsambara: Handeigebirge, Nderema, im Hochwald auf rotem Boden, $950 \mathrm{~m} \mathrm{ü.} \mathrm{M.} \mathrm{(Hexser} \mathrm{n.} \mathrm{6.} \mathrm{-}$ Blihhend im Februar. - H. Berl.!).

Abbildung auf Taf. X. B. - Zweig mit Blütenstand und Blatt.

20. Memecylon Heinsenii Gilg n. sp.; frutex glaberrimus, ramis manifeste 4-alatis; loliis 4.-7 mm longe petiolatis oblongis rel elliptico-oblongis, subcoriaceis, basin rersus sensim angustatis, apice longe acuminatis, acumine aculiusculo, supra nilentibus, subtus subopacis, 3-nerviis vel si mavis ö-nerviis, sed jugo inferiore tenuissimo vix conspicuo ad marginem ipsum percurente inter renas curvato, jugo superiore ralido $\breve{y-8} \mathrm{~mm}$ supra folii basin abeunte ef substricte sed margine subparallelo fere usque ad laminae apicem percurrente, renis inaequaliter dense reticulatis, nervis venisque utrinque subaequaliter prominentibus; lloribus in axillis foliorm fasciculatis, sessilibus, $3-6$ in fasciculo collectis; receptaculi parte superiore pateriformi, limbo fere usque ad basin 4-loho, lohis, i. e. sepalis ovato-oblongis; pelalis ut videtur anguste lanceolatis; staminibus lonse exsertis.

Blälter $\breve{b}-9 \mathrm{~cm}$ lang, $1, \breve{b}-4 \mathrm{~cm}$ breit. Blüten ca. $4 \mathrm{~mm}$ im Durchmesser.

Usambara: Handeigehirge, Nderema, im Hochwald auf rotem Boden, $930 \mathrm{~m} \mathrm{in.} \mathrm{M.} \mathrm{Heissex} \mathrm{n.} \mathrm{6a.} \mathrm{-}$ Bliihend in Februar. - H. Berl.!).

21. Memecylon virescens Hook. f. 1. c. 4.63; Cognianx 1. c. 1142.

Gabun: an Gabum-Fluss (Max. - H. Kew).

22. Memecylon calophyllum Gilg n. sp.; arloor $6 \mathrm{~m}$ alta glaberima, ramis ramulisque teretibus brunneis; folis manifeste petiolatis lanceolatis vel oblongo-lanceolatis, subcoriaceis vel coriaceis, basi sensim in petiolum angustatis, apice longe vel longissime acuminatis, acumine angusto sensim angustato apice acutissimo, margine manifeste emargimulatis, supra nitidulis, subtus opacis, 3-nerviis, jugo laterali $3-50$ mm a margine percurrente inter nervulos utrinque $9-10$ transversales valde curvato et illis manifeste conspicuis vix validiore, venis uirinque inconspicuis, nervis nervulisque supra manifesie impressis, subtus prominentibus; floribus 3 - ̋ mm longe pedicellatis, pedicellis ad basin et sub medio bracteolis 2 minimis instructis atque pedunculis $\check{\partial}-7 \mathrm{~mm}$ longis cymose impositis, cymis 5 -10-lloris; receptaculi parte superiore pateriformi, parce sed nanifeste emarginato; petalis obovatis, ut videtur manileste apiculatis.

Blätter $8-15 \mathrm{~cm}$ lang, $3-5,5 \mathrm{~cm}$ breit, Blattstiel $7-8 \mathrm{~mm}$ lang, Träufelspilze $1,4-2,4 \mathrm{~cm}$ lang. Blütenstände $1,5-2 \mathrm{~cm}$ lang, 1-1,3 cm breil. Blüten $3-4 \mathrm{~mm}$ im Durchmesser.

Gabun: Sibange-Farm, im Wald (Sorax n. 68. - Bluhend im Yärz. - H. Berl.!)

23. Memecylon hylophilum Gilg n. sp.; frutex 2-4. m altus, tenuis, glaberrimus, ramis teretibus vel leretiusculis; foliis bresiter petiolatis, oblongis, coriaceis vel saepius rigide coriaceis, basin rersus sensim in peliolum angustatis, apice longe acuminatis, acumine saepius paullo curvato, angusto, folii ca. $1 / 5$ longit. adaequante apjice acuto, utrinque opacis vel rarius supra nitidulis, pemninerviis, i. e. jugo marginali ad marginem fere ijsum percurente temissimo supra inconspicuo, subus parum prominente, inter nervulos utringue I 0 - I 2 Iransversales valde curvato et illis haud validiore, venis utrinque inconspicuis; lloribus ca. 3 - 6 mm longe pedicellatis, pedicellis tenuibus pedunculo axillari $3-7 \mathrm{~mm}$ longo subumbellato- revera cymose) impositis, bracteolis ad pedicellorum basin numerosis confertis; receptaculi parte superiore pateriformi obsolete emarginato; petalis late oboratis breviter apiculatis.

Bläiter $8-19 \mathrm{~cm}$ lang, $3-5 \mathrm{~cm}$ breit, Blattstiel ca. $30 \mathrm{~mm}$ lang, Trüufelspitze $1, \ddot{3}-2 \mathrm{~cm}$ lang. Blütenstände fast durchweg ca. 1,2-1,5 cm lang und fast ebenso breit. Blüten 5-6 mm im Durchmesser.

Kamerun: Lolodorf, als Unterbolz im Urwald auf dem Berg Mbanga, $500-600 \mathrm{~m}$ i. M., zerstrent (Sracot n. ̈̈4. - Bliblend im Februar. - H. Berl.!).

21. Memecylon Machairacme Gilg n. sp.; frutex 2-3 m altus glaberimus, ramis teretibus, junioribus nigrescentibus, demmm hrunnescentibus; foliis breviter pretiolatis, ellipticis vel elliptico-oblongis, subcoriaceis vel coriaceis, hasin versus sensim angustatis, apice longissime acuminatis, acumine folii $1 / 5-1 / 4$ longit. adaequante angusto, manifeste curvato, apice acutissimo, supra nitilulis, subtus opacis, 3-nerviis, jugo laterali ca. $\ddot{j}$ mm a margine pereurrente inter nervulos utrincue $5-7$ transversales valde curvato et illis manifeste conspicuis non vel vix validiore, vonis supla subtusque inconspicuis, nervis nervulisque supra manifeste impressis, subtus prominentibus; lloribus $2-3 \mathrm{~mm}$ longe pedicellatis, pedicellis tenuibus pedunculo $2-\mathbf{4}$ mm longo cymose vel saepius racenose impositis, bracteis ad pedicellorum basin 2 oppositis; receptaculi parte superiore pateriformi limbo emarginulato; petalis obovatis. 
Blätter $7-12 \mathrm{~cm}$ lang; $3,5-5 \mathrm{~cm}$ breit, Blattstiel ca. $3 \mathrm{~mm}$ lang, Träufelspilze $1,5-2,2 \mathrm{~cm}$ lang. Blütenstände ca. $8 \mathrm{~mm}$ lang und ebenso breit.

Kamerun: Bipinde, als Unterholz im Unwald, die jungen Triebe schön violett, $110 \mathrm{~m}$ ii. M. (Zexk:r n. 911. - Blühend in Mai. - H. Berl.!).

25. Memecylon candidum Gilg n. sp.; frutex $3 \mathrm{~m}$ altus glaberrimus, ramis ramulisque acule tetragonis, brumneis; foliis petiolatis oblongis, subcoriaceis, basi sensim in peliolum angustatis, apice manifeste acuminatis, acumine angusto aequilato, apice rotundato, supra nitidulis, subtus opacis, 3-nerviis, sed jugo laterali tenuissimo vix conspicuo ca. $2 \mathrm{~mm}$ a margine percurrente inter nervulos utrinque $\ddot{3-7} 7$ transversales subinconspicuos valde curvato, renis supra subtusque inconspicuis, nervis nervulisque supra subtusque parcissime prominentibus saepiusque evanescentibus; floribus candidis (ex Zexker) $5-6 \mathrm{~mm}$ longe perlicellatis, pedicellis ad basin bracleolis 2 suffultis al(que pedunculis $5-6 \mathrm{~mm}$ longis cymose impositis, cymis $3-6$-floris; receptaculi parle superiore pateriformi limbo emarginulato; pelalis ovatis apiculatis; staminibus pelala longit. manifeste superantibus.

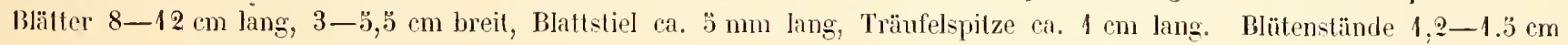
lang. Blüten $4 \mathrm{~mm}$ im Durchmesser.

Kamerm: Bipinde, in Urwald, $100 \mathrm{~m}$ ii. II. Zexker n. 966. - Blihend im Mai. — H. Berl.!

Diese Art ist sehr auffallend dadurch, dass die Nerven ihrer Blätter kaum hervortreten, obgleich sie, wie nicht zu bezweifeln, mit M. hylophilum und M. Machairacme nïchstrerwandt ist. Die Nervatur ist, obglejch die Blïter lieine grosse Dicke ljesitzen, so schwach, dass sie nur bei genaner Untersuchung nachzuweisen ist. Zu M. polyanthemos zeigt jedoch unsere Art keine weiteren Beziehnngen, und da sie in Blütenstand, Blütengrüsse und-ausbildung mit jenen Arten der Abteilung III. der Gattung fast völlig übereinstimmt, so habe ich sie in deren Nïhe gestellt.

26. Memecylon Englerianum Cogn. 1. c. 1194.

Memecylon nigrescens Engl. in Englers Bot. Jahrh. VII. 338 (non Ilook. ef Arn.).

Kamerun: Mungo, ein Strauch der fenchten Waldregion (Buchuoz. - Blihend im Ohtober. - H. Berl.!).

27. Memecylon Vogelii Naud. I. c. XVIII. 263 und 282; Hook. f. l. c. 462.

Spathandra memecyloides Benth. I. c. 337.

Sierre Leone: (Arzelus. - H. Kew).

Kamerungebiet: auf den Inseln Principe und Femando-Po (Bırter. - H. Kew); auf dem Festland am Cálabar-Flusse (Maxx, - H. Kew); am Rio del Rey (Johsston. - H. Berl.! ex H. Kew).

Memecylon Vogelii ist bisher stets nur in ungenügender Weise beschrieben worden, so dass ich nicht ganz sicher bin, ob ich die Art an der richtigen Stelle aufgeführt habe. Für mich galt eine Pllanze als $1 \%$. Vogelii, welche ron Joursrox am Rio del Rey in der Nähe des Old Calabar gesammelt, ron den Botanikern in Kiew als M. Togelii bestimmt wurde und auf welche die Beschreibung Hooker's passt. Soltte meine Annahme nicht zutreffen, so müsste diese Pflanze als neue Art beschrieben werden.

28. Memecylon Zenkeri Gilg n. sp.; frulex $1, \ddot{b}-2$ m altus glaherrimus ramulis acute tetragonis, hrunneis; foliis breviter petiolalis ellipticis vel elliptico-oblongis, subcoriaceis vel rigide chartaceis, hasi sul,rolundatis vel rarius acutiusculis, apice acuminalis, acumine brevi folii $v i x 1 / 8-1 / 10$ longit. adaequante sensin angustato, apice acuto, utrinque opacis, 3-nerviis, jugo laterali ca. $5-8 \mathrm{~mm}$ a margine percurrente in nervulos utrinque 12 - I 5 transversales valde curvato ef illis manifeste conspicuis aequivalido, renis supra inconspicuis, sublus inaegualifer laxissime reliculatis parce prominulis, nervis nervulisque supra valde impressis, subtus manifeste prominenlibus; lloribus $\mathbf{f - 3}$ mm longe pedicellatis, pedicellis in foliorum axillis fasciculatis ad nodos incrassalos numerosis vel pedicello $\ddot{0}-7 \mathrm{~mm}$ longo cymose impositis, cymis 4-7-lloris, bracteis ad pedicellorum basin numerosis conferlis; receptaculi parle superiore pateriformi obsolete emarginato; petalis obovatis; bacea oblonga, matura alba.

Blätter $8-15 \mathrm{~cm}$ lang, 4-7,5 cm breil, Blattstiel ca. $5 \mathrm{~mm}$ lang, Trüufelspilze ca. $1 \mathrm{~cm}$ lang. Blütenstände höchstens $1,2 \mathrm{~cm}$ im Durchmesser.

Kamerun: Yaúndestation, im Urwald als Unterholz, $800 \mathrm{~m}$ i.. M. (ZeNker n. 672 Imd 717; Zexker et

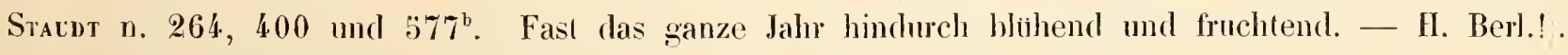

Nach Zenker ist diese Pflanze unter dem Namen Acofli Gibilli officinetl. Die Blätter werden beim Fener erwïrmt und dann auf durch Fall, Verrenkung etc. schmerzhaften Stellen gerieben.

Abbildung auf Taf. X. $D$. - $a$ Zweig mit Btütenstand und Blatt; $b$ Frucht im Längsschnitt.

29. Memecylon Poggei Gilg n. sj.; frutex vel abor ranis teretiusculis; foliis hreviter crassissimeque petiolatis, ovatis vel late ovatis, plerumque manifeste obliquis, inferne sensim late angustatis, apice longissime et angustissime acuminatis, apice ipso acutissimis, rigide coriaceis vel sublignosis, ulringue opacis, I-nerviis, 
nervis transtersalihus subtus non vel vix conspicuis, venis omnino inconspicuis; Horibus in foliorum axillis in cymas subumbelliformes brevipedunculatas dispositis, pedicellis hrevissimis; receptaculi parte superiore pateriformi angusto, sepalis vix evolutis denliculiformibus.

Blitter $8-11 \mathrm{~cm}$ lang, $3,5-5 \mathrm{~cm}$ breit, Blattstiel $5-7 \mathrm{~mm}$ lang. Blütenstand in ganzen $7-8 \mathrm{~mm}$ lang. Pedunculus 3 -4 $\mathrm{mm}$ lang. Blütenstielchen etwa $1 \mathrm{~mm}$ lang.

Oberes Congogebiel: Baschilauge, am Rande eines Bachwaldes zwischen Lulua und Kassai Pogge $\mathrm{n}$. 1066. - Blihenul im August. - H. Berl.!.

30. Memecylon polyanthemos Hook. f. I. c. 463; Cognianx 1. c. 1161.

Memecylon A/zelii R. Br. ex Triana 1. c. $1 \ddot{36}$.

Sierra Leone: Arzeurs. - H. Berl.!).

Oberguinea: am Bagroo-Fluss Max. - H. Kew); Togo, bei Misahöhe, ein schöner, bis $3 \mathrm{~m}$ hoher Strauch mit azublauen, wohtriechenden Blüten, im schattigen, feuchten Hochwalde zerstreut. Bacmaxs n. 270 und ว̆ร̆ı. - Blïhend in April und Mai. - H. Berl.!).

Unteres Congogrebief: an Congo (Tholon. - H. Paris ex Cognaux)

Oberes Congogebiet: am Luha, 6º s. Br. Pogge n. 937 und 938. - Blijhend im August. - H. Berl.!).

31. Memecylon myrianthum Gilg 1. s).; arhor excelsa (ex Bürrer) ramis albescentibus, junioribus acute tetragonis; foliis ovatis vel rarims ovato-ovalihus, basi subrotundalis vel saepius lale angustatis, apice longe acuminatis, apice ipso acuis, coriaceis, utringue opacis, I-nervïs, nervis transversalibus plerumque inconspicuis, rarius supra paullo prominulis, nervis renisque sublus omnino inconspicuis; floribus in foliorum axillis in paniculas multilloras plerumpue elongatas dispositis, perlunculo elongato valido superne plerumque subumbellato, pedunculi ramis plerumque iterun flores brevipedicellatos lense confertos umbellalos gerentilıs, rarius paniculae ramis in cymas regulares exemntibus; receptaculi parte superiore pateriformi; sepalis brevibus late ovatis subroluntatis; baccis globosis crassis, plerunque ab apice compressis.

Blätter 6-12 cm lang, $4-6 \mathrm{~cm}$ breit, Blattstiel $3-4 \mathrm{~mm}$ lang. Blütenstand 2-4 $\mathrm{cm}$ lang. Beere $6-8 \mathrm{~mm}$ hoch, $6-12 \mathrm{~mm}$ dick.

Gabun: (Bctrven n. 430. - Mil reifen Frichten im October. - H. Berl.!); Sibangefarm, am Maveliufe ${ }^{\circ}$ Soraux n. 271. - Blihend im April. - H. Berl!!.

Angola: (Welwitsci n. 911. - Bliihend und fruchtend. - H. Berl.!); am Quango-Fluss (Mecuow n. 515. - Blähend im August. - H. Berl.!).

Oberes Congogehiet: Baschilange, im Bachwald bei Mulienge, $6^{\circ}$ s. Br. (Pogge n. 940. - Blühend im September. - H. Berl.!).

Die Exemplare aus Angola, welche ich gesehen habe, besitzen nicht die grosse lispe der übrigen hierher gestellten Pflanzen. Trotzdem halte ich sie zu M. myrianthum gehörig, da die Exemplare von Wecwitsar anch lungelige, allerelings kleinere Beeren besitzen.

32. Memecylon Donianum Planch. in Hook. Niger Fl. 337; Hook. f. 1. c. 463; Cogniaux I. c. 1161.

Pavella lateriflora G. Don Gen. Sỵst. III. כ̈7̈.

Sierra Leone: (Dox. - H. Kew). — Vielleich gehör hierher auch eine mir in ungeniigenden Exemplaren vorliegente, von Scotr Elbot unter n. 5636 in Sierra Leone gesammelte Pllanze.

33. Memecylon flavovirens Bak. in hew Bull. 1897, S. 268.

"Frutex ommino glaber. Ramuli lignosi, supeme 4-angulati, nodis incrassatis. Folia sessilia, obovalocuneata, 2-3 poll. Longa, apice obtusa vel minute emarginata, havo-viridia, penninervia, venis primariis erectopatentibus. Cymae simplices, pauciflorae, axillares, breviter pedunculatae vel sessiles; pedicelli calycibus longiones. Calyx campanulatus, limbo patulo obsrure dentato, I lin. diam. Fruclus globosus, 3-i. lin. diam., calyce persistenter coronatus." Baker l. c.)

Nöralliches Nyassaland: Wurte. - H. Kew).

34. Memecylon Cogniauxii Gilg n. sp.; frutex glaberrinus, ramis teretibus; foliis subsessilibus (vix $1 \mathrm{~mm}$ longe petiolatis) cordalo-0rallis, hasi manifeste emarginatis, apice longe vel longissime apiculatis, acumine laminae ca. 1/s atequnte recto anguslo, apice rolundalo, supra nitilulis, subtus opacis, penninerviis, sed nervulis urinque 18-20 transversalibus costa rectangulis supra subtusque prominulis tenuissinis et vix conspicuis, venis omnino inconspicuis; Horilus prino roseis, denum coeruleis (ex collect.), 4-_ mm longe perlicellatis, pedicellis gracillimis perlmeulo axillari $2-3 \mathrm{~cm}$ longo tenui umbellatim impositis, floribus in umbella $7-18$; 
receptaculi parte superiore paterilormi, limbo vix emarginato; petalis obovatis, breviter apiculatis; bacca subglobosa coerulea.

Blätter $7-10 \mathrm{~cm}$ lang, $2,8-5 \mathrm{~cm}$ breit, Trüufelspitze 1,2-1,7 cm lang. Blüten $9-2,5 \mathrm{~mm}$ im Durchmesser. Beere 7-8 $\mathrm{mm}$ im Durchmesser.

Usambara: Handei-Gebirge, Nderema, $9.00 \mathrm{~m}$ ü. M., zwischen Unterholz im Hochwald (Heıssen n. 5. Blühend und fruchtend im Februar); bei Korrumo im Wald (Bucuwald n. 3弓̊9a, olne Blüten und Fruichte). H. Berl.!).

Zeigt mit keiner anderen Art der Gattung Verwandtschaft. Nach der Einteilung von Cogniaux ist M. Cogniauxii zwischen die Nr. 96 und 97 einzufügen und bildet eine besondere Gruppe, charakterisiert durch: »Folia brevissime petiolata, basi cordata *

Abbildung auf Taf. $X$. A. - a Zweig mit Blütenständen; $b$ Knospe; $c$ Blüte; $d$ Staubblatt von der Seite; $e$ Receptaculum und Fruchtknoten im Längsschnitt; $f$ Fruchtstand; $g$ Längsschnitt durch die Fruchl; $h$ Samen.

35. Memecylon erythranthum Gilg n. sp.; frutex vel arbor glaberrima, ramis teretilus brunneoflavescentibus; foliis brevissime petiolatis ovatis vel ovato-oblongis usque cordato-oblongis, subcoriaceis, basi obtusis vel plerumque paullo cordatis, apice acuminatis, acmmine lato brevi apice rotundato, supra nitidulis, subtus opacis, penninerviis, sed nerrulis utrinque 18-24 transversalibus costa rectangulis supra subtusque prominulis tenuissimis et vix conspicuis, venis ommino inconspicuis; floribus carmesinis (ex collect.), e hasi caulis defoliati supra radicibus enascentibus, ad nodos incrassatos fasciculatis, in fasciculo numerosis (20-40) confertis, pedicellis brevibus $2-3 \mathrm{~mm}$ longis suffultis; receptaculi parte superiore pateriformi limbo obsolete emarginulato; petalis ...; bacca immatura rubra, matura nigra subsphaerica.

Blätter $9-18 \mathrm{~cm}$ lang, $3,5-6,5 \mathrm{~cm}$ breit, Blattstiel $1,5-2 \mathrm{~mm}$ lang, Träufelspitze $9-12 \mathrm{~mm}$ lang. Blüten ca. $2,5 \mathrm{~mm}$ im Durchmesser. Beere ca. $1 \mathrm{~cm}$ im Durchmesser.

Usambara: Handei-Gehirge, Nderema, $960 \mathrm{~m}$ u. M., im Hochwald Hernsen 1. 3. - Blihend und fruchtend im Februar. - H. Berl.!).

Diese sehr interęsante Pflanze gehört zweifellos in die Verwandtschaft von $\boldsymbol{M}$, cordatum Desr., ohne aber zu derselben nähere Beziehungen aufzuweisen.

Abbildung auf Taf. X. $C$. - $a$ Stück des alten Stengels mit dem Blütenstand; $b$ Blatt; $c$ Frucht im Längsschnitt.

\section{Anteil der Melastomataceae an der Zusammensetzung der Vegetationsformationen} in Afrika.

Weitaus die Mehrzahl der etwa 2800 Arten der Melastomataceae ist gebunden an das feuchtheisse Klima der tropischen Regenwälder, ja man könnte mnsere Pflanzenfamilie geradezu als eines der besten Beispiele fïr einen grossen, fast ausschliesslich aus Hydromegathermen bestehenden Verwandtschaftskreis anführen. Dies zeigt sich in gleich charakteristischer Weise in Amerika, dem Hanptrerbreitungsgebiet, wie in Asien und Afrika. Es ist deshalb auch fast selbstrerständlich, dass durch die übereinstimmenden Vegetationsbedingungen die Vegetationsorgane — endomorph und exomorph — eine ausserordentlich gleichmässige Ausbildung erfabren haben und dass sich beliebig viele Fálle anfführen liessen, wo Arten Afrikas und Asiens in ihrem Aufbau völlig mit solchen Amerikas ubereinstimmen und sich nur-durch den Blitenbau unterscheiden. In Afrika finden wir nun, ähnlich wie in Brasilien, einige Formen, welche sich als Steppentypen entwickelt haben und in ihrem Habitus stark vom Normalverhalten der Familie abweichen. Ind aucl bei diesen zeigt es sich, dass sie vollständig übereinstimmende Vegetationsorgane erhalten haben, so sehr, dass manchmal hierhergehörige Arten verschiedener Gattungen bisher von den Bearbeitern ohne genaue Bliitenanalyse zusammengefasst wurden, wie z. B. Dissotis Irvingiana mit mehreren Arten von Osbeckia.

Wie schon hervorgehoben wurde, finden sich in der Vegetationsformation des feuchtheissen Regenwaldes weitaus die meisten Melastomataceae Afrikas. Daraus wirl ms auch schon ohne weiteres klar, warum ' etwa $4 / 5$ simtlicher afrikanischer Arten in Westafrika heimisch sind. Daselbst finden wir die Melastomataceae in sehr verschiedenartigen formen.

As kleine, niedere Kräuter treten auf Osbeckia Bnettneriana (Gabun) und 0 . Welwitschii (Angola), beide rom normalen Habitus ihrer Gattung, die zumeist aus Steppentypen besteht, durch ihren weichen Stengel und 
die schlaflen Blätter weit abweichend. Mit diesen im Habius sehr ibereinstimmend treflen wir an denselben Standorten die schön blühenden Arten der Gattung Ampliblcmma (meist Gabun), Ispische Vertreter der Flora feucht-sumpliger Wälder. Als Epiphylen auf mooshewachsenen Baumstimmen werlen beobachtet Medinilla Mammi Hook. f. (Fernando Po) und Prenssiella kamermensis (Kamerun), während mehrere Arten ron Tristemma als prächtige, in Folge ihrer grossen und schön gelärbten Bläter sehr decorative, hohe Stauden an Waldbachen verbreitet sind. Sehr localisiert ist offenbar das Vorkommen des in Folge ihres Blütenstandes selı auffallenden Myrianhemum mirabile Gabun, einer hohen Jiane, welche kurz iber ihrem Wurzelhals einen aus vielen Humderten, ja Tausenden von Bliiten bestehenden kugeligen Bliitenstand bildet. Besonters ist dann endlich noch Sakersia africana (Kamerun, Gabum) hervorzuheben, ein $\ddot{-}-10 \mathrm{~m}$ hoher Baum, welcher mit seinen prähtigen Błallern und lem Öberreichtum seiner hyacinthenroten, grossen, auffallenden Bliiten einen hohen Schmuck des Waldes bildet.

Ganz besonders sind zu erwahmen als Waldpflanzen die zahhreichen Arten der Gattung Memecylon, welche zum grössten Teil typische Unterholzpllanzen als Sträucher und kieine Bäme darstellen und nur selten (U. myriauhum) als hohe Baume auftreten.

Vit dem Walde dringt nun eine Anzahl ron Nemecylon-Arten weit ins Innere Afrikas vor, so Memecylon jasminoides bis ins Ghasalquellengebiet Land der Monlouttu. M. heterophyllum bis ins Seengebiet, während dagegen andere Arten dieser Gattung, die in den Waldgebieten Ostafritas (Usambara heimisch sind, oflenbar zu den Arten Westafrikas in absolut keiner naheren verwandtschaftlichen Beziehung stehen, sondern sich an Arten des indomalayischen oder madagassischen.Gebietes anlehnen oder sogar völlig vereinzelt in der Gattung stehen (Mcmecylon Cogniamii). Von rerbreiteten Waldpllanzen Afrikas ist zu emwihnen: Phaconeuron dicellandroides, eine schön blihende, hohe staude, welche in Kamerun sehr rerbreitet ist und auch' im Lande der Nonbuttu von Schwemfonth aufgefinden wurde, weiter Calvoa orienlalis, eine Pflanze, deren Verbreitung ausserordentlich interessant ist. Während nämlich alle iibrigen (7) Arten der Gatung auf den Inseln S. Thomé und Fernando-Po, zum Teil als Felsenptinzen, gedeihen, tritt Calvoa orientalis, eine typische weiche Waldpflanze, weit vom Gattungsareal entfernt zunächst in den Waldgebieten des Nianniam-Landes aul und erstreckl sich ron hier uber das Seengebiet his in die Gebirgswälder Usambaras. Eine der Arten mnserer Familie, welche fast iberall hin dem Zuge der tropischen Regenwajder Afrikas folgt und nur in den Gebirgswäldern Ostafrikas selbst felıt, ist Dissolis mulliflora. In keinem der Gebiete Westafrikas scheint sie zu fehlen; sie wurde aber auch noch im Monbutuland Ghasalquellengebiet) ron Scuwemfuntu und im Seengebiet ron Stumuxx festgestellt.

Ausschliesslich dem (Gebirgs-) Regenwalde Ostafrilias gehören an Dissotis polyantha, eine der schönsten Arten der Melustomalaceue wohl iberhaupt, ferner die Vertreter von vier nenen Gattungen: Lrolheca hylophila, Pelalonema pulchrum, Cincimnobotrys oreophila und Orthogonewron dasyanthum. Die sämtlichen vier letzteren Arten zeigen zu den ibrigen afrikamischen Melastomataceae absolut keine Verwandtsclıaft, sind dagegen - wie noch genauer ausgefiihrt werden wird - mit indomalayischen, ja sogar ostasiatischen Typen auf das engste verkuiiputt.

Sehr zahlreiche Arten unserer Familie lieben auch sumpfige standorte oder aber Bachufer, Wo ihnen jederzeit das für ihren Lebensunterhalt notwendige Wasser zur Verfigung steht. Manche derselben wachsen offenbar gleich gut im Waldestunkel oder aber an den soeben gekemzeichneten Standorten, so z. B. Arten von Amphiblemma, zahlreiche Arten von Dissolis und Tristemma, die vorhin schon angefïhrten Sakersia "fricana und Phaeoneuron dicellandroides in Westafrika, Petalonema pulchrum in Ostafrika.

Auch bei den Sumpf- und Bachuferpllanzen ist die Zahl derjeningen Arten, welche in Westafrika heimisch sind, derjenigen Ostafrikas bedeutend iiberlegen. In Westafrika, und zwar merkwirdigerweise auf oflenbar sehr beschrinktem Gebiete, nämlich in dem an Melastomulaceac auffallend reichen Senegambien und Sierra Leone, finden sich die drei eigenartigen monotypen Gattungen Nerophila gentianoides, Gunomia tenella mnd Afzeliella ciliula. Nan könnte nicht mit Unrecht behaupten, dass diese drei Gattungen dem Urtypus der Melastomatacear noch ausserordentlich nahe sind. Besonders die beiden letzteren. Guyomia und Afzeliella, besitzen noch fast keines von den sonst so ausserordentlich charakteristischen ausseren Kennzeichen der Familie und sind selbst von einem Fachmann erst nach einer eingehenden Untersuchung als Meluslomatuceae zu erkennen. Keine dieser interessanten Pllanzen wurde bisher ausserhalb Senegambiens und Sierra Leones beobachtet, ja jede einzelne ist bisher erst eimmal gesammelt worden. Dieses seltene Auftreten ist um so bemerhenswerter, 
als doch sonst háulig Pflanzen feuchter Ufer und von Simpfen — wie wir auch gleich sehen werden eine weite Verbreitung besitzen.

Auf Sierra Leone beschränkt ist auch die in Afrika ganz vereinzelt in der Gattung dastehende Osbeckia Iubulosa, bei der nach der Blüte das Receptaculum an der Spitze zu einem rerlängerten, cylindrischen Schnabel auswaichst Nur in Westafrika finden sich dann ferner mehrere Arten ron Tristemmu und Dissotis, welche an Bachränderı und in Sümpfen gedeihen.

Dagegen konnte ich auch eine ganze Reihe solcher hierhergehöriger Arten feststellen, welche eine weite, oft sogar eine sehr weite Verbreitung besitzen. So findet sich Dissotis segregata sehr verbrestet in ganz Westafrika, dringt aber östlich bis ins Seengebiet vor. Ferner kommt Dissotis debilis last im ganzen suidlichen tropischen Afrika vor, im Ghasalquellengebiet, Seengeliet, rom Nyassaland sidllich bis Transvaal und in Wrestafrika rom Congo bis ins Amboland. Fast genau dieselbe Verbreitung besitzen Dissolis pharolricha und Itssolis incana. Diese drei Arten zeigen, wie auch noch viele andere, dass den Verbindungsweg zwischen Westund Ostafrika das obere Cor gogebiet und das Sambesegebiet bildete.

Dissolis multiflor ist eine jener Pflanzen, welche an den Standort offenbar wenig specielle Anforterungen stellen. Sie liebt sumpfige Gebiete, wohl am meisten sumpfige Wailder, gedeiht jedoch auch an trockenen Standorten, d. h. wahrscheinlich an solchen, welche zeitweise austrocknen. Sie ist in allen Waldgebieten des tropischen Afrika festgestellt worden, jedoch nicht in Ostafrika selbst, also in Wrestafrika von Oberguinea bis zum Congo, ferner im Glıasal- und Seengebiet. Dissolis rolundifolia endlich, eine ausgesprochene Sumpfpflanze, fehlt im tropischen Afrika, Abyssinien ausgenommen, wohl iberhaupt nirgends. Sie gehört offenbar zu den rerbreitetsien Planzen Afrikis viberhaupt und bildet mil ilıren reichlichen, grossen und schön gefärbten Bliiten eine Zierde aller feuchten Orte.

Auch in lichten Gehölzen finden sich zahtreiche Melastomalaceae Afrikas, welche oft geradezu als Charakterpllanzen verlassener Schamben oder des Busches bezeichnet werden können, der nach dem Niederschlagen des Hochwaldes sich bildet. Als solche ist vor Allem Dinophor spemeroides hervorzuheben, welche in Westafirika von Oherguinea bis zum Congo nirgends fehtt. Ferner sind hier einige Arten anzufuihren, welche im sog. Gebirgsbusch anftreten und stellenweise fürmliche Bestände bilden, so am Kilimandschıro Dissotis alpestris und Dissolis cincimnalu, am Kamerungehirge Tetraphyllaster rosuceum und Tristemma oreophilum.

An diese Arten schliessen sich einige Formen an, welche ebenfalls trockenere Gehölze der Gebirge Atrikas bewolmen, welche aber auch haufig auf Bergtriften beobachtet werden, so in den Gebirgen Huillas Dissolis gracilis und Dissotis penicillata. An dieser Stelle möchte ich auch anfïhren Antherotoma Nandimi, eine der weitverbreitetsten Arten Ifrikas üherhaupt, welche offenbar ganz aussergewöhnlich befähigt ist, olıne Ruicksicht auf Temperatur- und Standortsrerhätnisse ihr Areal ausubreiten. Sie ist bisher beobachtet worden in den Gebirgen Madagascars und der Comoren, Abyssiniens, Usambaras, des Nyassalandes und Huillas, aber anch in Trockensteppen und Sumptsteppen des Ghasalquellengebiets, im Seengebiet und in Senegambien. Antherutoma Naudini ist eine niedrige, höchstens $20-25 \mathrm{~cm}$ Höhe erreichende, einjährige Pflanze, welche in ihrem Habitus ausserordentlich wechselt. Auf ihr zusagenden, ginstigen Standorten erreicht sie ihre Mlaximalgrösse und ist stark verzweigt, oft förmlich buschig entwickelt. In trockenen, ungiinstigen Standorten dagegen tritt unsere Ptlanze als ein oft nur $3-3 \mathrm{~cm}$ hohes, fast unverzweigtes und nur wenige Bliten hervorbringendes Gewächs auf. Auch fir diese Art ist es kaum zweifelhalt, dass sie ihre Verbreitung nach Westafrika iber das Sambesegebiet genommen hat.

Iuch Steppenpflanzen finden wir unter den Mclastomataceae Ifrikas nicht wenige. Allerdings sind dies nie solche Pllanzen. welche in Folge einer eigenartigen Ausbildung, einer " Inpassung " ihrer Vegetationsorgane hefuhigt erscheinen, Zeiten absoluter Trockenheil ungefährdet zu ïherstehen. Wir können unter ilınen leicht zwei rerschiedenartige Typen leststellen. Dem einen Typus hátten wir unterzuordnen Formen wie Osbeckia postpluvialis und einige andere Arten dieser Gattung, winzige, einjährige Pflinzchen, welche herdenweise erscheinen, sobald die Regenzeit begonnen hat, und die ilıre Samen reifen, ehe noch die Trockenheit herannaht. Mlit Eintritt derselben verschwinden sie vollständig.

Als zweiten Typus dieser Steppengewächse erwähne ich Formen wie Dissotis Irvingiana, D. Schwein/mrthii, D. scabra und D. Perkinsiae. Pllanzen ron hohem, oft Mannshöhe erreichendem Wuchs, mit meist grossen prächtigen Blitten und ausdauerndem, dickem, unterirdischem Wurzelstock. Auch sie werden durch die Regenfalle zum Leben erweckt, sind auch wohl befähigt, einige Zeit hindurch der spater folgenden Trockenzeit 
Trotz zn bieten, hellen dann aber auch mit ihren hohen, vertrockneten, zuletzı blattlosen btengeln das Bild der toten, öden Steppe zu verschärfen.

Nur eine einzige kleinc Gruppe afrikanischer Melastomalateae zeigl schon am Verhalten ihrer Vegetationsorgane, dass sic befahigt sind, Zeiten grosser Hitze und Trockenheit mbeschatet zu ibberstehen. Es sind dies einige Arten der Gattung Calrou, z. B. C. Molleri und C. crassimoda, welche offenbar (genauere Angaben liegen leider nicht vor) als Felsen-oder Geröllpflanzen der Gebirge von S. Thomé bezeichnet werden können. Diese Pflanzen sind durch ihre dickfleischigen Stengel, welche an den Knoten stark angeschwollen erscheinen, ferner durch ihre ausserordentich succulenten Blatter sehr charakteristisch und haben wohl in der ganzen Familie dieser sonst so typischen Hydromegathermen keine Analoga. Nicht alle Arten der streng geschlossenen Gattung Calvoa sind jedoch als feisenpflanzen zu bezeichnen. Wir lernten schon früher einen Vertreter der Gallung kennen, C. orientalis, welche der Naldllora angehört und deren Verbreitungsgebiet weit von dem aller ïlrigen Arten abliegt. Auch Arten von Calvoa, welche auf S. Thomé, Principe und Femando-Po gedeihen, sind oflenbar auf das Leben im Walde oder an fenchten Stellen angewiesen.

\section{Die rerwandtschaftlichen Beziehungen der afrikanischen Melastomataceae zu denen anderer Gebiete und zu einander.}

A. Beziehungen der afrikaniscluen Melastomalaceae zu denen anderer Gebiete.

Es ist eine sehr auffallende Thatsache, dass ron Beziehmgen zwischen den afrikanischen und den amerikanischen Arten der Mclastomataceae nicht oder kaum die Rede sein kam. Von den zahlreichen Gattungsgruppen unserer Familie sind die einen rein altweltlich, während die übrigen tler nenen Welt angehören. Nur in der Unterfamilie der Memecyloideae, welche sich verhältnismässig sehr locker der sonst so eng geschlossenen Masse der Melastomulaceae anglieder, finden wir eine Ausnahme, da hier in derselben Section (Nemecyleue) nebeneinander amerikanische und afrikanisch-asiatische Typen aufgeliuht werden. Aber auch hier sind die morphologisch meist sehr streng ron einander getrennten Gattungen, olggleich sie teilweise ausserordentlich artenreich sind (Memceylon 126, Momiria 4.1 Arten, entweder altweltlich oder neuweltlich, und es liesse sich wohl kaum etwas dagegen anfuhren, wäre sogar meiner Ansicht mach sehr angebracht, wenn man die Gattungen Mouriria und Olisbea als Memecyloideae - Monriricae (neuweltlich), die Gatungen Memecylon und Lijndenia (altweltlich) als Memecyloidea - Memecyleue einander entgegenstellen würde. Denn die Unterschiede zwischen den beiden Sectionen sind mindestens so schwerwiegend wie die bei der Gruppenbildung der Melastomatoidene verwendelen.

Es liesse sich vielleicht gegen dieses systematische hesultat, dass nämlich die amerikanischen und altweltlichen Gallungsverbände so streng von einander geschieden sind, vielleicht der Einwand erheben, dass die Gruppirung eine fehlerhafte oder wenigstens eine sehr unsichere sei. Und in der That ist es im 1llgemeinen nicht leicht, oft sogar recht schwierig, beim Bestimmen einer Art die richtige Gruppe aufzufinden, da dieselben meist nur durch sehr untergeordnete Nerknale getrenut sind. Diese Schwierigkeil beruht jedoch nicht auf einem Versiumnis oder auf einem Fehler der bisherigen s!stematischen Bearbeiter der Familie (Naidis,

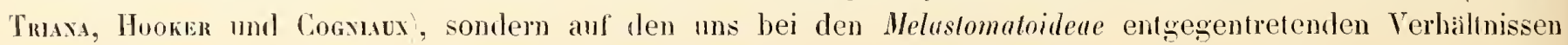
selbst.

Ich habe schon oben hervorgehoben, wie verhialtnissmassig iuberaus glejcharlig der morphologische Aufbau fast samtlicher Arten der Familie ist. Es ist demnach klar, dass morphologische Verhailtnisse nicht orler wenigstens laum zu Einteilungszwerken herangezogen werden kimnen. Aber auch der Grundplan der Bliitenbildung ist bei simullichen Arten dieser grossen Familie fast durchgaingig derselhe. So sind also verhälnissmassig nur sehr wenige und of sehr minutiöse Nerkmale vorhanden, welche dem Bearbeiter der Familic eine Eimteilung der Arten in Gattungen, in Gattmugsgruppen und Unterfamilien ermöglichen. Werden diesie minutiösen Nerkmale, welche natijrlich zu genaucster Untersuchung zwingen, in richtiger Woise verwendel, so ist klar, dass dadureh eine in jeder Hinsicht befriedigende Einteilung der Familie geschaflen werden kann, wie sie - ich sagte dies schon in der Einleitung - meiner Ansicht nach in den Hauptpunkten gegenwirtig 
feststehen durfte. Iuf der anderen Seite ist jedoch nich zu vergessen, dass die Bewertumg der minutiösen, gewöhulich auch zı selı kleimen, wenigghiedrigen Gatungen fiihrenden Merkmale, d. h. die Fesistellung, welche Charaktere Haupt- und Unterabteilungen zu Grunde gelegt werten können, ganz ausserordentlich erschwert ist. Denn stichhaltige Gründe, welche für das Vorwiegen des einen iiber ten anderen sprechen, können kaum jemals mit Bestimmtheit gefunden werden. Es ist deshalb selbstrerständlich, dass eine Einteilung der Melastomalaceae auf grosse Schwierigkeiten stösst. Und đloch wird jeder, der sich cingehender mit dieser. Familie beschaftigt, zuletzt zu dem Schlusse kommen, dass an der Haupteinteilung der Familie von späteren Bearbeitem wenig geändert werden dürfte, wenn sich auch in der Gathungsauffassung vielleicht die Ansichten :undern könnten. Demn üher den Wert oder Unwert von Gattungen zu entscheiden, ist in vielen Fallen reine "Ansichtssache" der hetreffenden Bearbeiter, und die Insichten iiber Gattungsbildung sind bekanntlich auch jetzt noch ausserordentlich rerschieden. Die Zusanmenfassung der Galtungen zu grösseren, natiirlichen Gruppen ist dagegen nicht in gleicher Weise in das Beliehen jedes Bearbeiters gelegt, sondern bei jedem Monographen bildet sich allmahlich im Laufe der fortschreitenden Untersnchung ein Gefuhl aus für die Zusammengehörigkeit der Formen, wekhes nicht nur auf kleinen ämsscrlichen Merkmalen beruht. Besitzen nun aber solche zusammengehörige Gruppen oleichmässig kleine, oft vielleicht nur minutiöse Merkmale, so können sie selbstverstindlich als Charakteristika fiir dieselben augefiilnt werden, also z. B. die Connectivbildungen der Melastomalaceae in gleicher Weise wie die Pollenstructur bei Acamlhaceae und Gentianaceat. Wenn wit besonders finden, dass nach den monographischen Bearbeitungen von Forschern wie Naudis, Traxa, Ноoker und Cogxucx die Gruppenbildung der Velastomalaceae im grossen und ganzen die gleiche geblichen ist, so durfen wir wohl mit ziemlicher Sicherheit annehmen, dass dieselbe eine natiorliche ist, wenn anch die trennenden llerkmale nur untergeordneter Natur crschieinen.

Es bestehen also nach dem bisher Ausgefiihrten zwischen den Melastomatacene der alien und denen der neuen Welt absoht keine naheren verwandschaftichen Beziehmgen. Desto ausgeprigter sind die Beziehungen jedoch zı den Formen der indo-malayischen Flora. Es sind ja allerdings der indischmalayischen und der afrikanischen Flora nur 2 (oder 3) Gattungen der Melastomalaceae gemeinsam, nämlich Osbeclia und Memecylon (Medimilla?'), aber zahlreiche andere Gattungen Afrikas zeigen an diese Gattungen oder an Gattungen des indo-malayischen Gebietes den engsten Anschlıss. So sind die Gattungen der $0_{s-}$ beckiene fast alle einander ausserordentlich nahestehend, die Gattung Tristemma ist mit der indo-malayischen Gattung Otumthera so deutlich verwandt, dass man sic ohne weiteres vereinigen könnte, die auffallende Gattung Myrianthemum der westafrikanischen Urwilder ist nit der indo-malayischen Gattung Dichaetanthera ebenso eng verknüpft wie Preussiella mit Medimilla. Sehr dentlich sind auch die Beziehnngen der specifisch ostafrikauischen Gattungen zu solchen des indo-malayischen Gebietes. So diuften die Gattungen Lrotheca und Petulonema Ostafrikas sich am meisten an Kendrickia auf Ceylon anlehnen, Orlhogoneuron (Ostafrika) an Pachycentria (malayisch. Sehr auffallend ist endlich die zweifellos sehr nahe Verwandtschaft von Cincimobotrys Ostafrika) mit der chinesischen Gattung Gymnagalhis, welche abes doch ein Analogon findet in dem bekannten und jetzt in unseren Warmhiusern vielfach kultivierten „Usambaraveilchen“, Saintpanlia ionanlha, die ja auch ihre nächsten Verwandten in China besitzt.

Sehr bemerkenswert ist der Umstand, dass zwischen der Melastomataceenllora Afrikas und derjenigen Madagascars, obgleich diese Insel an Arten unserer Familie sehr reich ist, kaum irgend welche nähere Beziehungen bestehen. Ausser den weitverbreiteten und in den Tropengebieten der alten Welt kaum irgendwo fehlenden Gattungen Osbeckia und Memecylon teilt nimlich Afrika mit dem madagassischen Gebiet nur die Gattung Tristemma, welche mit 14. Arten uber das ganze tropische Afrika zerstreut ist, mit einer mehreren afrikanischen Arten nahe verwandten Art (T. virnsmmm) jedoch auf den madagassischen Inseln auftritt. Es erscheint deshalb zum mindesten sehr wahrscheinlich, dass diese Gattung tropisch-afrikanisch ist und dass die eine Art von hier aus in jenes Gebiel vordrang. Tristemma möchte ich nämlich, geradeso wie die Gattungen Dissolis, Barbeyastrum, Dinophora, vielleicht auch Amphiblemma, Calvoa und Dicellandra als einen alten afrikanischen Stamm der Melastomataceae betrachten, welcher sich friihzeitig von den ubrigen altweltichen Arten abtrennte und in Afrika zu einer lokalisierten, ausgedehnten Entwicklung gelangte. Es kann dies jedoch erst erfolgt sein, nachdem sich die Familie der Melastomatuceae in der alten und in der nenen Welt nach verschiedener Richtung hin selbständig entwickelt hatte. 
B. Bedeutung der afrikanischen Melastomataceae für die Gliederung der afrikanisehen Flora.

Wie wir im vorhergehenden Absehnitt gesehen haben, konnten bei zahlreichen, auf ganz bestimmte Vegetationsformationen angewiesenen Arten ausserordentlich ibereinstimmende Verloreitungsgebiete festgestellt werden, welehe zweifellos dazu himreiehen, um mit Sicherheit aus dem Vorkommen einer der Arten auch auf die Vegetationsverhältnisse des Standortes Rückschlüsse ziehen zı dïrfen. Diese Feststellungen hätten zweifellos noch viel wichtigere und allgemein giultigere Resultate ergeben, wenn die Angaben der alteren und auch leider noch der neueren englischen Sammler über die Standortsverhältnisse nicht so ausserordentlich dürftige wären.

Wir konnten feststellen, dass eine Anzahl typischer Waldpflanzen, welehe in Westalrika eine weite Verbreitung besizen, ostwirts bis zum sidlichen Ghasalquellengebiet und dem centralafrikanischen Seengebiet vordringen, während sie in den Waldgebieten Ostafrikas fehlen (Phaeonenron dicellandroides, Dissotis multiflora, Arten des westafrikaniselıen Stammes der Gattung Memecylon), dass also jene Gebiete pflanzengeographiseh ganz oder wenigstens teilweise zn Westafrika gerechnet werden müssen. Auch für manche Arten der Sumpf- und Bachufervegetation trilit diese Feststellung durchaus zu.

Aus der charakteristischen Verbreitung maneher dieser letzteren Arten liess sich folgern, dass das Vordringen derselben von einer Seite des Continentes zu der anderen durch das Thal des Sambese und das obere Congogelsiet staltgefunden haben wird. Wahrscheinlich dirfte dies auch durch folgende Thatsaehen gemacht werden. Wenn wir die Flora Ostafrikas an Melastomataceae genau analysieren, so können wir zuniehst constatieren, dass wir es hier in den Hauptpunkten mit zweierlei streng geschiedenen Typen zu thun haben, eimmal solchen, die olfenbar zu einem speeifisch afrikanischen, in Westafrika weitaus seine grösste Entwicklung besitzenden Stamm gehören, und dann solchen, welelıe indiseh-malayischen Verwandisehaftsverbinden angegliedert werden miissen.

Als Vertreter dieses afrikanisehen Stammes möchte ieh z. B. die charakteristische Gattung Dissotis, die mit ihren 51 Arten auf das Festland Afrikas besehrinkt ist, anfuhren. Sehen wir zunächst von den weit verbreiteten Arten ab, von denen ein Teil ohne weiteres klar zeigt, dass die Verbreitung durch das Sambesegebiet statigefunden haben wird (D. incana, D. debilis, D. phaeotricha), so finden sieh im Sambesegebiet und Nyassaland 5, in den Usambaragebirgen (mit Kilimandscharo) 3, im Seengebiet 6, im Ghasalquellengebiet. 2 Arten mit beschränkitem Verbreitungsgebiel. Alle ïbrigen Arten sind typisch westafrikaniseh. Wenn wir nun in Betraeht ziehen, dass die Arten des Seengebietes meist der westafrikanischen Waldflora angehören, so sehen wir klar, dass vom Sambesegebiet aus nach Norden die Zahl der Arten von Dissolis immer melı abnimmt, dass sich hier in weiten Gebieten nur ganz rersprengte Arten finden und keine einzige Abyssinien, das doeh für die Besiedelung von Melnstomataceae so hervorragend geeignet wäre, erreicht hat. Beriicksiehtigen wir endlieh noeh, dass sich in Ostafrika kein einziger selbständiger Typus der Gattung gebildet hat, sondern dass alle ostafrikanischen Arten auf das bestimmteste mit westafrikanisehen oder aber zunäehst mit siidostafrikanisehen (und dureh diese mit den westafrikanischen) verbunden sind, so kann es kaum bezweifelt werden, dass die Gattung von einem westafrikanisehen Stamm ausging, dass sie von Angola, einem ihrer Hauptverbreitungsgebiete, ihren Weg iber das obere Congo- und das Sambesegebiet genommen hat und mit wenigen Arten die Waldgebiete Ostafrikas erreichte. 


\section{Verzeichnis der afrikanischen Gattungen und Arten der Melastomataceae.}

Afzeliella Gilg 3, 4 .

A. ciliata (Ilook. f.) Gilg 5, 46.

Amphiblemma Naud. 3, 29, 46 .

A. acaule Cogn. 29.

A. ciliatum Cogn. 29, 30, Taf. V $B$.

A. cymosum (Schrad.) Nand. 29, 30.

A. Iateriflorum $\operatorname{Cog}$. $29,30$.

A. molle Hook. f. 29.

A. setosum Hook. f. 29.

A. Soyauxii Cogn. 29, 30, Taf. V $A$. Antherotoma Hooli. $f .3,5,9$.

A. Afrelii Ilook. f. 6.

A. antherotoma Krasser 9 .

A. Naudini Hook. f. 9, 47, Taf. I $F$.

Argyrella Naud. 10.

A. incame Nand. 17.

A.? phaeotriche Nand. I't.

Barbeyastrum Cogn. 3, 23.

B. corymbosum Cogn. Q3, Taf. I $G$.

Calroa Hook. f. 3,31 .

C. crassinoda Jlook. f. 3i, 48.

C. grandifolia Cogn. 31 .

C. Henriquesii $\operatorname{Cognn} .31,32$.

C. hirsuta Hook. f. 31, 32, Taf. Y E.

C. integrifolia Cogn. 34 .

C. Molleri Gilg 3I, 48, Taf. $\mathrm{I} C$.

C. orientalis Taub. $31,32,46,48$, Tab. Y $D$.

C. sinuata Hook. f. 31 .

Cincinnobotrys Gilg 3, 30 .

C. oreophila Gilg 30,46 , Taf. VI $A$.

Dicellandra Hool. f. 3, 32.

D. Barteri Hook. f. 33 .

D. liberica Gilg 33, Taf. V $G$.

D. setosa Hook. f. 33.

Dinophora Benth. 3, 27.

D. spenneroides Benth. 27, 47, Taf. I $H$. Dissochaeta Baill. 32.

Dissotis Benth. 3, 10, 46 .

D. Afzelii Hook. f. 10, 13.

D. alpestris Taub. 12, 20,47.

D. alpestris Taub. p. p. 20.

D. angolensis Cogn. 11, 17 .

D. antennina (Sm.) Triana 10, 15.

D. Autraniana Cogn. 10, 13.

D. Barteri Hook. f. 12, 20.

D. Bravraei Cogn. 48.

D. Candolleana Cogn. 11, 19.

D. canescens Ilook. f. 17.

D. capitata (Vahl) Hook. f. 10, 13.
D. capitata, var. $\beta$. Togelii (Benth.) Ilook. f. 13.

D. capitata, var. $\%$ Barteri Hook. f. 13.

D. cincinnata Gilg 12, 20,47.

D. cordata Gilg 11,17 , Taf. III $B$.

D. cornifolia (Benth.) Hook. f. 10, 13.

D. crenulata Cogn. 12, 23.

D. eryptantha Bak. 11, 1\%.

D. debilis (Sond.) Triana 10, 14, 47, 50, Taf. II $D$.

D. decandia Triana $\mathrm{I}$.

D. decumbens (P. B.) Triana $11,15$.

D. decumbens, var. minor $\operatorname{Cog} n .45$.

D. Elliotii Gilg 11, 19.

D. eximia Hook. f. 22.

D. falcipila Gilg 12, 23, Taf. III $A$.

D. gracilis Cogn. 10, 14 .

D. grandiflora (Afz.) Benth. 12, 21.

D. Hensii Cogn. 11, 19.

D. hirsuta Hook. f. 10, 14 .

D. incana (E. Mey.) Triana 11, 17, 47, 50.

D. Irringiana Engl. 7, 8.

D. Irvingiana Ilook. f. 12, 20, 45, 47.

D. Johnstoniana Bak. f. 13.16.

D. laeris Hook. f. 15.

D. lanceolata Cogn. 14

D. Iongicaudata Cogn. 11, 19.

D. macrocarpa Gilg 11, 18.

D. magnifica (iilg 12, 22.

D. Melleri Ilook. f. $1 \mathbf{4}, 18$.

D. minor Gilg 10, 12, Taf. If $C$.

D. multiflora (Sm.) Triana 11, 18, 47, 49, Taf. II $F$.

D. penicillata Gilg 10, 14 .

D. Perkinsiae Gilg 12, 21, 4\%, Taf. III $D$.

D. petiolata Hook. f. 10, 12.

D. phaeotricha (Hochst.) Triana 10, 14, 47. 30 .

D. phaeotricha, var. sericea Triana 14.

D. plumosa Hook, f. 15.

D. polyantha Gilg $11,16,46$, Taf. II $E$.

D. princeps Cogn. p. p. 21.

D. princeps Taub. p. p. 22.

D. princeps (Bonpl.) Triana 12, 22.

D. pulcherrima Gilg 11,20 , Taf. III $F$.

D. radicans Hook. f. 10, 14.

D. rotundifolia $(\mathrm{Sm}$.) Triana $11,15,47$.

D. scabra Gilg 12, 21, 47, Taf. III $E$.

D. Schweinfurthii Gilg 12, 21, 47.

D. segregata (Benth.) IIook. f. 10, 12, 47.

D. segregata Taub. 12.

D. senegambiensis Triana 8.

D. Sizenandii Cogn. 11, 19.
D. speciosa Taub. 11, 18, Taf. III $C$.

D. theifolia (G. Don) Hook. f. I0, 13, Taf. II $A$.

D. Thollonii $\operatorname{Cog} n .11,19$.

D. tristemmoides Cogn. $11,16$.

D. Trothae Gilg 11, 19, Taf, II $B$.

D. tubulosa Trisuna 9.

D. rillosa Engl. 14.

D. villosa Hook. f. 14.

D. violacea Gilg 19, 22.

D. Welwitschii Cogn. 11, 18 .

D. Whytei Bak. 11, 16.

Guyonia Naud. จ, 4.

G. tenella Naud. 4, 46 , Taf. I $B$.

Heterotis Benth. 10.

H. antemina Benth. Is.

H. capitata Benth. 13.

H. comifolia Benth. 13.

H. laeris Benth. 15.

H. plumosa Benth. I5.

H. prostrata Benth. 13.

H. segregata Bienth. IQ.

$H$. thenefolin Benth. 13.

H. triplinervia Kitotzsch 15 .

H. Vogelii Benth. 13.

Lepidanthemum Klotzsch 10.

L. triplinemium Klotzsch 15.

Medinilla Gaud. 3, 3i, 49.

M. Mannii llook. f. 34, 46.

Melastoma Af:clianum D. Don 18

M. albiflorum (i. Don 25.

II. capitata Vahl 13.

1. corymbosa sims 30.

M. cymosum Schrad. 30 .

11. decumbens P. Beaur. 15 .

M. elongatum D. Don 21 .

M. involucrata D. 1)on 24.

MI. leonensis Lodd. 30.

II. plumosum D. Don 15.

M. prostrata Sch. et Th. 13 .

II. sessilis Sch. et Th. 26 .

M. theaefolia G. Don 13.

1I. virusanum D. Don 26.

Melastomastrum Naud. 10.

II. erectum Naud. 43.

Memecylon L. 3, 36, 46, 49, 50 .

M. Afrelii R. Br. 4.4.

M. Barteri Hook. f. $3 \pi, 41$.

M. Buchananii Gilg $3 \pi, 40$. 
M. calophyllum Gilg 37, 42.

M. candidum Gilg 37, 43.

IM. cinnamomoides Gilg 37, 39 .

M. coervleum Buettn. 39.

I. coeruleum Hook. f. 38 .

M. coevuleum, var. B. Hook. f. 38.

M. Cogniauxii Gilg $38,44,46$, Taf. $\mathrm{X} A$.

M. Donianum Planch. 38, 44.

M. Englerianum Cogn. 37, 4.3 .

M. erubescens Gilg 37, 41, Taf. $\mathrm{X} B$.

M. erythranthum Gilg 38, 45, Taf. I $C$.

M. fasciculare (Planch.) Naud, 37, 41 .

M. flavovirens Bak. 38, 44 .

M. Heinsenii Gilg 37, 4.?.

M. heterophyillum Gilg $37,39,46$.

1I. Heudelotii Naud, 41.

M. hylophilum Gilg $37,42$.

M. jasminoides Gilg $37,39,46$.

M. Ieucocarpum Filg 37, 40.

M. Iongicauda Gilg 37,40 , Taf. $\times E$.

M. Machairacme (iilg 37, 42.

M. Mannii Hook. f. 37, 39.

1. membranifolium Cogn. p. p. 39.

M. membranifolium Hook, f. 37, 41.

M. memleranifolium Taub. 40.

II. Millenii Gilg 37, 38 .

M. myrianthum Gilg 38 , 44, 46 .

M. nigrescens Engl. 43.

M. nitidulum Cogn. 37, 38 .

M. Poggei Gilg 38, 43 .

II. polyanthemos Hook. f. 38, 44.

Pf. polyneuron Gilg 37 , 41 .

M. pulcherrimum Gilg $3 \bar{\tau}, 1$

M. purpureo-coeruleum Gilg 37,38 .

II. sansibaricum Gilg 37, 40 .

M. Spathandra B]. 37,38 .

II. strychnoides Gilg 37,39 .

II. virescens llook. f. 37, 42.

M. Vogelii Nand. 38, 43.

M. Zenkeri Gilg 38, 43, Taf. X $D$.

Myrianthemum Gilg 3, 33.

M. mirabile Gilg 33, 46, Taf. VII.

Nerophila Nand. \&, 4 .

N. gentianoides Naud. 4 , 46 , Taf. I $A$.

Osbecliastrum Naud. 10.

(). Heulelotii Nand. 21.
Opthogoneuron Gilg 3, 36.

0 . dasyanthum Gilg 36,46 , Taf. VI $B$.

0sbeckia $L .3,4,49$.

O. Sect. Antherotoma Nand. 9.

O. Sect. Macrodesmiae Naud. 10.

0. abyssinica Gilg 5, 8.

0. Afzelii (Ilook. f.) Cogn. 5, 6, Taf. I $C$.

O. antennina Sm. 15.

O. antheiotoma Naud. 9.

0. Brazzaei Cogn. 6, 9.

0. Buettneriana $\operatorname{Cog} n .5,6,45$.

0. Buraeavi Cogn. 6, 9.

0. calotricha Gilo 6,8 .

O. canescens E. Mey. 17.

0 . congolensis Cogn. 5, 6 .

0. congolensis. $\beta$. rolustior Cogn. 6 .

$O$. debilis sond. 14.

0 . decandra DC. 5,7 .

O. decumbens DC. 15 .

o. densiflora Gilg 6,8 .

0 . drepanosepala filg 5,7 .

O. eximia Sonder 22.

O. grandiflora Afz. 2I.

O. hirsuta Cogn. 14.

O. incana E. Mey. 17.

O. multiflora sm. 18.

O. phaeotricha (Ilochst.) Triana 14.

0 . postpInvialis Gilg $30,6,47$.

O. princeps. DC. 22.

O. rotumlifolia Sm. 15.

0. saxicola Gilg 5,7 , Taf. I $D$.

0 . senegambiensis G. et P. $\ddot{b}, 8$.

0. tubulosa Smith 6, 9, 47, Taf. I $E$.

O. Umlaasiana Hochst. 17.

O. vimusana Baill. 26.

0. Welwitschii Cogn. 6, 4.5.

0. zambeziensis Cogn. $5,6$.

O. Zanibrriensis Naud, 1:5.

O. reylanica, var. decandra $\mathrm{Sm} . \%$

Prevetta lateriflora G. Don 14.

Petalonema Gilg 3, 38.

P. pulchrum Gilg 28, 46, Taf. IV $B$.

Phaeonenron Gilg 3, 34.

$\mathrm{Ph}$. dicellandroides Gilg $350,46,50$, Taf. VIII $B$.

Preussiella Gilg 3, 3 .

P. kamerunensis Gilg 36, 46, Taf. IX.
Rhexia pinceps Bonpl. 22.

Sakersia Hook. f. 3, 32.

S. africana Hook. f. 32, 46, Taf. V F.

S. echinulata Hook. f. 32.

Spathandra Guill. et Perr. 36.

S. coerulea Guill. et Perr. 38.

S. fascicularis Planch. 41.

S. memecyloides Benth. 43 .

Tetraphyllaster Gilg 3, 34 .

T. rosaceum Gilg 34,47 , Taf. VIII $A$. Tristemuna Juss. 3, 23, 46, 49 .

T. albiflorum Benth. 20̈.

T. angolense Gilg 24, 27.

T. cropitatum Triana 13.

T. cormifolizm Triana 13.

T. coronatum Benth. 24, 23, Taf. I $L$.

T. Dusenii Gilg 24, 27.

T. erectum Guill. et Perr. 13.

T. fruticulosum Gilg 24, 26, Taf. I $M$.

T. grandifolium (Cogn.) Gilg 24, 26, Tar. I $N$.

T. hirtum Vent. 2', 26.

T. incompletum R. Br. 24, 25.

T. involucratum (Don) Benth. 24 Taf. I $K$.

T. leiocalyx Cogn. 24.

T. littorale Benth. 24, 25.

T. manritianum Pers. 26.

T. neglectum Nand. 13.

T. oreophilum Gilg $24,25,4 \pi$.

T. ovalifolium Engl. 13.

T. papillosum Gilg $24,25$.

T. roseum Gilg 24, Taf. IJ.

T. Schumacheri Guill. et Perr. 25.

T. Schumacheri Taub. 26.

T. Schumacheri, $\gamma$ albiflorum Ilook. f. 23.

T. Schumacheri, 3. grandifolia Cogn. 26.

T. Schumacheri, 3. littorale Itook. f. 25.

T. segregatnom Triana 12.

T. Ulecuefolin Triana 13.

T. vincoides Gilg 23,24 .

T. virusanum Comm, 24, 26, 49 .

Urotheca Gilg 3, 28.

T. hylophila Gilg 28,46 , Taf. IV $A$. 

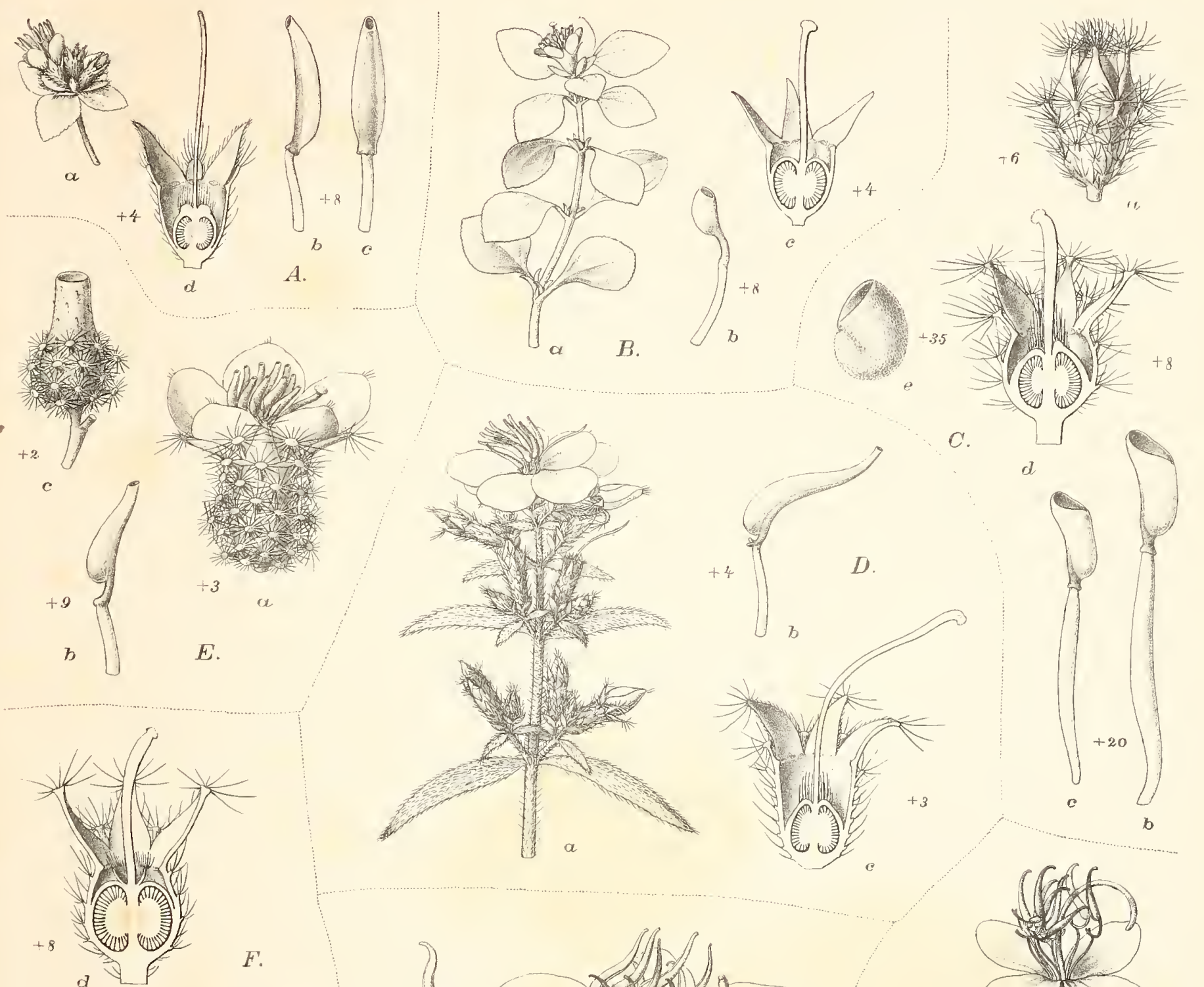

E.
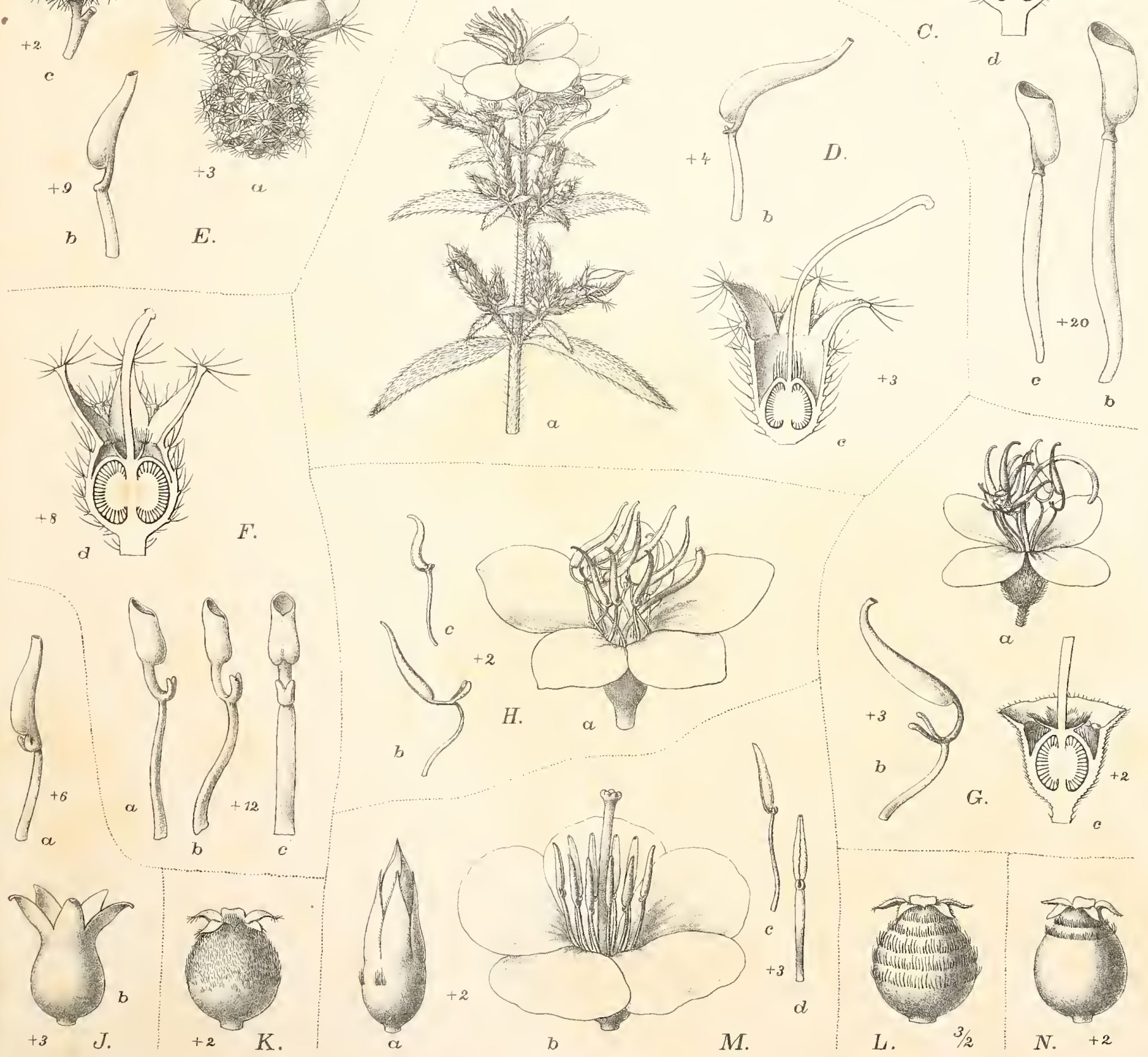

$+$

$J$

$+2 K$.

K. $\quad$ a

$M$.
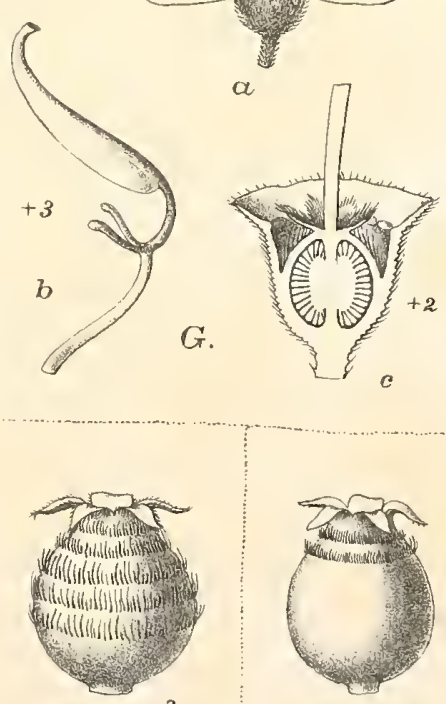

$L$

N. $\quad+2$

Nerophila, Guyonia, Osbeckia, Antherotoma, Barbeyastrum, Dinophora,Tristemma,

A. N. gentianoides Naud, B. G. tenella Naud, C. O. Afzelii Hook.f., D.0.saxicola Gilg, E. O.tubulosa Smith, F. A. Naudini Hook.f., G. B. corymbosum Cogn., H.D. spenneroides Benth., J. T.roseum Gilg. K.T.involucratum (Don)Benth, $L$. T. сотоnatum Benth., M.T. fruticulosum Gilg, $\quad N$. T. grandifolium Gilg. 

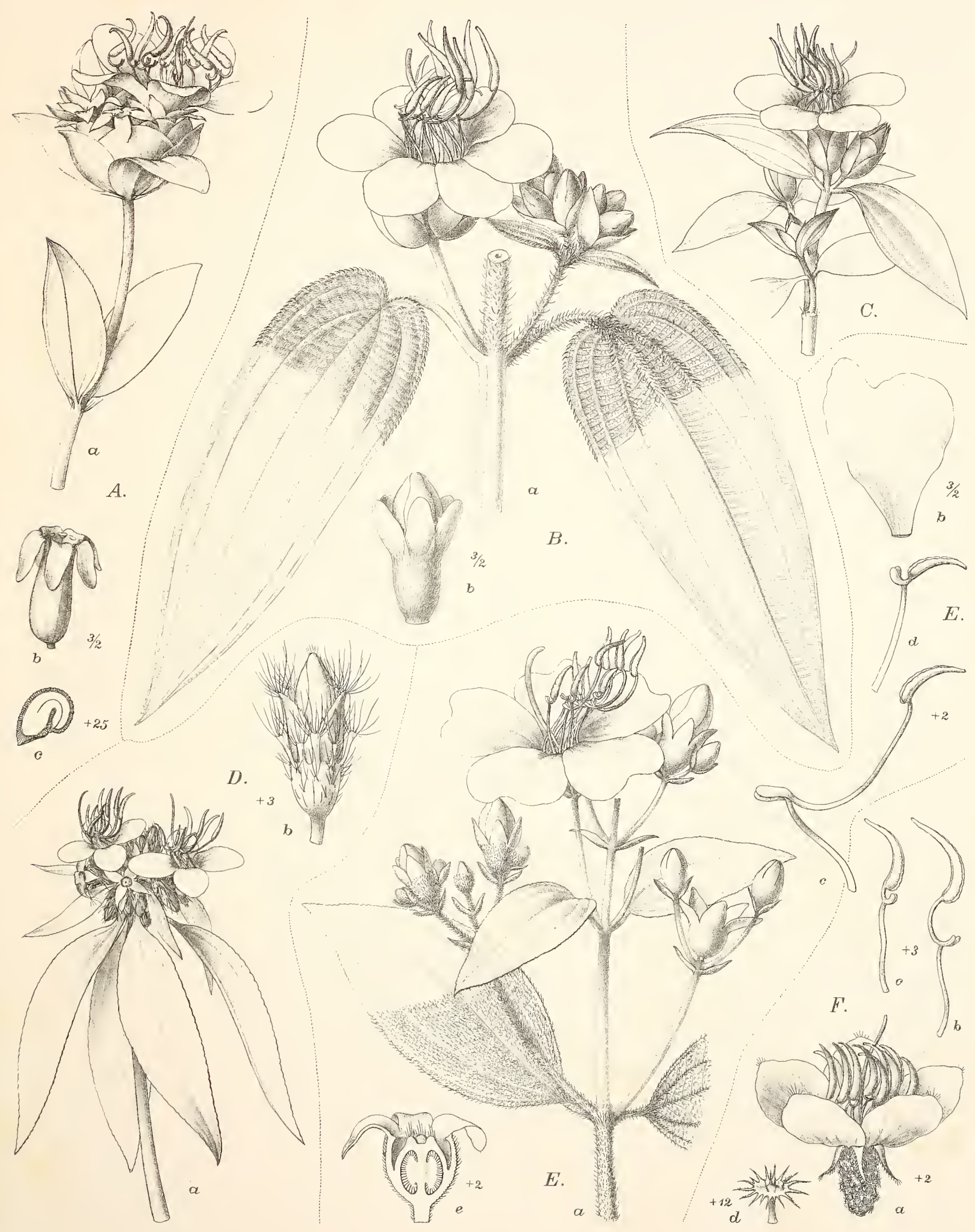

A. ENGLER, Monoǵraphieen afrikanischer Pflanzenfamilien u. Gattungen

II. E. Gilg, Melastomataceae

Taf. III.
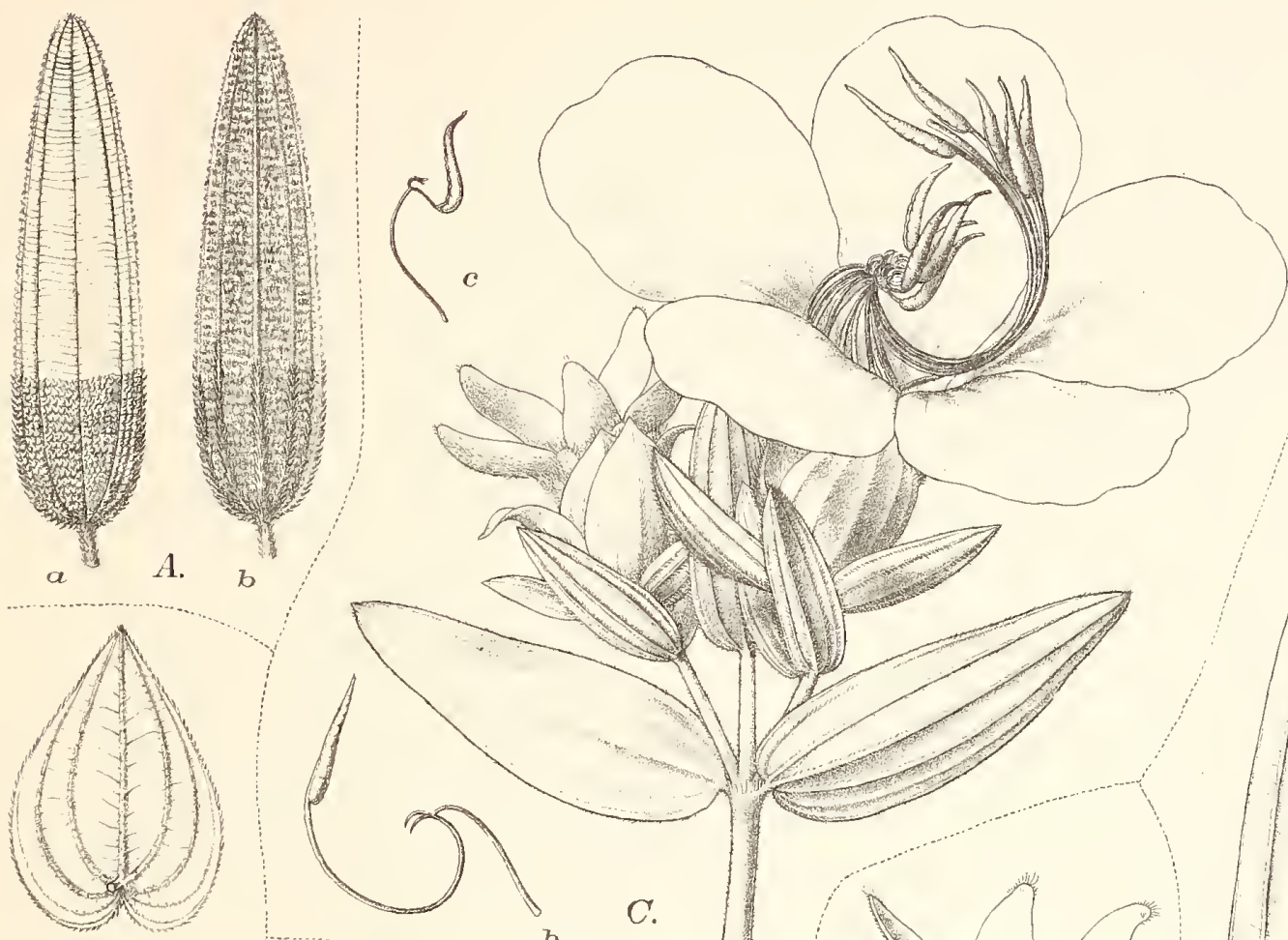

$B$.
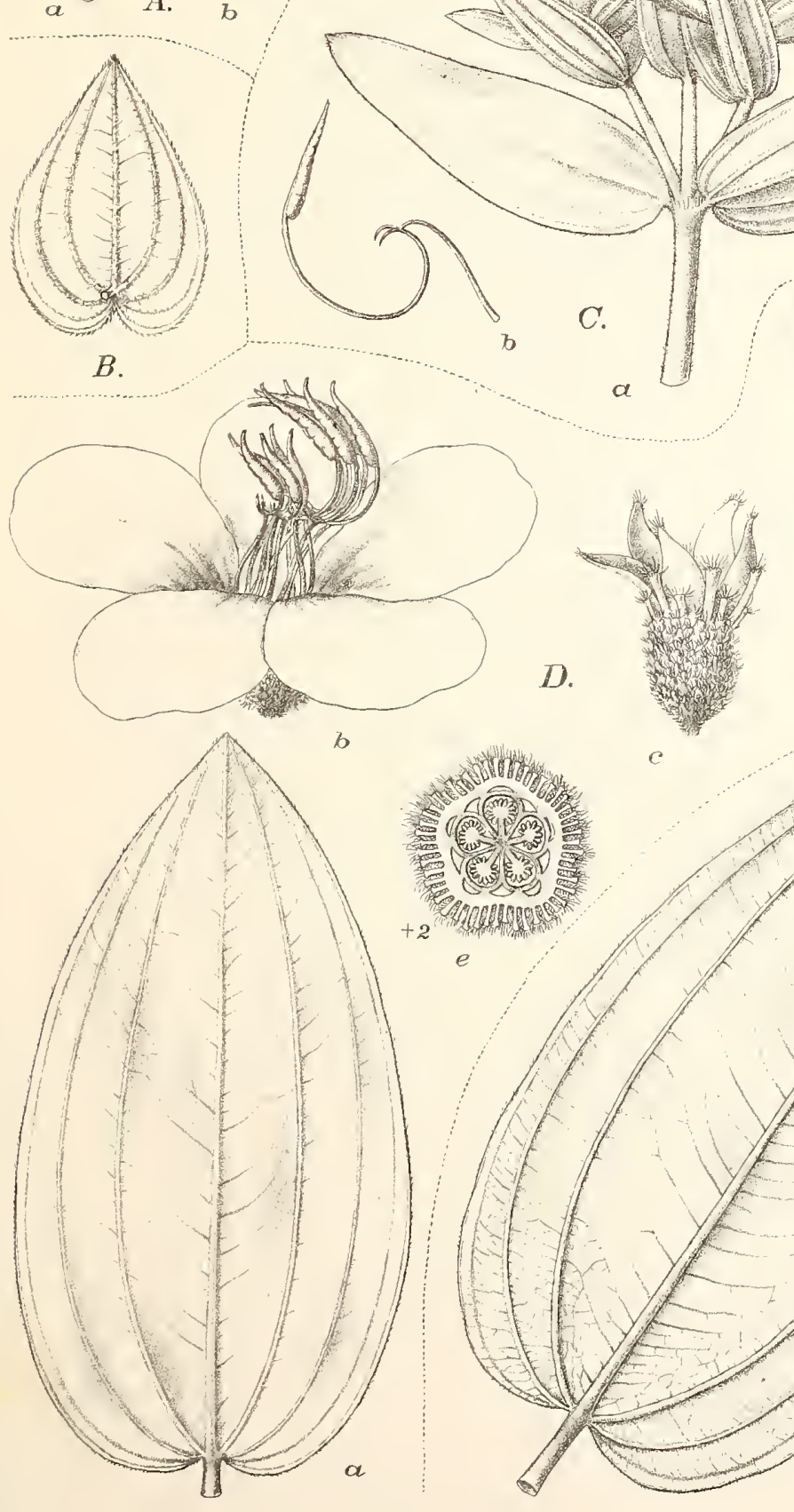

D.
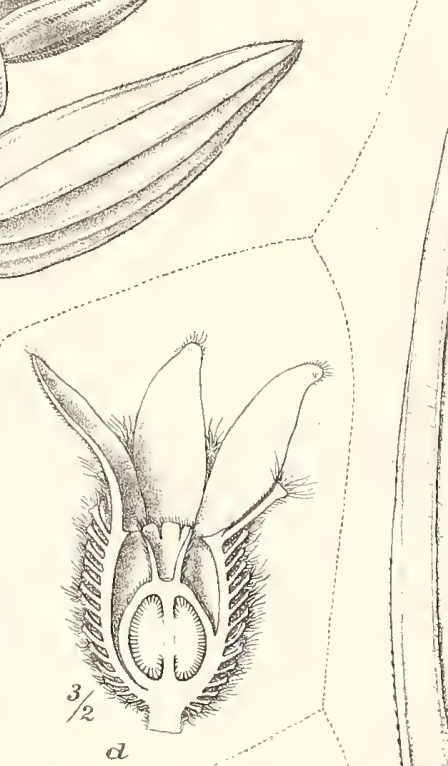
A. ENGLER, Monographieen afrikanischer Pflanzenfamilien u. Gattungen

II. E. Gilg, Melastomataceae.
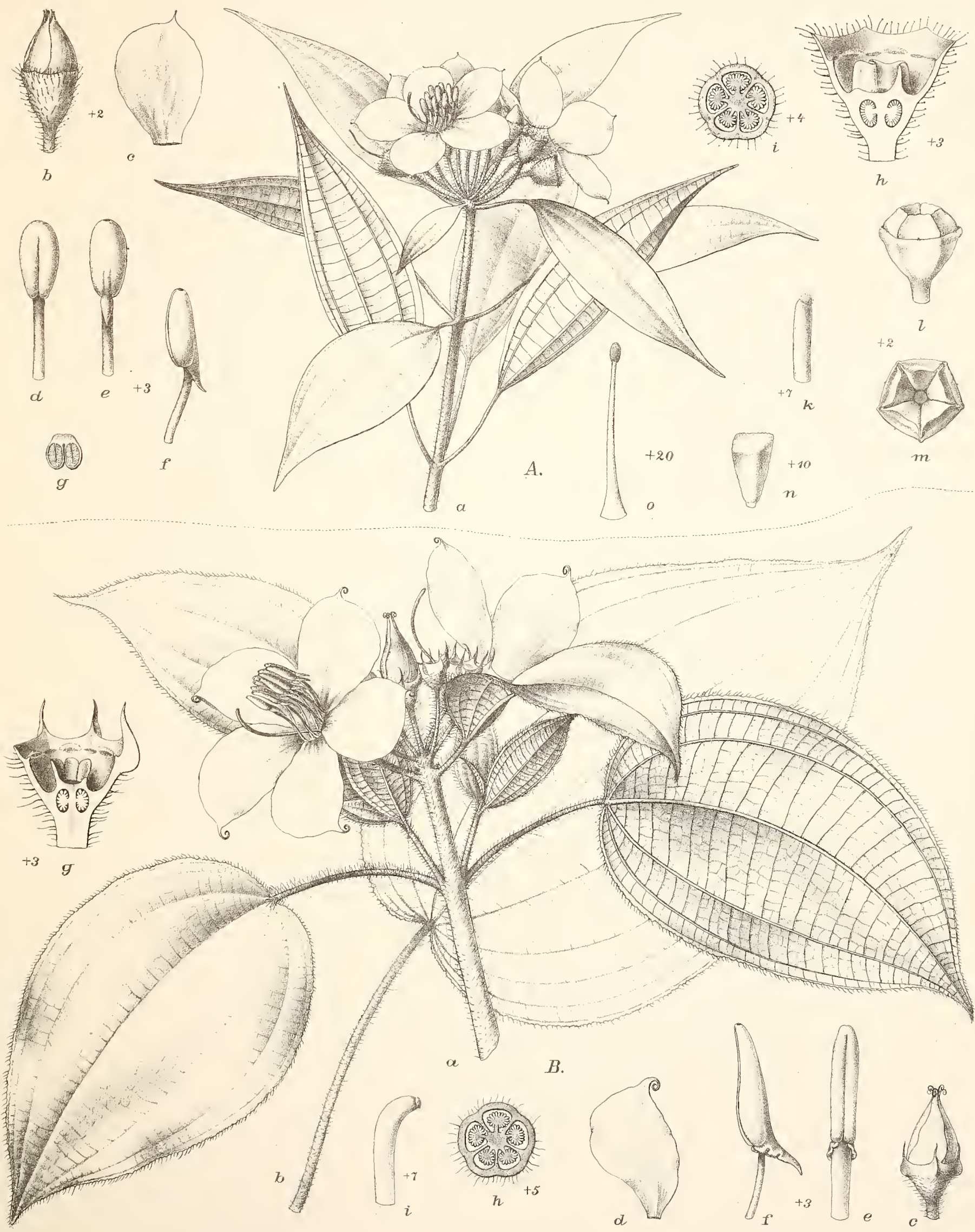

Urotheca, Petalonema,

A. U. hylophila Gilǵ, B. P. pulchrum Gilǵ 

A. ENGLER, Monographieen afrikanischer Pflanzenfamilien u. Gattungen

II. E. Gilg, Melastomataceae.

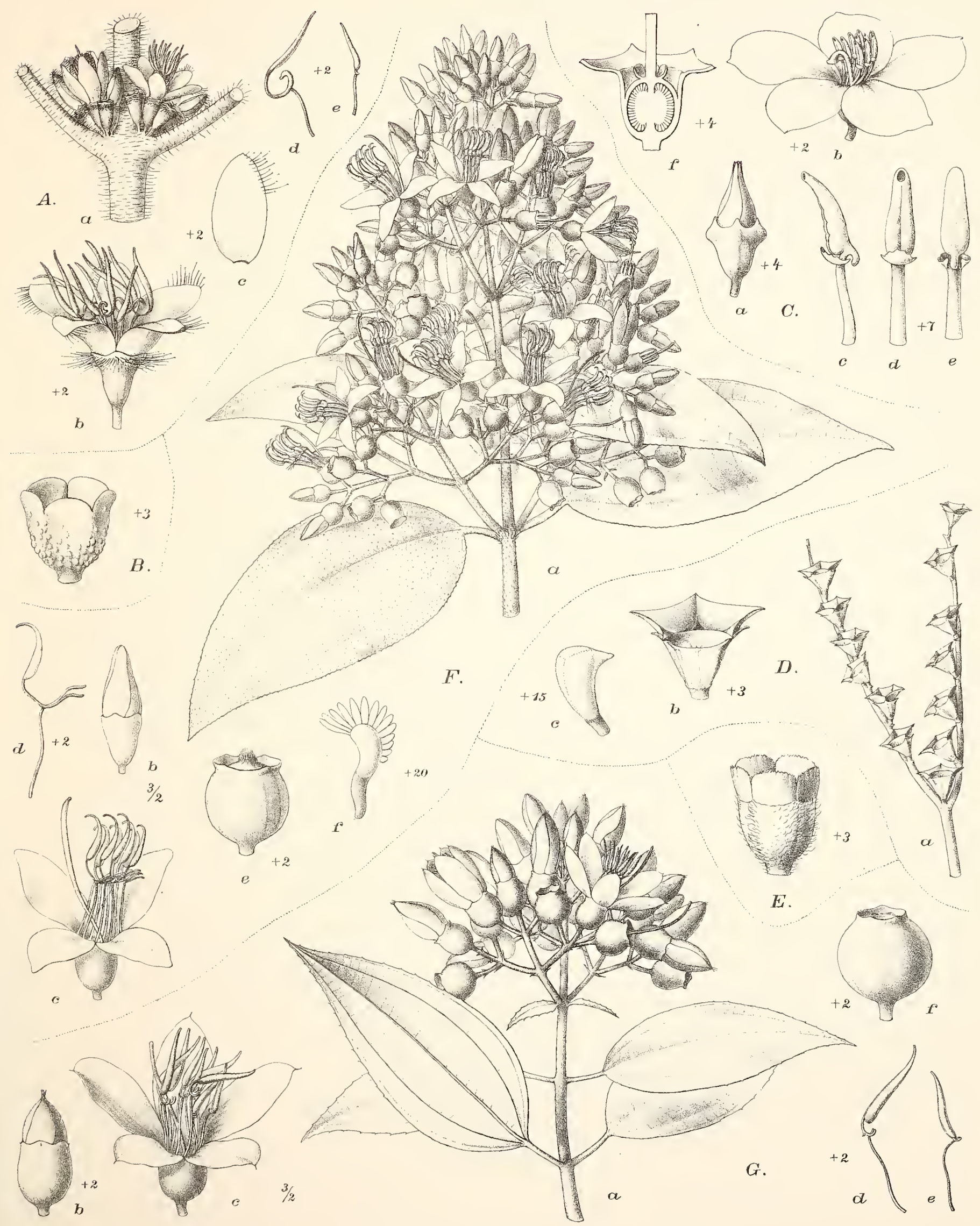

Amphiblemma, Calvoa, Sakersia, Dicellandra,

A. A. Soyauxii Cognn., B. A. ciliatum Cogn., C. C. Molleri Gilg, D. C. orientalis Taub,

E. C. hirsuta Hook.f., F. S. africana Hook.f., G. D. Iiberica Gilg. 

A. ENGLER, Monographieen afrikanischer Pflanzenfamilien u. Gattungen

II. E. Gilg, Melastomataceae.

Taf. VI.
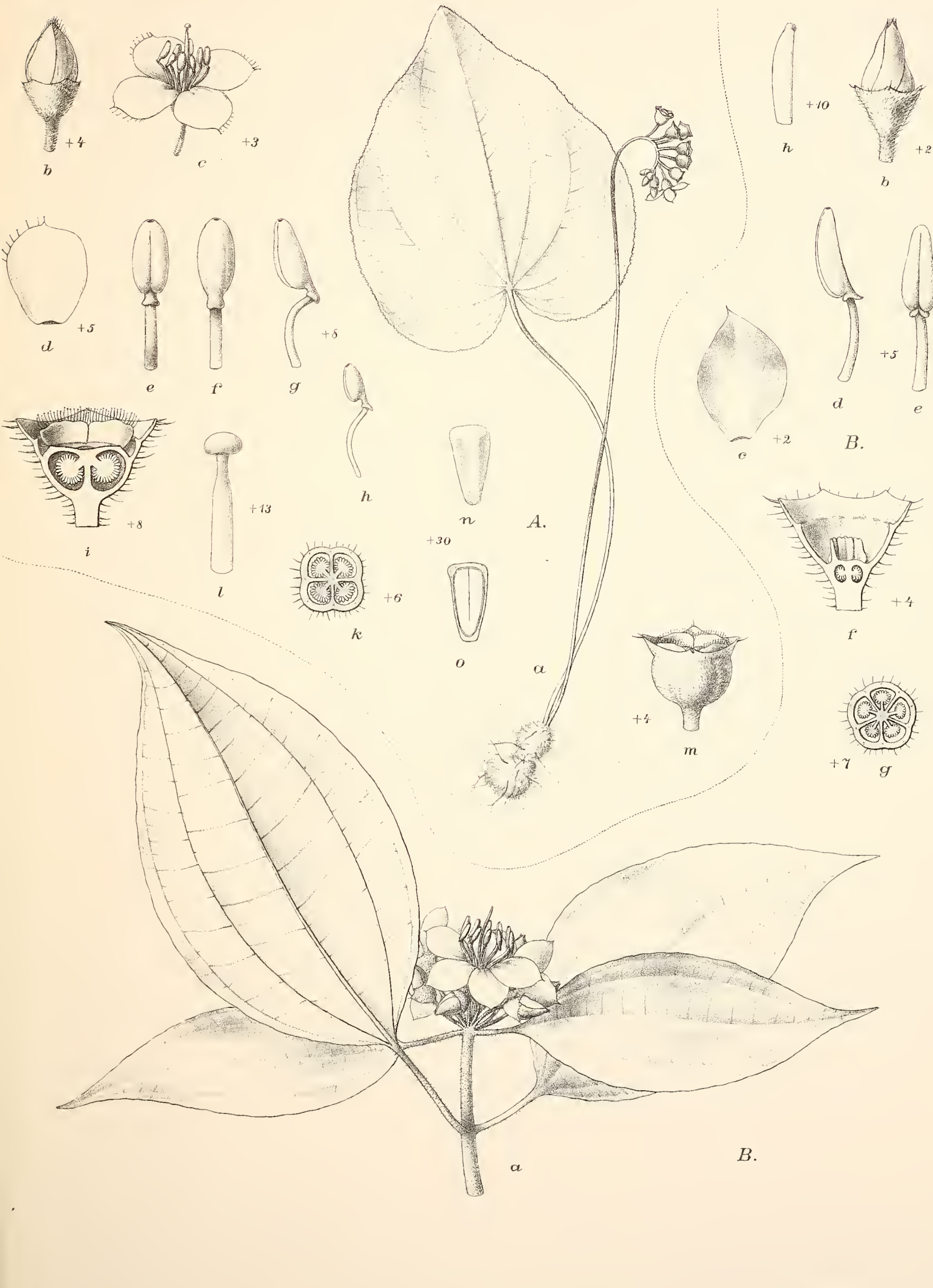

$k$
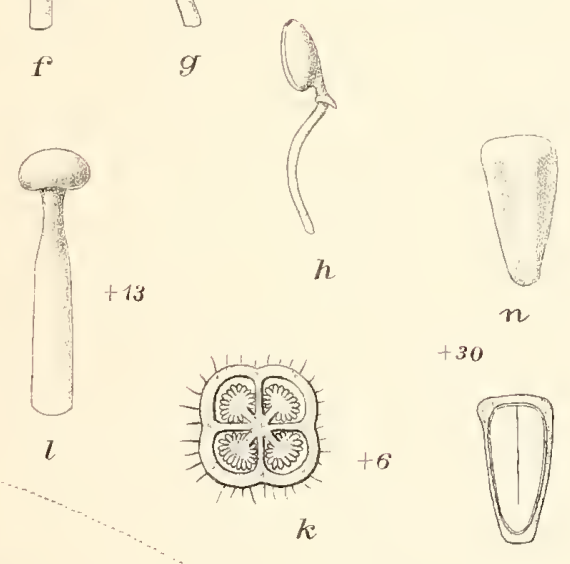

A.

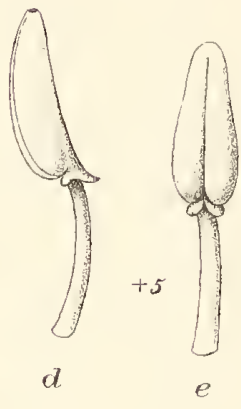

$B$.
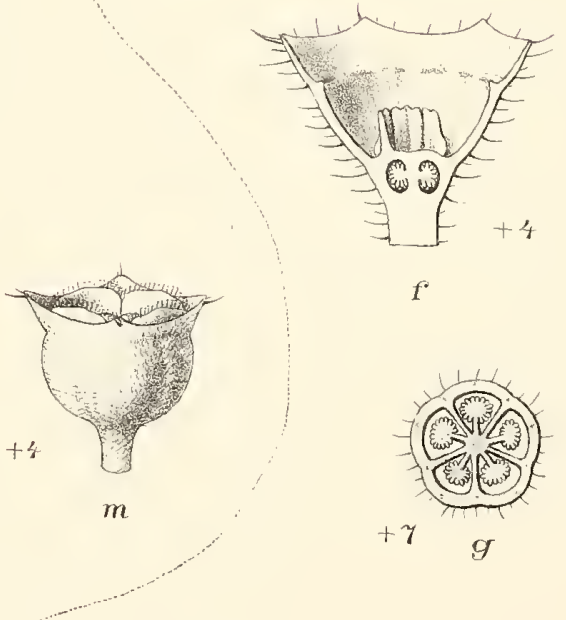

$f^{\circ}$

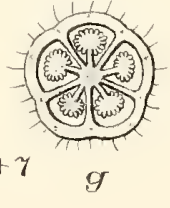

Cincinnobotrys, 0rthogoneuron,

A. C. oreophila Gilg, B. 0. dasyanthum Gilg. 

A. ENGLER, Monographieen afrikanischer Pflanzenfamilien u. Gattungen

II. E. Gilg, Melastomataceae.

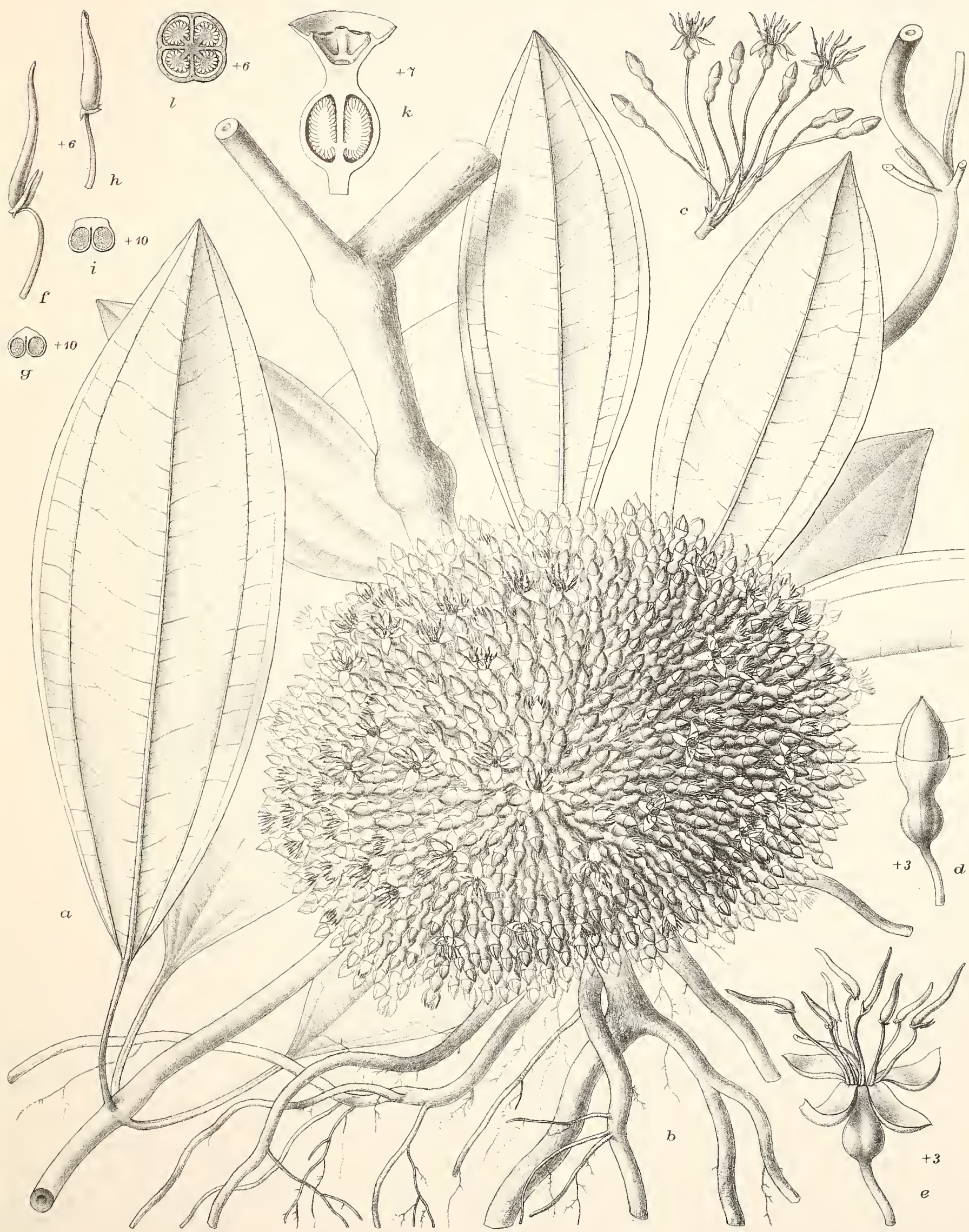

Myprianthemum, 

A. ENGLER, Monographieen afrikanischer Pflanzenfamilien u. Gattungen.

II. E. Gilg, Melastomataceae.

Taf. VIII.
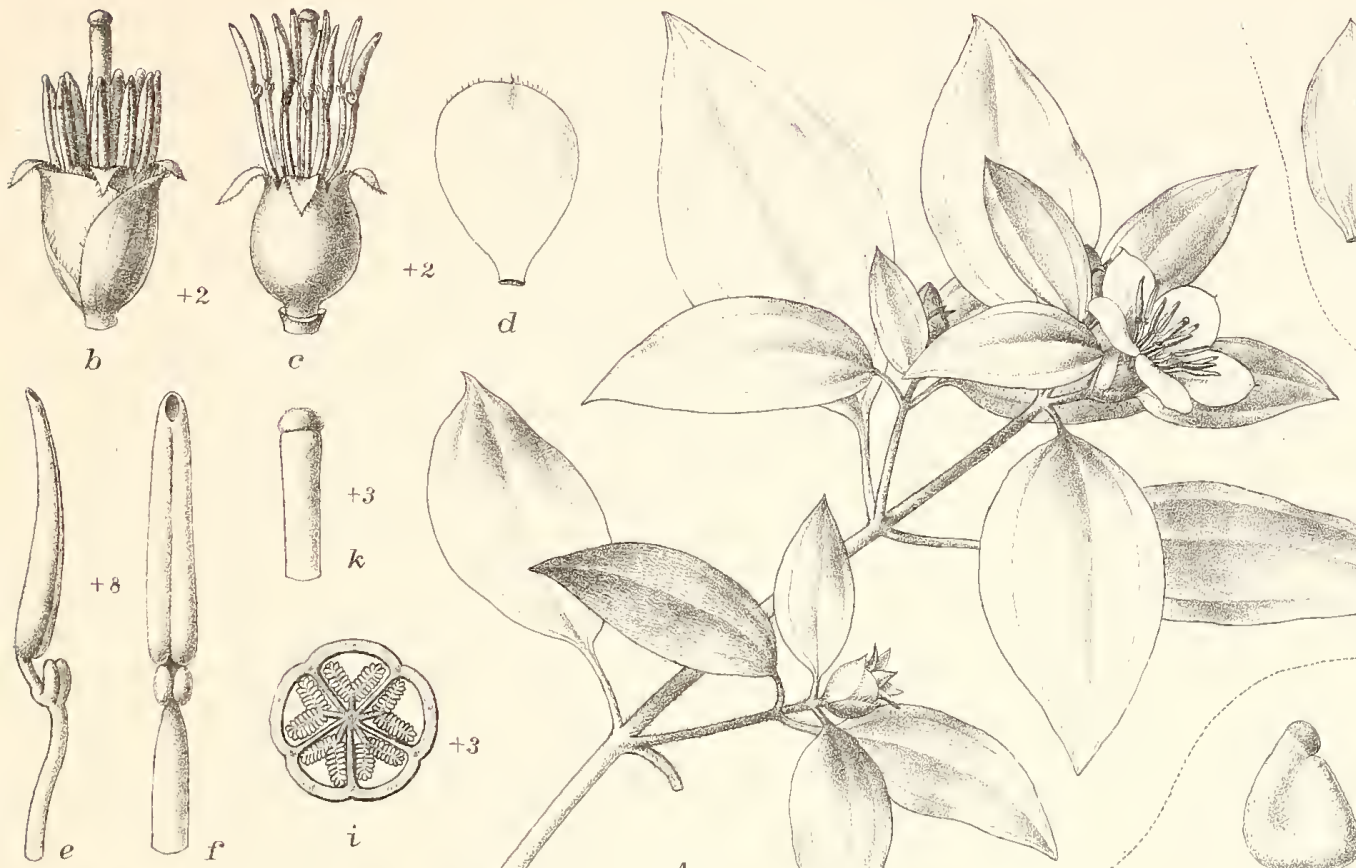

10 . 9
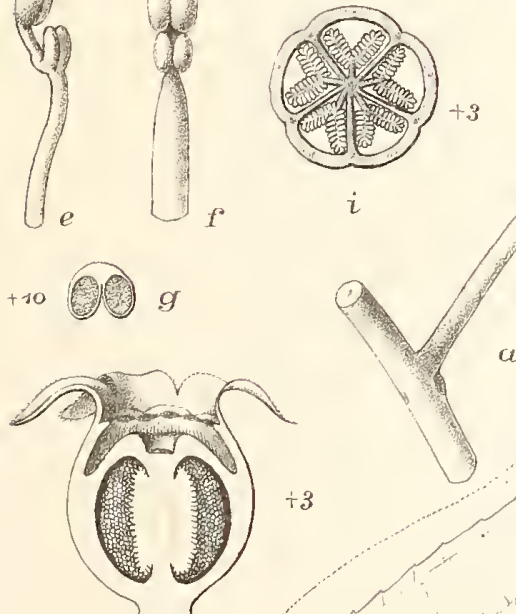

A.
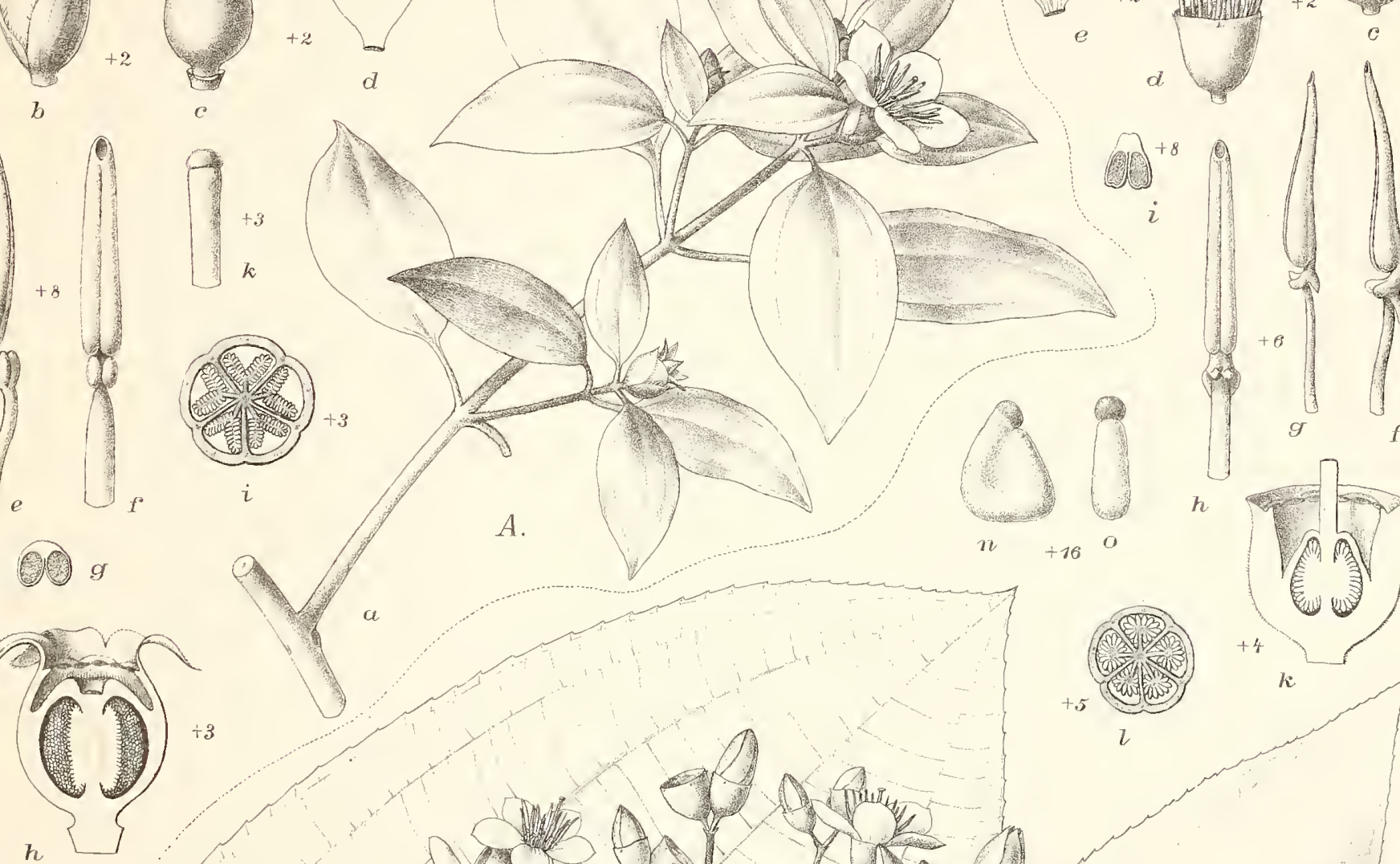
A.ENGLER, Monographieen afrikanischer Pflanzenfamilien u. Gattungen

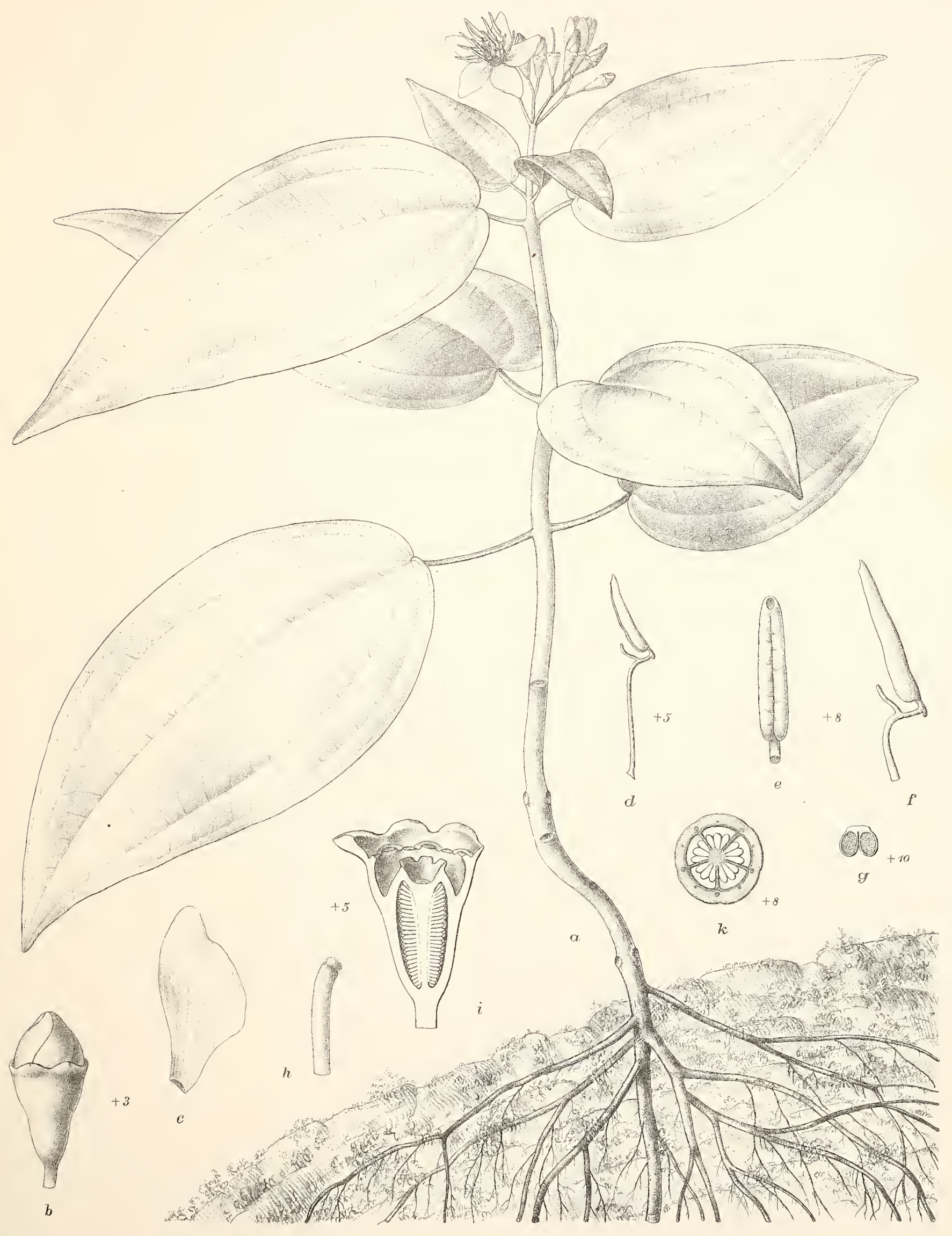

J.Pohl ad nat. Wut. Awhn derexit

Preusiella,

P. kamerunensis Gilg. 


